\title{
Internal Condensing Flows inside a Vertical Pipe - Experimental/Computational Investigations of the Effects of Specified and Unspecified (Free) Conditions at Exit
}

\author{
A. Narain ${ }^{1}$, J. H. Kurita, M. Kivisalu, A. Siemionko, S. Kulkarni, T. W. Ng, N. Kim, and L. Phan \\ Department of Mechanical Engineering-Engineering Mechanics \\ Michigan Technological University \\ Houghton, MI-49931
}

\begin{abstract}
Reported experimental and computational results confirm that both the flow features and heat transfer rates inside a condenser depend on the specification of inlet, wall, and exit conditions. The results show that the commonly occuring condensing flows' special sensitivity to changes in exit conditions (i.e. changes in exit pressure) arise from the ease with which these changes alter the vapor flow field in the interior. When exit pressure is changed from one steady value to another, the changes required of the interior vapor flow towards achieving a new steady flow are such that they do not demand removal of the new exit pressure imposition back to the original steady value - as is the case for incompressible single phase flows with an original and "required" exit pressure. Instead, new steady flows may be achieved through appropriate changes in the vapor/liquid interfacial configurations and associated changes in interfacial mass, heat transfer rates (both local and overall), and other flow variables. This special feature of these fows is for the commonly occurring large heat sink situations for which the condensing surface temperature (not heat flux) remain approximately the same for any given set of inlet conditions while exit condition changes. In this paper's context of flows of a pure vapor that experience film condensation on the inside walls of a vertical tube, the reported results provide important quantitative and qualitative understanding as well as exit-condition based categorization of the flows.

Experimental results and selected relevant computational results that are presented here reinforce the fact that there exist multiple steady solutions (with different heat transfer rates) for multiple steady prescriptions of the exit-condition even though the other boundary conditions do not change. However for some situations that do not fix any specific value for the exit condition (say exit pressure) but allow the flow the freedom to choose any exit pressure value within a certain range, experiments confirm the computational results that, given enough time, there typically exists, under normal gravity conditions, a self selected "natural" steady flow with a "natural" exit condition. This happens if the vapor flow is seeking (or attracted to) a specific exit condition and the conditions downstream of the condenser allow the vapor flow a range of exit conditions that includes the specific "natural" exit condition of choice. However, for some unspecified exit condition cases involving partial condensation, even if computations predict that a "natural" exit condition choice exists, the experimental arrangement employed here does not allow the flow to approach its steady "natural" exit condition value and, instead, it only allows oscillatory exit conditions leading to an oscillatory flow. For the reported experiments, these oscillatory pressures are induced and imposed by the instabilities in the system components downstream of the condenser.
\end{abstract}

Key-words: film condensation, phase-change heat transfer, two-phase flows, interfacial waves.

\footnotetext{
${ }^{1}$ To whom correspondence should be addressed.

E-mail: narain@mtu.edu, Phone: 906-487-2555

Fax: 906-487-2822
} 


\section{NOMENCLATURE}

D Inner diameter of the test-section, $\mathrm{m}$

G Inlet mass flux, $\mathrm{kg} /\left(\mathrm{m}^{2} / \mathrm{s}\right)$

$\mathrm{h}_{\mathrm{fg}}(\mathrm{p}) \quad$ Heat of vaporization at pressure $\mathrm{p}, \mathrm{J} / \mathrm{kg}$

$\overline{\mathrm{h}} \quad$ Average convective heat coefficient, $\mathrm{W} /\left(\mathrm{m}^{2}-\mathrm{K}\right)$

Ja Condensate liquid Jacob number

L Length of the test-section, $\mathrm{m}$

$\dot{\mathrm{M}}_{\text {in }} \quad$ Vapor flow rate at test-section inlet, g/s

$\dot{\mathrm{M}}_{\mathrm{L}} \quad$ Liquid flow rate at test-section exit, $\mathrm{g} / \mathrm{s}$

$\dot{\mathrm{M}}_{\mathrm{V}} \quad$ Vapor flow rate at test-section exit, $\mathrm{g} / \mathrm{s}$

$\mathrm{p}_{\mathrm{b}} \quad$ Evaporator (boiler) pressure, $\mathrm{kPa}$

$\mathrm{p}_{\mathrm{D} 2} \quad$ Pressure at the location near the rotameter, $\mathrm{kPa}$

$\mathrm{p}_{\mathrm{T}^{\prime \prime}} \quad$ Pressure at the location outside the test section, $\mathrm{kPa}$

$\mathrm{p}_{\text {in }} \quad$ Pressure at location at the test-section inlet, $\mathrm{kPa}$

$\mathrm{p}_{\text {exit }} \quad$ Pressure at location at the test-section exit, $\mathrm{kPa}$

$\operatorname{Pr}_{1} \quad$ Condensate liquid Prandtl number.

$\mathrm{p}_{\mathrm{xi}} \quad$ Test-section pressures at different locations $\mathrm{x}=\mathrm{xi}(\mathrm{i}=1,2, \ldots), \mathrm{kPa}$

$\overline{q^{\prime \prime}} \quad$ Average convective heat flux, W/m $\mathrm{m}^{2}$

$\dot{\mathrm{Q}}_{\mathrm{b}} \quad$ Net heat rate into the evaporator, $\mathrm{W}$

$\dot{\mathrm{Q}}_{\text {out }} \quad$ Net heat rate out of the test-section, $\mathrm{W}$

Re Inlet vapor Reynolds number

$\mathrm{T}_{\mathrm{b}} \quad$ Evaporator temperature, ${ }^{\circ} \mathrm{C}$

$\mathrm{T}_{\mathrm{R}} \quad$ Rotameter temperature, ${ }^{\circ} \mathrm{C}$

$\mathrm{T}_{\text {sat }}(\mathrm{p}) \quad$ Saturation temperature at pressure $\mathrm{p},{ }^{\circ} \mathrm{C}$

$\mathrm{T}_{\mathrm{s}-\mathrm{xi}} \quad$ Condensing surface temperatures at different locations $\mathrm{x}=\mathrm{xi}(\mathrm{i}=1,2, \ldots),{ }^{\circ} \mathrm{C}$

$\overline{\mathrm{T}}_{\mathrm{w}} \quad$ Mean uniform condensing surface temperature, ${ }^{\circ} \mathrm{C}$

$\mathrm{T}_{\mathrm{w}}(\mathrm{x}) \quad$ Non-uniform steady condensing surface temperature, ${ }^{\circ} \mathrm{C}$

$\mathrm{T}_{\mathrm{V} \text {-in }} \quad$ Vapor temperature at test-section inlet, ${ }^{\circ} \mathrm{C}$

$\mathrm{T}_{\mathrm{C} \text {-in }} \quad$ Temperature of the counter-current coolant water flow at the approach to the test-section, ${ }^{\circ} \mathrm{C}$

$\mathrm{X}_{\mathrm{fc}} \quad$ Approximate length needed for full condensation (estimted by computations), $\mathrm{m}$. 
$\mathrm{x}_{\mathrm{e}} \quad$ Ratio of test section length to test section inner diameter (L/D).

$\overline{\Delta \mathrm{T}} \quad \mathrm{T}_{\mathrm{sat}}(\mathrm{p})-\overline{\mathrm{T}}_{\mathrm{w}},{ }^{\mathrm{o}} \mathrm{C}$

$\Delta \mathrm{T}_{\text {sup }} \quad$ Vapor superheat, $\mathrm{T}_{\mathrm{V} \text {-in }}-\mathrm{T}_{\text {sat }}(\mathrm{p}),{ }^{\circ} \mathrm{C}$

$\Delta \mathrm{p} \quad \mathrm{p}_{\mathrm{in}}-\mathrm{p}_{\mathrm{exit}}, \mathrm{kPa}$

$\mathrm{Z}_{\mathrm{e}} \quad$ Ratio of exit vapor flow rate to total inlet flow rate

$\mathrm{Z}_{\mathrm{e}-\mathrm{expt}} \quad \mathrm{Z}_{\mathrm{e}}$ as obtained by experiments

$\mathrm{Z}_{\mathrm{e}-\mathrm{comp}} \quad \mathrm{Z}_{\mathrm{e}}$ as obtained by computations

$\rho_{2} \quad$ Density of vapor, $\mathrm{kg} / \mathrm{m}^{3}$

$\rho_{1} \quad$ Density of liquid, $\mathrm{kg} / \mathrm{m}^{3}$

$\mu_{2} \quad$ Viscosity of vapor, $\mathrm{kg} /(\mathrm{m}-\mathrm{sec})$

$\mu_{1} \quad$ Viscosity of liquid, $\mathrm{kg} /(\mathrm{m}-\mathrm{sec})$

\section{Subscripts}

exit Test-section exit

in Test-section inlet

$\mathrm{Na} \quad$ Natural steady case

\section{INTRODUCTION}

This paper outlines a fundamental and novel experimental investigation of effects of exit conditions on internal condensing flows. Reported experimental results confirm the existing computational results ([1], [2], [3]) that both the flow features and heat transfer rates inside a condenser are sensitive to exit conditions and therefore depend on the specification of inlet, wall (particularly condensing surface temperature), and exit conditions. The condensing surface temperature (not heat flux) is assumed known (and fixed) or knowable (through consideration of approriate conjugate problem). This is true because, geneally, heat is removed from the condensing flow through a wall and put in a large heat sink which may be a steady coolant flow in contact with the other side of the wallsurface or a suitabe arrangement of thermo-electric coolers. The paper identifies and establishes 
multiplicity of steady/quasi-steady solutions - and/or oscillatory flows - under different conditions at the exit. Experiments support the existing simulation results ([1], [2], [3]) that have already shown the presence of different steady/quasi-steady solutions for different steady specifications of the exit condition. Exit condition for condenser is specified by exit pressure. For partial (incomplete) condensation flows, specification of exit pressure is equivalent (see Fig. 6 in [1]) to specification of exit vapor quality (the ratio of vapor mass flow rate at the exit to the inlet mass flow rate). The computational simulations ([1], [2], [3]) for the gravity driven partial condensation cases inside a vertical tube predict that, for a certain set of inlet and wall conditions, even if the exit condition is not specified and a suitable range of exit conditions is available for the flow to choose from, the flow seeks and attains a specific "natural" exit condition (in Narain et al. [1] this situation is also termed natural unspecified steady exit condition due to the presence of an "attractor", i.e., an attracting solution). Unfortunately many planned system designs incorporate a condenser and assume that the condenser will always attain a steady flow even if no exit conditions are specified. This is not generally true. The attainment of steady flows under unspecified exit conditions occur more readily (over a larger parameter zone) for gravity driven condensate flows as opposed to shear driven flows (see [3]). The reported experimental results for gravity driven partial condensation cases under unspecified exit conditions support the computational results - both qualitatively and quantitatively. However the steady "natural" exit condition may or may not exist depending on whether or not a steady "attractor" exists (e.g., as shown in [3], it does not exist for most slow inlet flowrates in horizontal or zero gravity conditions) and even if an "attractor" does exist, its realization depends on whether the attracting "natural" exit condition value falls within the range of the available steady choices at the exit. In the absence of active specification of a steady exit condition, the available range of steady exit conditions is determined by the components downstream of the condenser and the specific nature of the flow loop design. Furthernore, because of the small pressure drops (see [3] or experimental runs reported here), 
when a steady "natural" exit condition is achieved under unspecified conditions, or the specified exit condition is not too far from this "natural" steady exit value, typically, vapor flows are close to incompressible.

The fact that, for partial condensation flows, one can achieve quite different values of average heat transfer coeffiecients under different realizations of quasi-steady flows that correspond to different specifications of exit vapor quality (or pressure) is not surprising - as this follows from a simple overall energy balance. In the context of boundary value problems for internal condensing flows, what is new is that our computational and experimental results unequivocally show that the commonly occuring condensing flows are very sensitive to the nature of exit conditions as well as to the changes in exit conditions (due to changes in exit pressure). This sensitivity arises from the ease with which these changes alter the vapor flow field in the interior. Therefore when only exit condition is changed from one steady value to another, the changes required for the interior vapor flow towards attaining a new steady flow are such that they do not demand removal of the new exit pressure imposition - as is the case for incompressible single phase flows with only one allowed exit pressure. Instead, for condensing flows, new steady flows are achieved for new exit conditions through appropriate changes in the vapor/liquid interfacial configurations and associated changes in interfacial mass, heat transfer rates (both local and overall), and other flow variables.

The vertical in-tube internal condensing flows - partial or complete (full) - are investigated here for downflow configuration. Though numerous in-tube condensation experiments have been done, most of the well known in-tube vertical downflow experiments done by Goodykoontz and Dorsch [4][5], Carpenter [6], etc. either limit themselves to sufficiently fast flows that do not significantly depend on exit conditions or operate under a particular set of exit conditions (that automatically gets determined by the employed experimental set up) and, therefore, results may vary from one experimental system to another. In addition to our group's very early (see Yu [7]) and subsequent ([1], 
[2]) computational findings on the importance of exit conditions for internal condensing flows, experimental findings of Rabas and Arman ([8]) have also indicated the significance of exit conditions through their observation that presence or absence of valves at the exit affected some of their in-tube vertical downflow results. Rabas and Arman [8] also pointed out an important fact that, in the annular regime, even for complete condensation in a vertically downward flow inside a tube (for which, at exit, the condensate is collected in a vapor plenum), the condensing flow is usually annular all the way up to the exit - that is, a continuous liquid phase never fills the entire tube. This ensures that the flow remains annular (or, at most, has a few liquid bridges that encapsulate vapor bubbles) in the segment downstream of the point of complete condensation. Beyond this point, average vapor flow rate and interfacial mass flux remain zero for all practical purposes. Additionally Rabas and Arman [8] have also pointed out that, in the case of horizontal in-tube complete condensation, the flow regime near the point of complete condensation (where vapor flow rate is nearly zero) is known to vary from gravity dominated stratified to gravity dominated plug-annular depending on whether the inlet mass flow rate is above or below a certain critical value.

Furthermore, on a related topic, several experimental results and analyses ([9] - [17]) indicate that, for certain physical arrangements leading to a specific class of inlet and outlet conditions, transients and instabilities are expected in complete condensation internal condensing flows. Since these experiments and the corresponding modeling techniques in the literature ([9] - [17]) limit themselves to a particular type of inlet and exit conditions, they do not directly apply to the presence or absence of observed transients and instabilities in other feasible categories of exit-condition specifications.

Since understanding of internal condensing flows' transients is not entirely possible in the context of traditional two-phase flow analyses based on homogeneous, separated, or drift flux formulations (see Wallis [18]), more sophisticated averaged model equations of varying degrees of 
complexities (see, e.g., Lahey and Drew [19]) have been proposed. Despite this, appropriate drift-flux and/or virtual mass force based analyses of Liao et al. ([20], [21]) and Wang ([22]) report some ability to capture transients in certain internal condensing flows of the type studied by Wedekind et al. ([9],[12],[15]), Bhatt et al. ([10],[11],[13]), Kobus et al. ([16]-[17]), Boyer et al. [14], etc. Furthermore Liao et al. ([20],[21]) have also reported difficulties in employing multi-dimensional, four field, twofluid model of Lahey and Drew [19] towards modeling transients and instabilities that are observed in internal condensing flow cases of their concern. Other analyses of Wedekind et al. ([9],[12]), Bhatt et al. ([10],[11]), and Kobus et al. ([16],[17]) employ the system mean void fraction (SMVF) model which allows one to ignore the momentum balance equation. These simpler integral analyses have been somewhat successful in capturing some features of the experimentally observed transients and flow oscillations that have been reported ([9],[11]) for certain in-tube horizontal condensing flows involving complete condensation. In these cases, a fixed-pressure tank (plenum) at sufficiently high pressure pushes vapor through an inlet valve to the inlet of a horizontal condensing section where the vapor is fully condensed and then the liquid flows out of the condenser exit, through an exit valve, to a fixed pressure tank (plenum) at low pressure.

To understand exit condition issues more clearly, the approach taken here has been to seek experimental confirmation of key results obtained from employing our fundamental and nearly exact computational technique ([1]-[3]) to obtain steady and unsteady simulations for laminar-vapor/laminarcondensate initial boundary value problems - in the limited context of separated quasi-steady annular condensing flows. Therefore, simulation results regarding internal condensing flows' sensitivity to exit conditions ([1]-[3]) have been central to the planning and development of the reported experiments and to the interpretation of the experimental results reported here. Fundamentally, internal condensing flows' exit condition sensitivity arises from governing equations being "elliptic" or requiring "twoway" space co-ordinates in the flow direction (see, e.g., Patankar ([23] or Fig. 1c). However this 
sensitivity to exit conditions or "two-way" behavior (i.e. flow variable at a point is influenced both by upstream and downstream local neighbors) is special and does not result from the typical "ellipticity" associated with slow flows and flow reversals (which are, as described in Patankar [23], associated with the changes in the sign of local Peclet numbers). In fact, it is found (for simulations in [1]-[3]) that even when vapor and liquid flows are unidirectional and local Peclet numbers (which appear in local discretization equations for the velocity components - see eqs. (5.61) - (5.64) in [23]) are very large, the flows exhibit "elliptic" or "two-way" behavior leading to sensitivity to exit conditions. This special sensitivity to exit condition is due to "two-way" behavior of the vapor pressure fields (reflected, in the context of our computational methodology [1], by the "two-way" behavior of the pressure equations given by eqs. (6.30) - (6.31) in [23]). These equations for condensing flows are such that the coefficients that multiply the pressures at the locally upstream and downstream neighbors are comparable even for large Peclet numbers. Due to this, effects of changes in the exit pressure are felt by the entire vapor flow field that is able to accommodate these changes because of the extra degree of freedom associated with multiple interface locations and associated heat transfer rates. As a result, when exit condition is changed from one steady value to another, the changes required for the interior vapor flow towards attaining a new steady flow are such that they do not demand removal of the new exit pressure imposition back to the original and "natural" steady value - as is the case for incompressible single phase flows. In stead, new steady flows are achieved through appropriate changes in the vapor/liquid interfacial configurations and associated changes in interfacial mass, heat transfer rates (both local and overall), and other flow variables.

The simulation results ([1]-[3]) supporting the experiments in this paper have already established that, for partial condensation, conditions at the exit of a condenser can be specified by unsteady or steady specification of the exit vapor quality (see Fig. 6 in [1]). Equivalently, and, more generally (for partial and full condensation cases), the exit-condition can be specified by specifying the 
exit pressure values. The underlying simulations ([3]) and experiments reported here also show that, for cases where the flow loop does not actively specify any exit condition (as is often the case with many condenser applications), given enough time, the flow may or may not be able to select a quasi-steady flow with a "natural" exit condition. This is because the unspecified exit condition cases, though commonly used in applications, are essentially "ill posed" boundary value problems and therefore existence of steady solutions are at the mercy of other factors (such as whether or not an "attracting" steady solution exists and, if it does, whether or not downstream conditions are conducive to the attainment of this "attracting" solution). Typically, for gravity dominated annular flows of the type considered here, a "natural" exit condition does exist. In the literature, condensing flows have been classified as to whether they are shear dominated or gravity dominated, internal or external, smooth or wavy at the interface, laminar or turbulent in the two phases, etc. It is proposed here that one can only make sense of the vast literature on internal condensing flows if they are also classified in different categories based on the conditions imposed at the inlet and the exit. The following three categories (termed categories I - III) proposed here cover most cases of interest.

\section{Category I (with complete or incomplete condensation under specified exit conditions)}

- Prescribed or known values of total inlet mass flow rate $\dot{\mathrm{M}}_{\mathrm{in}}(\mathrm{kg} / \mathrm{s})$, inlet vapor quality, inlet pressure $\mathrm{p}_{\mathrm{in}}$, and inlet temperature at all times $\mathrm{t}$. Without loss of generality, one can focus on an all vapor flow (an inlet vapor quality of unity) at the inlet with known values of total inlet (all vapor) mass flow rate $\dot{\mathrm{M}}_{\mathrm{in}}(\mathrm{kg} / \mathrm{s})$, inlet pressure $\mathrm{p}_{\mathrm{in}}$, and inlet temperature (at saturation temperature $\mathrm{T}_{\text {sat }}\left(\mathrm{p}_{\text {in }}\right.$ ) or at some superheat) at all times t. This means the prescription could be steady or unsteady.

- Prescribed or known wall temperatures $\mathrm{T}_{\mathrm{w}}(\mathrm{x}, \mathrm{t})<\mathrm{T}_{\mathrm{sat}}\left(\mathrm{p}_{\mathrm{in}}\right)$ for all $\mathrm{x}$-locations over which film condensation occurs. Typical wall temperature conditions of interest are steady, but unsteady conditions are relevant to start-up and shutdown. 
- Prescribed or known exit condition. For example, for steady exit conditions, exit pressure $p_{e}=$ constant, which is equivalent, for partial condensation cases, to setting exit mass quality $\mathrm{Z}_{\mathrm{e}} \equiv \dot{\mathrm{M}}_{\text {Vapor@xit }}(\mathrm{kg} / \mathrm{s}) / \dot{\mathrm{M}}_{\text {in }}(\mathrm{kg} / \mathrm{s})=$ an appropriate constant, where $\dot{\mathrm{M}}_{\mathrm{Vapor} @ \mathrm{exit}}(\mathrm{kg} / \mathrm{s})$ is the vapor mass flow rate at the exit at time $t$.

\section{Category II (with complete or incomplete condensation under unspecified exit conditions)}

- Prescribed or known values of inlet mass flow rate $\dot{\mathrm{M}}_{\mathrm{in}}(\mathrm{kg} / \mathrm{s})$, inlet pressure $\mathrm{p}_{\mathrm{in}}$, and inlet temperature (at saturation temperature $\mathrm{T}_{\mathrm{sat}}\left(\mathrm{p}_{\mathrm{in}}\right)$ or at some superheat) at all times t. Without loss of generality, it is assumed that the flow is all vapor at the inlet.

- Prescribed or known wall temperatures $\mathrm{T}_{\mathrm{w}}(\mathrm{x}, \mathrm{t})<\mathrm{T}_{\text {sat }}\left(\mathrm{p}_{\text {in }}\right)$ for all $\mathrm{x}$-locations over which film condensation occurs.

- No exit condition is prescribed, except for some system hardware limitations that may restrict the range of exit conditions available to the condenser.

Category III (complete condensation involving special specified conditions at the inlet and the exit)

Though, technically, this is a special form of category I flows, it is listed separately because it correlates with a different experimental set-up whose choice of hardware facilitate imposition of this special class of inlet and outlet prescriptions. This class has been extensively investigated in the literature ([9]-[16]) for oscillatory condensing flows.

- In this case there is a constant pressure reservoir, with a high pressure $\mathrm{p}_{\text {Tank-in }}$, that feeds the vapor flow (at inlet pressure $\mathrm{p}_{\mathrm{in}}$, temperature $\mathrm{T}_{\mathrm{V} \text {-in }}$, and density $\rho_{\mathrm{V} \text {-in }}$ ) into the test section through an inlet valve (with valve coefficient $\mathrm{k}_{\mathrm{i}}$ ). This requires that the inlet pressure, $\mathrm{p}_{\mathrm{in}}$, satisfy:

$$
\mathrm{p}_{\text {in }} \cong \mathrm{p}_{\text {Tank-in }}-\mathrm{k}_{\mathrm{i}} \frac{\dot{\mathrm{M}}_{\text {in }}(\mathrm{t})^{2}}{\rho_{\mathrm{V} \text {-in }}}
$$


- Also there is a constant pressure exit tank with a lower pressure $\mathrm{p}_{\text {Tank-exit }}$ to which the condensate flows through an exit valve of valve coefficient $\mathrm{k}_{\mathrm{e}}$. The exit valve handles an all liquid flow because this case is only for complete condensation flows. At the exit of the condenser, the flow rate is $\dot{\mathrm{M}}_{\text {exit }}$ at any time, $\mathrm{t}$, and the liquid density is $\rho_{\mathrm{L}-\mathrm{exit}}$. This requires that the test section exit pressure, pexit, satisfy:

$$
\mathrm{p}_{\text {exit }} \cong \mathrm{p}_{\text {Tank-exit }}+\mathrm{k}_{\mathrm{e}} \frac{\dot{\mathrm{M}}_{\text {exit }}(\mathrm{t})^{2}}{\rho_{\text {L-exit }}}
$$

- Prescribed or known steady wall temperatures $\mathrm{T}_{\mathrm{w}}(\mathrm{x})<\mathrm{T}_{\mathrm{sat}}\left(\mathrm{p}_{\mathrm{in}}\right)$ for all $\mathrm{x}$-locations over which film condensation occurs.

In the above context, the experiments and computations in this paper focus only on category I and category II flows. The reported experiments also define specific flow loop arrangements that allow realization of flows in these two categories. The experimental and/or modeling analysis papers of Wedekind et al. ([9],[12]), Bhatt et al. ([10]-[11],[13]), Kobus et al. ([16],[17]), Liao et al. ([18],[19]), etc. focus on category III flows for a horizontal condenser. Category III flows are not the subject of this paper. As a result, the flow transients and system instabilities reported in this paper, as far as flows within the test-section are concerned, are necessarily of different origin. However, at a system level, the experimentally observed flow oscillations' relationship to the better known ([11],[13]) results for category III flows in the downstream auxiliary condenser is discussed here.

The experimental runs reported here largely involve laminar condensate and turbulent vapor situations with possible vapor compressibility effects. Despite this, both qualitative and quantitative comparisons with simulation results based on the laminar-vapor/laminar-condensate methodology given in [1]-[3] are possible, and are presented here, for a feasible subset (within the boundaries for steady annular flows) of experimental runs. This comparison is possible because turbulent vapor often 
laminarizes in the vicinity of laminar condensate as the condensate is slow and remains laminar approximately up to $\mathrm{Re}_{\delta} \leq 1800$ (see film Reynolds number $\mathrm{Re}_{\delta}$ definition in Phan and Narain [24]). Also, for gravity driven condensate cases considered here, existence of turbulent vapor zones in the core and entrance zone of the condenser has only minor second order impact on pressure variations in the condenser. The far field vapor turbulence often tends not to be a significant player because the overall flow features (local and average heat transfer coefficients) are dominated by interfacial mass and heat transfer rates which are dominated by the typically laminar nature of the gravity driven condensate flow and the associated laminar nature of vapor flow in the vicinity of the interface. Because of the above, all experimental runs reported here for partial (or incomplete) condensation cases involving laminar condensate show a very good qualitative agreement with the simulations as far as existence of multiple steady solutions for multiple steady exit conditions (category I) and a "natural" steady solution for the unspecified exit condition cases (category II) are concerned. The agreement with simulations, with regard to exit vapor quality and general consistency with overall heat transfer rates, are also quantitatively very good for experimental runs that fit the annular flow assumption for the simulations. It should be noted that, additionally, the accuracy of the employed simulation methodology ([1] - [3]) and its quantitative compatibility with a different set of experimental runs (Lu and Suryanarayana [25]) for shear dominated flows (category II) have also been established (see [2]). Furthermore, computational results for internal condensaing flows are obtained from a simulation tool that has a proven ability (see Phan and Narain [24]) to make good quantitative predictions for wave phenomena and their effects on heat transfer rates for the benchmark classical problem of Nusselt [26]. Besides this, since the simulation yields all flow variables including interface locations, it can potentially be used towards validating/supporting more complex averaged equations (such as Lahey and Drew ([19]) which would necessarily be needed for more complex flow regimes (dispersed, bubbly, intermittent plug-slug, etc.). 
Experimental investigation of annular complete condensation cases reported here are less complete and limited to "natural" steady flows in category-II. Computational simulations for these cases are also limited because the flow often condenses completely somewhere within the test-section and the current simulation technique can only cover the zone from the inlet to the point of full condensation. The simulation tool has not yet been enhanced to automatically identify and handle the exit-pressure sensitive adiabatic two-phase annular flow between the point of full condensation and the exit. The reported experiments cover "natural" full condensation cases under unspecified exit conditions and the hardware needed to investigate complete condensation category-I flow (i.e., prescribed exit condition case) is being developed as an important ongoing area of research.

The exit condition sensitivity for internal condensing flows and hitherto nonexistent accounting of this fact in the categorization of these flows is perhaps one of the reasons for the large uncertainities and deficiencies noted by Palen et al. [27] with regard to poor usefulness of quantitative information available from existing correlations for heat transfer coefficients.

The experiments reported here involve a single pure working fluid (viz. FC-72 by 3M Corp.) and focus on inlet mass flow rates that correspond to inlet vapor Reynolds numbers in the range of 10,000 - 40,000 and vapor to wall temperature differences of $3-60^{\circ} \mathrm{C}$ (i.e. $0 \leq \mathrm{Ja} \leq 0.4$ ).

An experimental oscillatory-flow example of a relevant system-instability arising from the coupling of the condenser's exit condition with flow instability in a component downstream of the condenser is also presented here.

\section{FUNDAMENTAL SIMULATION RESULTS AND FLOW-LOOP FACILITY}

\section{DEVELOPMENT}

The condenser section, which is of the type shown in Figure 1a, is typically a part of a closed flow loop. The flow loop, which maintains a steady input pressure $p_{\text {in }}$ and mass flow rate $\dot{\mathrm{M}}_{\text {in }}$ at the 
inlet, while maintaining a prescribed steady (and nearly uniform) condensing surface temperature, may be designed to provide different categories of exit conditions. Exit condition specifications for category I and category II flows defined earlier in section-1 are realized through flow arrangements indicated in Fig. 2 and Fig. 3 respectively. Section 4 on experimental procedures further describes how these flow loops are able to provide, respectively, a steady specified condition and a range of unspecified conditions at the exit of the condenser (test section).

The flow condition at a point $\mathrm{P}$ (or a zone containing such points) is called "one-way" or "parabolic" (see Patankar [23]), if only or mostly the upstream neighbor (besides the side neighbors, as in Fig. 1b) affects the values of all the flow variables at P. The flow condition at a point $\mathrm{P}$ (or the zone containing such points) is called "two-way" or "elliptic" (see Patankar [23]), if both the upstream and downstream neighbors (as in Fig. 1c) affect the value of any one flow variable at $\mathrm{P}$ (which, in this case, is found to be pressure in the vapor). Our theory/computations (see [1] - [3]) establish that the flow condition at a point inside the two-phase zone of internal condensing-flows are always "two-way" or "elliptic" because of vapor flows' sensitivity to exit condition. Exit condition values are externally imposed for category I and category III flows of section-1 and they are, however, unspecified (but may be self-selected) for some category II flows. Therefore, technically, category II flows come under "ill posed" boundary value problem category and existence/attainment of steady solutions are at the mercy of other factors (such as whether or not a steady "attractor" solution exists for the available range of exit conditions and how the available exit condition range is affected by components downstream of the condenser). These flows' exit-condition sensitivity (or "ellipticity") is because the discretization equation for vapor pressure field (see the pressure discretization equations for SIMPLER procedure in Patankar [23]) is such that both the upstream and downstream neighbors of point P (Fig. 1c) influence the pressure at that point. This pressure field behavior is there even as the velocity components are governed by discretization equations that are "one-way" with only upstream neighbors (Fig. 1b) 
influencing the velocity at that point. As a result, even if the wall conditions and inlet conditions are steady/quasi-steady, the flow in the condenser can be steady or unsteady depending on whether the exit conditions (i.e. exit pressure or vapor quality) are steady or unsteady.

When the exit conditions on internal condensing flows are not specified, as for category II flows defined in section-1, there may or may not exist (see [1] - [3]) a long-term "natural" steady flow. Existence of long-term "natural" steady/quasi-steady flow corresponds to the existence of an attracting (see Narain et al. [1]) steady "natural" exit condition. When natural attractors are weak or do not exist, as is the case for some horizontal and zero gravity condensing flows ([3]), the concave bowl analogy schematic for "attractors" given in Fig. 9 of Narain et al. [1] needs to be replaced by a bowl shape which is either weakly concave or completely flat. Furthermore, for category II flows, in Phan et al. [3], existence of an "attractor" leading to a long-term steady exit condition was termed a long-term "one-way" or "parabolic" behavior. Similarly, non-existence of an "attractor" (typically an indicator of flows that lie outside the annular regime and are more complex in the sense that they exhibit certain degrees of randomness or indeterminacy) was termed long-term "two-way" or "elliptic" behavior.

For category-I partial condensation flows with steady specified exit conditions, the computational simulations in Fig. 4 (for the flow condition specified in Fig. 2 and Table 1 of Phan et al. [3]) show three different steady solutions for three different specified vapor qualities $Z_{e}$ at the exit (viz. $\mathrm{Z}_{\mathrm{e} 1}=0.15, \mathrm{Z}_{\mathrm{e} 2}=0.215$ and $\left.\mathrm{Z}_{\mathrm{e} 3}=0.3\right)$

For category-II flows, in Fig. 4, it is computationally shown that if exit vapor quality specification constraints at $\mathrm{Z}_{\mathrm{e} 1}=0.15$ or $\mathrm{Z}_{\mathrm{e} 3}=0.3$ are removed at some time $(\mathrm{t}=0)$ - and subsequently $(t>0)$ one does not specify any exit condition - this particular incomplete condensation flow seeks its own long term and steady "natural" exit vapor quality $\mathrm{Z}_{\mathrm{e} \mid \mathrm{Na}}=\mathrm{Z}_{\mathrm{e} 2}=0.215$ and an associated steady "natural" flow. 
To validate the above results as well as to address additional issues associated with the condensate flows' sensitivity to ever-present minuscule wall noise ([1], [2]), start-up, steady flow realizability issues, flow regime issues, and flow stability issues - a flow-loop is developed with a vertical condenser as a test-section.

\section{EXPERIMENTAL FACILITY}

A 0-500 W evaporator/boiler in Figs. 2-3 is used to evaporate the working fluid (FC-72). The vapor mass flow rate out of the evaporator, $\dot{\mathrm{M}}_{\text {in }}$, is fed into the test section. This mass flow rate is measured by a Coriolis flow meter $F_{1}$ and, during transients, this value can be controlled by the pneumatically actuated control-valve $V_{1}$ (shown connected to $F_{1}$ in Figs. 2-3). Under steady conditions though, the value of $\dot{\mathrm{M}}_{\text {in }}$ gets approximately fixed by the net steady electrical heating rate for the evaporator. This is due to the restriction imposed by the evaporator energy balance, viz., $\dot{\mathrm{M}}_{\mathrm{in}} \approx \dot{\mathrm{Q}}_{\mathrm{b}} / \mathrm{h}_{\mathrm{fg}}\left(\mathrm{p}_{\mathrm{b}}\right)$. Here $\dot{\mathrm{Q}}_{\mathrm{b}}$ is the net heat rate into the evaporator, $\mathrm{p}_{\mathrm{b}}$ is the steady evaporator pressure, $\mathrm{T}_{\mathrm{b}} \approx \mathrm{T}_{\text {sat }}\left(\mathrm{p}_{\mathrm{b}}\right)$ is the steady evaporator temperature (which is nearly equal to the saturation temperature of the fluid at pressure $\mathrm{p}_{\mathrm{b}}$ ), and $\mathrm{h}_{\mathrm{fg}}$ is the heat of vaporization at the liquid/vapor surface pressure $\mathrm{p}_{\mathrm{b}}$ in the evaporator. Towards reduction in start-up time to steady state in the evaporator, the liquid flowing in the evaporator is warmed up (between points $\mathrm{P}^{\prime}$ and $\mathrm{B}$ ' in Figs. 2 - 3) so its temperature is nearly equal to the evaporator temperature $\mathrm{T}_{\mathrm{b}} \approx \mathrm{T}_{\mathrm{sat}}\left(\mathrm{p}_{\mathrm{b}}\right)$.

The test-section is a $0.8 \mathrm{~m}$ long vertical stainless steel $(316 \mathrm{SS})$ tube with $6.6 \mathrm{~mm}$ inner diameter $\mathrm{D}$, and $12.7 \mathrm{~mm}$ outer diameter. At the entrance of the test-section, the inlet vapor temperature is denoted as $\mathrm{T}_{\mathrm{V} \text {-in, }}$, the inlet pressure is denoted as $\mathrm{p}_{\mathrm{in}}$, and the inlet vapor is kept slightly superheated $\left(3-5^{\circ} \mathrm{C}\right.$ superheat obtained by heating a relevant portion of connecting tubes by a rope heater). A suitable thermocouple and an absolute pressure transducer respectively measure the 
temperature $\mathrm{T}_{\mathrm{V} \text {-in }}$ and pressure $\mathrm{p}_{\mathrm{in}}$ of the vapor at the inlet. The dynamic view from an axial borescope, mounted at the top of the test-section shown in Fig. 5, is able to visualize and ascertain the nature of the flow in the first half of the test-section. However, because of sharpness and contrast improvements that are needed for the images, snapshots and video clips of the flows can not currently be included in this paper. They are, however, expected to be available in the near future. We are currently able to use these views to ascertain whether or not annular film condensation begins near the indicated "start of condensation" point in Fig. 5 and also to ascertain (and then to ensure) dryness of the vapor up to the test-section inlet.

The test-section (see Fig. 5) is suitably instrumented with various sensors (thermocouples, pressure transducers, etc.). For future work, there is an arrangement to obtain local film thickness data through integration of our recently invented non-intrusive film thickness sensors that utilize the principle of fluorescence and fiber-optic technology (see $\mathrm{Ng}$ [28]) and are able to measure "local" timevarying thickness of dynamic liquid films. The technique used for mounting all the sensors is indicated in Fig. 6. The sensor tips are flush with the inner surface of inner cylinder to within $\pm 50 / 1000$ " and none of the sensor diameters exceeds $1.1 \mathrm{~mm}$. In Fig 6, the transducer is secured in to a stainless steel sleeve with waterproof epoxy - ensuring no air gaps were present between the transducer probe and the sleeve. The sleeve and sensor tip sit in a groove that accommodates an O-ring of a specific dimension chosen for consistency with the sensor size. This O-ring when compressed by compression fitting, expands and presses against the walls of the groove and makes certain that, over the pressure range of the interest, neither the condensing fluid (in liquid or vapor phase) in the inner cylinder nor the cooling water in the annulus can cross the O-ring barrier to mix with one another.

The test-section in Fig. 5b (not shown to size relative to the outer tube in Fig. 5a) is centrally aligned in the hollow space of a larger diameter stainless steel (314 SS) tube. This outer tube has an inner diameter of $23.62 \mathrm{~mm}$ and an outer diameter of $25.40 \mathrm{~mm}$. The test-section tube is cooled by flow 
of cold water in the annulus formed by the outer surface of the test-section tube and the inner surface of the outer tube. As shown in Figs. 2-3, the flow of coolant water is arranged by a separate closed loop consisting of the shell-side of the shell-in-tube heat exchanger (flow is on shell-side) and a pump. A separate loop, not shown in Figs. 2-3, assures cold-water flow at a steady constant temperature and a steady flow rate through the tube-side of the heat exchanger in Figs. 2-3. This loop (see Kurita [30]) replaces the open drain water loop used in the preliminary experiments. This loop has two chillers in series (one for coarse and one for finer control of temperature) and this provides for a good control of the steady value of temperature $\mathrm{T}_{\mathrm{C}-\text { in }}$ (marked in Fig. 5a) at the coolant inlet location in Figs. 2-3. This, in turn, enables repetition of experimental runs regardless of seasonal variations in drain water temperature.

The sensors and the controllers employed in the flow loop are described next. Resistance temperature detectors (RTDs) and type-T thermocouples measure temperatures at different locations of the test-section (see Fig. 5) and at other flow loop locations marked by points B, B', T', $\mathrm{C}_{1}, \mathrm{C}_{2}, \mathrm{D}_{1}$, $\mathrm{D}_{2}, \mathrm{P}_{1}^{\prime}, \mathrm{P}_{2}^{\prime}$, and $\mathrm{P}^{\prime}$ in Figs. 2-3. A barometer measures outside atmospheric pressure. Flow meters at locations marked $\mathrm{F}_{1}$ (Coriolis meter that directly measures mass flow rate), $\mathrm{F}_{2}$ (a volume flow rate measuring rotameter), $\mathrm{P}_{1}$ (volume flow rate meter imbedded in pump $\mathrm{P}_{1}$ ), and $\mathrm{P}_{2}$ (volume flow rate meter imbedded in pump $\mathrm{P}_{2}$ ) yield mass flow rates through those locations. Absolute pressure transducers measure pressures at test-section inlet (location 1 in Fig. 5), and at locations $\mathrm{B}$ and $\mathrm{D}_{2}$ in Figs. 2-3. Differential pressure transducers measure pressure differences in the test-section (in Fig. 5a, this is between locations 1 and 9, location 3 and outside atmosphere, and location 6 and outside atmosphere). Two electronically controllable displacement pumps $\mathrm{P}_{1}$ and $\mathrm{P}_{2}$ (see Figs. 2-3) can pump liquid FC-72 at a steady or unsteady specification of volume or mass flow rates. A pneumatically controlled valve $V_{1}$ is used, as needed, to control mass flow rate through $F_{1}$. Most of the sensors' signals are in a 4-20 mA range with the exception of thermocouples $(0-100 \mathrm{mV})$, absolute pressure 
transducers $(0-150 \mathrm{mV})$, RTDs $(100 \Omega)$, and two of the differential pressure transducers $(0-10 \mathrm{~V})$. All the sensors' signals are acquired and conditioned with the help of National Instrumets' SCXI modules (SCXI-1102, 1102B, and 1122) and all the controllers' signals are sent out (in 4-20 mA range) by an SCXI-1124 module to the respective instruments (e.g. pumps $\mathrm{P}_{1}$ and $\mathrm{P}_{2}$ and valve $\mathrm{V}_{1}$ ). These four SCXI modules are multiplexed together via an SCXI-100 chassis that communicates with the M-series PCI-G251 DAQ card from National instruments.

For convenience, the system in Figs. 2-3 is broken into the following sub-systems. (i) Subsystem $\mathrm{A}$ is the portion of the flow loop between points $\mathrm{B}^{\prime}$ and $\mathrm{T}^{\prime}$ (this portion contains the flow into the evaporator, the evaporator, the flow meter $F_{1}$, valve $V_{1}$, and the tubing leading the flow into the test-section). (ii) Sub-system B is the portion of the flow loop between points $\mathrm{T}^{\prime}$ and $\mathrm{T}^{\prime \prime}$ (this portion consists of the test-section). (iii) Sub-system C is the portion of the flow loop between points $\mathrm{T}^{\prime \prime}$ and $\mathrm{P}^{\prime}$ (this portion consists of the L/V separator, the two branches of the flow in the liquid line and the auxiliary-condenser line, and the pump or pumps). (iv) Sub-system D is the portion that consists of the primary coolant loop shown in Figs. 2-3 and a secondary coolant loop (not shown here but shown in Kurita [30]). The sub-systems A-D defined above are not marked in Figs. 2-3 but the definitions introduced here are necessary for later discussions of the experimental results.

Additional details of this experimental facility (in fact of a similar earlier version), dataacquisition, and LabView 7.1 based data processing and instrument control strategies are available in Siemionko [29].

\section{EXPERIMENTAL PROCEDURE}

Here we describe the procedure for investigating partial and full condensation cases under different exit conditions. Note that results from different exit condition cases are to be compared for approximately the same inlet mass flow rate $\dot{\mathrm{M}}_{\text {in }}$, inlet pressure $\mathrm{p}_{\mathrm{in}}$, and temperature difference 
$\overline{\Delta \mathrm{T}}=\mathrm{T}_{\text {sat }}$ (pin) $-\overline{\mathrm{T}}_{\mathrm{w}}$, where $\overline{\mathrm{T}}_{\mathrm{w}}$ is the mean condensing surface temperature. Pure vapor may be allowed to enter the test section with a superheat of $2-10^{\circ} \mathrm{C}$. The purging process (see [29]) ensures that the vapor flowing in the test section is pure over the duration of the experimental run and that noncondensable air in the flow loop has zero to insignificant presence. Note that vapor Jacob numbers Jal $\left.\right|_{V}$ $\left(\equiv \mathrm{C}_{\mathrm{p}} \mathrm{l}_{\mathrm{V}} \cdot \Delta \mathrm{T}_{\mathrm{sup}} / \mathrm{h}_{\mathrm{fg}}\left(\mathrm{p}_{\mathrm{in}}\right)\right.$, where $\mathrm{C}_{\mathrm{p}} \mathrm{l}_{\mathrm{V}}$ is the specific heat of the vapor and $\mathrm{h}_{\mathrm{fg}}$ is the heat of vaporization) represent the ratio of sensible cooling of vapor to heat of vaporization. Since these numbers are very small $\left(<1.0 * 10^{-5}\right)$ in comparison to liquid Jacob numbers $\mathrm{Ja}\left(\equiv \mathrm{C}_{\mathrm{p}} \mathrm{L}_{\mathrm{L}} \cdot \Delta \mathrm{T}_{\mathrm{sup}} / \mathrm{h}_{\mathrm{fg}}\left(\mathrm{p}_{\mathrm{in}}\right)\right.$, where $\left.\mathrm{C}_{\mathrm{p}}\right|_{\mathrm{L}}$ is the specific heat of the liquid condensate), vapor temperature can be effectively modeled as a steady constant equal to the inlet saturation temperature. The steadiness of $\dot{M}_{\text {in }}$ primarily depends on the constancy of heat supply to the evaporator (which is easily achieved by constant electric heating at a known wattage) and the eventual approximate steadiness of the evaporator pressure $\mathrm{p}_{\mathrm{b}}$. Even if the steady value of $\mathrm{p}_{\mathrm{b}}$ changes somewhat for different start-ups, as long as the corresponding evaporator saturation temperature $\mathrm{T}_{\mathrm{b}}$ changes negligibly, it is found that the remaining flow loop pressures relative to a single effective boiler pressure are the same for two independent repetitions of the same experimental run (i.e. same $\dot{\mathrm{M}}_{\mathrm{in}}, \overline{\Delta \mathrm{T}}, \overline{\mathrm{T}}_{\mathrm{w}}$, and $\mathrm{Z}_{\mathrm{e}}$ ). This is true because all other pressures are effectively characterized by changes relative to this pressure. Alternatively, a previously obtained steady value of $\mathrm{p}_{\mathrm{b}}$ can be regained by bringing the new evaporator pressure back to roughly this same value by suitably switching the heater on and off under same steady heating rate, or, by gradually venting the evaporator from a higher pressure to the desired earlier value. Both of the above described processes have been used to successfully assess the repeatability of a few representative experimental runs. With regard to constancy, over time, of water temperature $\mathrm{T}_{\mathrm{C} \text {-in }}$ at the coolant inlet for the testsection (see Fig. 5), achieving constancy of water temperature and its flow rate in the secondary coolant loop (not shown here) is sufficient. 


\section{$\underline{\text { Specified Exit Conditions (Category I flows) }}$}

\section{Incomplete or partial condensation flows}

For investigation of specified conditions (through a steady and specified exit vapor quality) at the exit that involve partial condensation flows through the test-section, the arrangement in Fig. 2 is used. In this arrangement, the liquid at the exit flows out of the test-section at a mass rate of $\dot{\mathrm{M}}_{\mathrm{L}}$, goes through the liquid/vapor $(\mathrm{L} / \mathrm{V})$ separator, and is pumped by pump $\mathrm{P}_{1}$ back into the evaporator. Both the pumps $\mathrm{P}_{1}$ and $\mathrm{P}_{2}$ (displacement pumps made by Masterflex) in Fig. 2 allow digital control of flow rates. The vapor at the exit flows out of the test-section at a mass flow rate of $\dot{\mathrm{M}}_{\mathrm{V}}$ and is measured through a volume and mass flow rate measuring rotameter $F_{2}$. This vapor then flows through an auxiliary condenser where the vapor is completely condensed into liquid, goes through the pump $\mathrm{P}_{2}$, and then, on its way to the evaporator, merges near point $\mathrm{P}^{\prime}$ (see Fig. 2) with the liquid flowing out of pump $\mathrm{P}_{1}$.

The control strategy, to achieve a specified steady flow with a prescribed exit vapor quality $\left(\dot{\mathrm{M}}_{\mathrm{V}} / \dot{\mathrm{M}}_{\mathrm{in}} \equiv \mathrm{Z}_{\mathrm{e}}\right)$ for a given inlet and wall conditions, is to initially hold valve $\mathrm{V}_{1}$ open at a fixed level of opening while ensuring (as described in the first paragraph of this section) desired steady values of $\dot{\mathrm{M}}_{\text {in }}, \mathrm{p}_{\mathrm{b}}$, and $\Delta \overline{\mathrm{T}}$. Then the exit vapor mass rate $\dot{\mathrm{M}}_{\mathrm{V}}$ through pump $\mathrm{P}_{2}$ (or rotameter $\mathrm{F}_{2}$ ) is held fixed at a value less than the inlet mass rate $\dot{\mathrm{M}}_{\text {in }}$ while exit liquid mass flow rate $\dot{\mathrm{M}}_{\mathrm{L}}$ is varied through pump $\mathrm{P}_{1}$ at a value given by the tracking equation: $\dot{\mathrm{M}}_{\mathrm{L}} \mathrm{I}_{\mathrm{P}_{1}}=\dot{\mathrm{M}}_{\mathrm{in}}-\dot{\mathrm{M}}_{\mathrm{V}} \mathrm{I}_{\text {Rotameter }}$.

As the flow through the evaporator becomes steady, $\dot{\mathrm{M}}_{\text {in }}$ becomes steady, and, at that time, we may or may not need to hold this value actively fixed with the help of controllable valve $\mathrm{V}_{1}$. At this stage, active control of valve $\mathrm{V}_{1}$ does not achieve much except that it eliminates some unwanted minuscule drifts in the inlet mass rates. For a given set of inlet $\left(\dot{\mathrm{M}}_{\mathrm{in}}, \mathrm{p}_{\mathrm{in}}, \mathrm{T}_{\mathrm{V}-\mathrm{in}}\right)$ and wall $\left(\overline{\mathrm{T}}_{\mathrm{w}}\right)$ 
conditions, different specified steady states are achieved by the above strategy for different values of $\dot{\mathrm{M}}_{\mathrm{L}}$. Experimentally achieved examples of specified exit category-I flows are discussed in the next section.

\section{Complete or full condensation flows}

The experimental technique for prescribing different exit pressures in full condensation cases is important but has not yet been implemented. Typically, one would need to specify different pressures at the exit of the test-section, which is downstream of the "point of full condensation." This requires active pressure control at the inlet of the displacement pump $\mathrm{P}_{1}$. This is part of an ongoing research and therefore this important case is not investigated here.

\section{Unspecified Exit Condition Cases (Category II flows)}

\section{“Natural” Partial Condensation}

For obtaining/investigating existence of "long term" steady natural exit condition for category II flows (under unspecified exit conditions) with all other conditions being kept the same as in a corresponding specified exit condition case in category I, the flow is required to go through the testsection and onwards under the arrangement shown in Fig. 3. Note that this arrangement has a single displacement pump as opposed to the two displacement pumps used in the arrangement of Fig. 2. The approach is to hold values of $\dot{\mathrm{M}}_{\mathrm{in}}, \mathrm{p}_{\mathrm{b}}$, and $\Delta \overline{\mathrm{T}}$ nearly the same as in one of the specified category-I cases while the pump $\mathrm{P}_{1}$ in Fig. 3 is controlled such that the mass flow rate through it tracks the equation: $\dot{\mathrm{M}}_{\mathrm{L}} \mathrm{I}_{\mathrm{P}_{1}}=\dot{\mathrm{M}}_{\text {in }}$. If start-up and other conditions allow, a steady state flow is attained in which, by the exit, the inlet vapor mass flow rate is split, by a natural selection process, into liquid condensate flow rate $\left.\dot{\mathrm{M}}_{\mathrm{L}}\right|_{\mathrm{Na}}$ and a vapor flow rate $\left.\dot{\mathrm{M}}_{\mathrm{V}}\right|_{\mathrm{Na}}$. Clearly these values satisfy the equation: 
$\dot{\mathrm{M}}_{\mathrm{in}}=\dot{\mathrm{M}}_{\mathrm{L}} \mathrm{I}_{\mathrm{Na}}+\dot{\mathrm{M}}_{\mathrm{V}} \mathrm{I}_{\mathrm{Na}}$. Experimentally achieved examples of specified exit category-II flows are discussed in the next section.

Complete or full condensation flows with a "natural" steady state

For achieving full condensation flows in the test-section, valve $\mathrm{V}_{3}$ in Fig. 2 is shut and the arrangement in Fig. 2 is then used. Here, we choose the controlling temperature difference $\overline{\Delta \mathrm{T}}=$ $\mathrm{T}_{\mathrm{sat}}(\mathrm{p})-\overline{\mathrm{T}}_{\mathrm{w}}$ to become sufficiently large for a fixed inlet mass flow rate to ensure that one achieves, through the indicated procedures for the set up and in Fig. 2, a steady flow with a "natural" $\dot{\mathrm{M}}_{\mathrm{V}}=0$.

For natural full condensation case, the valve $\mathrm{V}_{1}$ in Fig. 2 is left open at a fixed opening and pump $\mathrm{P}_{1}$ is controlled to always satisfy, in time, the relation $\dot{\mathrm{M}}_{\mathrm{L}} \mathrm{l}_{\mathrm{P}_{1}}=\dot{\mathrm{M}}_{\text {in }}$. If steady state is achieved, this leads to a "natural" steady (i.e. $\mathrm{X}_{\mathrm{fc}}<\mathrm{L}$ ) full condensation flow. The word "natural" is also used here because use of displacement pump P1 in the arrangement downstream of the test-section allows the test-section vapor flow to attain whatever pressure it desires by the test-section exit or by the point of full condensation. Because of experimental limitations, at present, $\mathrm{X}_{\mathrm{fc}}<\mathrm{L}$ is assured only through a computational simulation. Also note that, because of unspecified (free) exit condition, this way of achieving steady full condensation flows is expected to keep vapor density nearly uniform.

\section{EXPERIMENTAL RESULTS, DISCUSSIONS, AND COMPARISONS WITH SIMULATIONS}

The column headers in Tables 1-3 indicate accuracies of the values of key measured variables obtained through flow loops' instruments and sensors. Overall accuracy bounds for the reported calculated variables are also shown. The non-dimensional numbers $\mathrm{Re}_{\mathrm{in}}, \mathrm{x}_{\mathrm{e}}=\mathrm{L} / \mathrm{D}=106, \mathrm{Ja}, \rho_{2} / \rho_{1}$, and $\mu_{2} / \mu_{1}$ in Tables 1-3 define the flows and they are defined in [1]-[3]. In Tables 1-3, the heat flow rate 
$\dot{\mathrm{Q}}_{\text {out }}$ and associated average heat transfer coefficients $(\overline{\mathrm{h}})$ are obtained through the relation: $\dot{\mathrm{Q}}_{\mathrm{out}} \approx \dot{\mathrm{M}}_{\mathrm{L}} \mathrm{h}_{\mathrm{fg}}=\overline{\mathrm{h}}(\pi \mathrm{DL}) \overline{\Delta \mathrm{T}}$. The inlet vapor mass-flux $\mathrm{G}$ in Tables 1-3 is defined as $4 \dot{\mathrm{M}}_{\mathrm{in}} /\left(\pi \cdot \mathrm{D}^{2}\right)$

All (except the Coriolis meter F1) of the instruments' accuracies for measured variables were established after their in-house calibrations with the help of suitable and reliable reference instruments of known resolution and appropriate reference physical conditions (temperature, flow rate, pressure, etc.). The accuracy of the Coriolis meter was established by the vendor support staff at the time of its installation. The reference instruments were more trustworthy but not necessarily of higher resolution than the sensors being calibrated. For example, accurate mercury-in-glass thermometer for temperature, accurate liquid-column manometers and mercury-column barometers for pressure, and timed (using a stop-watch) collection of liquid in a graduated cylinder for liquid flow rates were used as reference instruments. The calibrations ensured zero systematic (or bias) error (see [31]) for all measured variables because of the definition of the calibration curve given below. The measured variables' random errors $\left(\Delta \mathrm{E}_{\mathrm{T}}\right)$ indicated in Tables 1-3 were calculated as square mean value of the following three: (i) vendor supplied precision error for the instrument denoted as $\Delta \mathrm{E}_{\mathrm{P}-\mathrm{I}}$, (ii) precision of the reference instrument denoted as $\Delta \mathrm{E}_{\mathrm{P}-\mathrm{R}}$, and (iii) root mean square variation $\Delta \mathrm{E}_{\mathrm{RMS}}$ obtained from the curve fitting process that yielded the calibration curve for the instrument from a given set of reference instrument data from the calibration experiment. The in-house calibrations provided both the offset (also called bias) and slope modifications for typically linear sensor outputs (which is the initial vendor recommended linear relationship between the sensor's signal range and the range of the physical variable that the sensor is supposed to measure). Thus $\Delta \mathrm{E}_{\mathrm{T}} \equiv \sqrt{\Delta \mathrm{E}_{\mathrm{P}-\mathrm{I}}^{2}+\Delta \mathrm{E}_{\mathrm{P}-\mathrm{R}}^{2}+\Delta \mathrm{E}_{\mathrm{RMS}}{ }^{2}}$ was used. The measurements of volume flow rates obtained from the two liquid pumps and the vapor flow rotameter were converted to mass flow rates through suitable experimentally verified density multiplication factors. The calculated variables were related, through the right side of an explicit 
equation, to other measured variables alone or measured and calculated variables of known accuracies. The error estimates for the calculated variables reported in Tables 1-3 were obtained by well-known standard procedures (see, e.g., eqs. (3.27)-(3.28) in [31]). The accuracies of individual calculated variables in a column were taken into account to report maximum values of the errors in the column headers of Tables 1-3. All the individual values of errors were either less than or equal to these reported error values.

The experimental runs reported in the next section were taken after ensuring that: (i) representative runs were repeatable, (ii) the mass flow rates added up for partial condensation cases, (iii) overall energy balance for the test section was satisfied i.e. $\dot{\mathrm{M}}_{\mathrm{in}} \cdot \mathrm{h}_{\mathrm{fg}} \approx \dot{\mathrm{M}}_{\mathrm{w}} \cdot \mathrm{C}_{\mathrm{pw}} \cdot \overline{\Delta \mathrm{T}}$ for a representative full condensation case, and (iv) various data were reasonable (based on simulation estimates) and consistent with one another. The experimental data for category II (unspecified exit condition) partial condensation cases in Table-1 include exit vapor quality $\mathrm{Z}_{\mathrm{e}}$ and its value obtained from simulations. Table 2 reports the experimental data for category I (specified exit condition) cases. The experimental data for category II full condensation cases is reported in Table 3. The values for pressure drop across the test section were found to be negative for almost all of the cases that have been reported here, indicating that pressure at the exit was greater than that at the inlet. This is because of the typical range of $\dot{\mathrm{M}}_{\mathrm{in}}$ and $\overline{\Delta \mathrm{T}}$ we have been operating in $\left(0.5 \mathrm{~g} / \mathrm{s}\right.$ to $2 \mathrm{~g} / \mathrm{s}$ and $2^{\circ} \mathrm{C}$ to $12^{\circ} \mathrm{C}$ respectively). Further, the magnitude of experimental pressure rise was found to be higher than predictions obtained from laminar vapor/laminar condensate simulation tool employed in this paper. The results and discussions for exit condition categories I and II are described below separately for partial and full condensation flows. 


\section{$\underline{\text { Partial condensation flows }}$}

\section{Specified Exit Condition (Category I) and Unspecified Exit Condition (Category II) Cases}

The experimentally obtained partial condensation cases in category II (unspecified exit) are listed in Table 1 with all the essential details. The corresponding flow cases under category I (specified exit condition cases) are listed in Table 2. For partial condensation, Fig. 7a shows attainment of two specified exit condition cases' steady/quasi-steady flows marked Specified-1 $\left(\mathrm{t}_{2} \leq \mathrm{t}(\min ) \leq \mathrm{t}_{2}+20\right)$ and Specified-2 $\left(\mathrm{t}_{3} \leq \mathrm{t}(\min ) \leq \mathrm{t}_{3}+30\right)$. The Specified -1 and Specified -2 cases respectively correspond to run 1 and run 18 in Table- 2 . The results over time interval $t_{4} \leq t(\min ) \leq t_{4}+20$ show the experiment's ability to approximately repeat the data for a case that is approximately the same as Specified-1 and is termed as Specified-1 Approx. Following the method described in section 4, Figs. 7a-7b also show, over the time interval $\mathrm{t}_{1} \leq \mathrm{t}(\mathrm{min}) \leq \mathrm{t}_{1}+76$, the attainment of a corresponding "natural" steady exit condition and associated steady flow variables for an unspecified exit condition (category-II) case. This case corresponds to run 1 in Table 1. The Natural-1, Specified-1 and Specified-2 steady states (in Fig $7 \mathrm{a}-7 \mathrm{e}$ ) have the same values of $\dot{\mathrm{M}}_{\mathrm{in}} \approx 1.40 \pm 0.05 \mathrm{~g} / \mathrm{s}$ and $\overline{\Delta \mathrm{T}} \approx 11 \pm 1{ }^{\circ} \mathrm{C}$ but different values of $\dot{\mathrm{M}}_{\mathrm{L}}$ and $\dot{\mathrm{M}}_{\mathrm{V}}$ that satisfy $\dot{\mathrm{M}}_{\mathrm{L}} \mathrm{l}_{1}+\dot{\mathrm{M}}_{\mathrm{V}} \mathrm{l}_{1}=\dot{\mathrm{M}}_{\mathrm{L}} \mathrm{I}_{2}+\dot{\mathrm{M}}_{\mathrm{V}} \mathrm{l}_{2}=\dot{\mathrm{M}}_{\text {in }}$. The differences between the Specified-1 and Specified-2 cases are: (i) they have different heat transfer rates (since, energy balance gives: $\dot{\mathrm{Q}}_{\text {out }} \approx \dot{\mathrm{M}}_{\mathrm{L}} \mathrm{h}_{\mathrm{fg}}$ ), the two cases respectively have approximate heat transfer rates of $78 \pm 4 \mathrm{~W}$ and $64 \pm 4$ $\mathrm{W}$ and average heat transfer coefficients of $416 \pm 40 \mathrm{~W} / \mathrm{m}^{2}-\mathrm{K}$ and $377 \pm 40 \mathrm{~W} / \mathrm{m}^{2}-\mathrm{K}$ ), and (ii) different hydrodynamics - the signature of which is clear through corresponding computational simulations and, also, through the differences between experimentally obtained mean values of $\Delta \mathrm{p}$ for the two cases (they are, in Table 2, respectively, $-1.82 \mathrm{kPa}$ and $-0.65 \mathrm{kPa}$ ). Furthermore, specified (category-I) and unspecified (category-II) flows have different dynamic responses to a disturbance (in Figs. 7a-7e, a disturbance in $\mathrm{p}_{\mathrm{b}}$ and other variables were induced by momentarily shutting or decreasing the opening in the valve V1 shown in Figs. 2-3). The difference in dynamic response is seen by comparing 
Specified-2 and Natural-1 cases for transients' decay time $\tau_{\mathrm{D}}$ associated with exit vapor flow rate $\dot{\mathrm{M}}_{\mathrm{v}}$ in Fig. $7 \mathrm{a}$ or $\tau_{\mathrm{D}}$ associated with $\Delta \mathrm{p}$ in Fig. $7 \mathrm{~b}$. In Fig. $7 \mathrm{a}$ the rapid shutting or closing of valve V1 caused the indicated responses in $\dot{\mathrm{M}}_{\mathrm{in}}$ time history. For the Natural- 1 case, the response is as shown in Fig. 7a but a more rapid response for Specified-2 case is not captured by the resolution of the figure and hence it is indicated by a dotted line. With regard to dynamic responses to a disturbance - it is clear that Specified-2 case of Fig. 7a (though it is farther from a "natural" case) is more stable than the case for Natural-1 because its transients decay time $\tau_{\mathrm{D}}$ is much shorter. In other words, "natural" steady states for unspecified exit conditions (category-II) are generally more noise-sensitive because the exit in this case is not as isolated from the downstream flows (and thus from the variations at the exit itself) as is the exit for specified exit condition cases (category-I) - and this causes additional lingering impact of noise arising from the flow variables in the exit zone.

The cases shown in Fig. 7a-7e are representative runs taken from a set of partial condensation runs for specified (category-I) and unspecified (category-II) exit condition cases in Tables 1-2. The data matrix associated with these partial condensation category I and category II cases is best represented by Figs. 8a-8b. The test matrix for all partial condensation (including both the categories I and II) cases is limited by the system limits and flow regime boundaries indicated on the plane marked by inlet mass flow rate $\dot{\mathrm{M}}_{\text {in }}$ and temperature difference $\overline{\Delta \mathrm{T}}$ values. Figure $8 \mathrm{a}$ shows all the partial condensation cases plotted on the two dimensional plane formed by $\dot{\mathrm{M}}_{\mathrm{in}}$ and $\overline{\Delta \mathrm{T}}$. These parameters were found to be the key variables controlling the dynamics of the condensing flows in the test section. The typical overall values for lower and upper limits for inlet mass flow rate were found to be $1 \mathrm{~g} / \mathrm{s}$ and $2 \mathrm{~g} / \mathrm{s}$ respectively and that for the $\overline{\Delta \mathrm{T}}$ were recorded to be $2^{\circ} \mathrm{C}$ and $12^{\circ} \mathrm{C}$ respectively. The interior shaded zone in Fig. 8a represent $\dot{\mathrm{M}}_{\mathrm{in}}$ and $\overline{\Delta \mathrm{T}}$ values for which steady flows were attained for both specified (category -I) and unspecified (category-II) exit condition cases. As the category II partial 
condensation cases were associated with the corresponding category I partial condensation cases (i.e. there existed a unique "natural" category II case for a set of category I cases), they are represented with the same point on $\dot{\mathrm{M}}_{\text {in }}-\overline{\Delta \mathrm{T}}$ plane. The bounding curve-B in Fig. 8a indicates lower threshold of $\overline{\Delta \mathrm{T}}$ such that steady condensing flows attained below that curve (see points marked in Fig. 8a) were drop wise patchy - i.e. not annular - on the condensing surface near the inlet. Below this curve, the condensation - as observed from the inlet borescope - indicates that the flow is no more film annular near the point of onset of condensation as there are wet and dry patches associated with drop-wise condensation. This happens because $\overline{\Delta \mathrm{T}}$ value is below a lower threshold. The bounding curve-B is partly experimental and curve-C on the right in Fig. 8a is, at present, entirely schematic (i.e. not fully explored by experiments). Curve-C represents expected transition to wispy-annular flows (see Fig. 10.3 in Carey [32]) at very high $\dot{\mathrm{M}}_{\text {in }}$ at any $\overline{\Delta \mathrm{T}}$. The dotted curve-A on the left bottom has been experimentally noticed. It does not represent a flow regime boundary for the test-section, as it is a result of the exit pressure oscillations or unsteadiness in test section imposed by oscillatory or other plug/slug instabilities occurring in the auxiliary condenser downstream of the test section. The auxiliary condenser is a $0.5 \mathrm{~m}$ long straight tube with $3^{\circ}$ downward inclination and experiences a fully condensing flow due to a cold-water flow - of known temperature and flow rate - in the surrounding annulus. The bounding curve in the upper left corner of Fig. 8a is marked as curve-D. This curve represents transition from partial condensation to full condensation. If $\dot{\mathrm{M}}_{\text {in }}$ is reduced and $\overline{\Delta \mathrm{T}}$ is increased further, computations show that the left side of curve-D represent the zone for which the entire vapor coming in condenses inside the test section (i.e., for category II flows, $\mathrm{X}_{\mathrm{fc}}$ in Fig. 10 starts satisfying $\mathrm{X}_{\mathrm{fc}} \leq \mathrm{L}$ on the left side of curve-D as opposed to $\mathrm{X}_{\mathrm{fc}}>\mathrm{L}$ on the right side of curve-D). Since the area on the left side of curve is a domain of full condensation, it is discussed in the next subsection. 
For a few data points in Fig. 8a, the rotameter $\mathrm{F}_{2}$ data was corrupted by the float's occasional stickiness to the rotameter walls. These cases are marked by unfilled circles in Fig. 8a. and all the rest of the good cases (also based on comparisons with computational simulations) are marked by dark filled circles. These dark filled circles representing good partial condensation cases in Fig. 8a are actually the projections on the $\dot{\mathrm{M}}_{\text {in }}-\overline{\Delta \mathrm{T}}$ plane of the points reported in three dimensional data matrix which has $\dot{\mathrm{M}}_{\mathrm{in}}, \overline{\Delta \mathrm{T}}$ and $\mathrm{Z}_{\mathrm{e}}\left(\equiv \dot{\mathrm{M}}_{\mathrm{V}} / \dot{\mathrm{M}}_{\mathrm{in}}\right)$ as three axes. This three-dimensional data matrix is shown in Fig. $8 \mathrm{~b}$ and it depicts all the cases of category II (unspecified exit) as well as category I (specified exit) partial condensing flows. Each vertical line perpendicular to the $\dot{\mathrm{M}}_{\mathrm{in}}-\overline{\Delta \mathrm{T}}$ plane in Fig. 8b represents a set of partial condensation cases involving category II and associated category I case/cases. The category II cases are shown by circles and category I cases are shown by squares. Some vertical lines contain only category I flows (category II flows were not experimentally obtained for these data sets) and some of them contain only category II flows (category I flows were not experimentally obtained for these data sets). The rest of the vertical lines contain both category I and category II flows. The projections for Fig. 8a were taken for the data sets which contain either both category I and II flows or just the category II flows. The points representing only category I flows in the three-dimensional Fig. $8 \mathrm{~b}$ were not included in Fig. 8a. A few data sets (vertical lines) have more than one category I cases associated with corresponding category II case. However, there can be only one category II (unspecified exit) case associated with each vertical line. This category II flow along a vertical line has

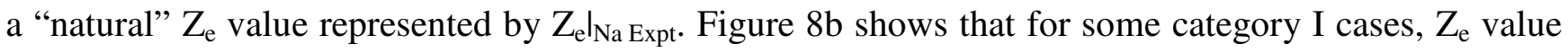
of the flow is higher than the "natural" $Z_{\mathrm{e}}$ and for some cases, it is lower than that. The vertical lines in Fig. $8 \mathrm{~b}$ passing through the $\mathrm{Z}_{\mathrm{e}} \mathrm{I}_{\mathrm{Na}}$ Expt data points indicate, by themselves, the possibility of many different steady flows that are possible if one chooses the specified exit condition (category I) approach for achieving steady flows for the same $\dot{\mathrm{M}}_{\mathrm{in}}$ and $\overline{\Delta \mathrm{T}}$ values. As discussed earlier, these category I flows were found to be robust and stable as compared to their associated category II counterparts. 
Figure $8 \mathrm{~b}$ also marks an oscillatory case marked by two dark triangles. These two points represent an oscillatory exit pressure case and they indicate the fact that the vapor quality (or the exit pressure) for this flow was oscillating between the two values shown. This is an example of category II flow where oscillations are induced by flow instabilities in the auxiliary condenser downstream of the test section. This case is briefly but separately discussed in section 6 .

\section{Comparisons With Relevant Computational Results (Partial Condensation)}

Figure 9 shows the computationally obtained (employing the tools reported in [3]) details of local film thickness and heat flux variations for the specified and unspecified "natural" cases marked as Specified-2 (run no. 18 in Table 2) and Natural-1 (run no. 1 in Table 1) in Figs. 7a-7e. The vapor quality for Specified-2 case was greater than that of the associated Natural-1 case. As a result, higher amount of vapor condenses into liquid for Natural-1 case and this makes heat transfer rate $\dot{\mathrm{Q}}_{\text {out }}$ to be on the higher side (see Table 1 and 2 for details). For all other conditions remaining the same, as observed from the computational results in Fig. 9, this makes Natural-1 case's liquid film thickness to be lower and wall heat flux to be higher than the values for Specified-2 case. Such details of representative local variations in film thickness and heat-flux are very important and should also be obtained from experiments before heat-transfer correlations are developed for suitable categories and sub-categories of internal condensing flows. However reliable experimental information on "local" spatial variations of these quantities is not expected until later incorporation of film thickness sensors in these experiments. Observe that the computationally obtained prediction of "natural" exit vapor quality $\mathrm{Z}_{\mathrm{e}} \mathrm{l}_{\mathrm{Na}}$ Comp $(\approx 0.33)$ for category-II flow in Fig. 7a-7e is in a very good agreement with the experimentally obtained $\left.Z_{\mathrm{e}}\right|_{N a \text { Expt }}(\approx 0.33)$ value (see Table 1$)$. In fact very good agreement between $\left.Z_{\mathrm{e}}\right|_{N a \text { Comp }}$ values and $\mathrm{Z}_{\mathrm{e}} \mathrm{N}_{\mathrm{Na}}$ Expt values is found for all category II cases in Fig. 8b and this is also clear from their numerical values in Table-1. Note that good agreement between experimental and theoretical $\mathrm{Z}_{\mathrm{e}}$ values 
have been obtained and reported (see [2]) for channel flow (category II) experiments of Lu and Suryanarayana [25].

The values of pressure drop $\Delta \mathrm{p}\left(\mathrm{p}_{\mathrm{in}}-\mathrm{p}_{\text {exit }}\right)$ obtained from simulations for all the category II partial cases were negative and below $50 \mathrm{~Pa}$ indicating $\mathrm{p}_{\text {exit }}$ was greater than $\mathrm{p}_{\text {in }}$ for all the condensation cases in given $\dot{\mathrm{M}}_{\text {in }}$ range. This is confirmed by the experimental values of $\Delta \mathrm{p}$ (see Table 1, 2, and 3) which are also all negative (except a very few cases). However, as expected, the magnitudes for experimental values of $\Delta \mathrm{p}$ were found to be greater than those from simulations. The reason behind this is that the simulations assume laminar vapor/laminar liquid flows while, in reality, the vapor Reynolds number are in the higher range (20000-30000) and this makes vapor flows significantly turbulent in the core (see Tables 1-3). The turbulence in vapor core does not affect the mass transfer across the interface by much because condensate motion is gravity dominated. However, turbulent vapor core significantly increases the $\Delta \mathrm{p}$ values in the vapor domain. Because of this, the values of vapor quality obtained from the simulation are in good agreement with the experiments but the values for pressure drop $\Delta \mathrm{p}$ obtained from experiments are higher in magnitudes. The predicted pressure drop $\Delta \mathrm{p}$ values can be corrected for vapor turbulence by an approximate procedure. This involves re-solving the vapor domain (as defined by the predicted interface locations from the laminar/laminar simulation tool) flow in FLUENT (using turbulence $\mathrm{k}-\varepsilon$ model) for the given inlet velocity while values of vapor velocity at the interface boundary are assigned to be the same as the same ones that were obtained from the underlying laminar/laminar simulation technique. Under these conditions, a more representative pressure variation in the vapor domain is obtained. The pressure variation information can, in principle, be iteratively fed back (until overall convergence) into solving the liquid domain (see " $\tau$-p" method in [1]-[3]) solution technique of the current laminar/laminar solution methodology. Though this recommended procedure was not iteratively implemented, for one representative case, the first 
approximate correction of the predicted pressure values yielded $\Delta \mathrm{p}$ values that were of the same order of magnitude as the experimental ones.

\section{Complete or Full Condensation Flows}

\section{Specified Exit Condition Cases (Category I flows)}

As mentioned earlier, this case has not been investigated experimentally because the current set- up does not have active pressure control strategies for fixing different pressures at inlet to pump $\mathrm{P}_{1}$ (point $\mathrm{P}_{1}^{\prime}$ in Figs. 2 or 3 ). However, current computational simulations show that the point of full condensation, shown in the schematic of Fig. 10, is extremely sensitive to exit pressure. The doubly shaded zone, between the point of full condensation (FC) and the point of test-section exit (E), experiences nearly zero interfacial mass or heat transfer and nearly zero average vapor velocity or average vapor mass flow rate.

\section{$\underline{\text { Unspecified Exit Condition cases (Category II flows) }}$}

The test matrix (Table 3) for the "natural" steady full condensation cases under category II accommodates a range of vapor mass flow rates and temperature differences $\overline{\Delta \mathrm{T}}$ that are shown in Fig. 11. The shaded region in Fig. 11 contains most of the data points obtained for steady full condensation cases. More details on these cases are given in Table 3 along with the accuracies of measured and calculated variables. For representative full condensation cases in Table 3, Figs. 12a - 12e show three steady states: the Natural-1 over $\mathrm{t}_{1} \leq \mathrm{t}(\mathrm{min}) \leq \mathrm{t}_{1}+30$ (Table-3, run no. 1 with $\dot{\mathrm{M}}_{\text {in }} \approx 0.69 \pm 0.05 \mathrm{~g} / \mathrm{s}$ and $\left.\overline{\Delta \mathrm{T}}=23 \pm 1{ }^{\circ} \mathrm{C}\right)$, the Natural-2 over $\mathrm{t}_{2} \leq \mathrm{t}(\mathrm{min}) \leq \mathrm{t}_{2}+30$ (Table-3, run no.18 with $\dot{\mathrm{M}}_{\mathrm{in}} \approx 1.30 \pm 0.05$ $\mathrm{g} / \mathrm{s}$ and $\overline{\Delta \mathrm{T}}=30 \pm 1{ }^{\circ} \mathrm{C}$ ), and Natural-1 Repeated over $\mathrm{t}_{3} \leq \mathrm{t}(\mathrm{min}) \leq \mathrm{t}_{3}+30$ (run no.1 repeated). The mass flow rates for these three and other steady state full condensation cases are plotted along with their $\overline{\Delta \mathrm{T}}$ values in Fig. 11. The steady pressures measured at different locations along the test section are plotted in Fig. 12b. Fig. 12c shows the steady temperatures at different points along the test section. 
Figure $12 \mathrm{~d}$ shows the temperatures and pressures for sub-systems $\mathrm{A}$ and D. The sub-system C temperatures and pressures are shown in Fig. 12e. For run no.1 in Table-3, Figs. 12a-12e show its repeatability as all the parameters, including pressures and mass flow rate values, were regained after run no. 18

The full condensation cases reported in Table 3 lie in a zone bounded by semi-schematic curves $\mathrm{X}$, and $\mathrm{Y}$ as shown in Fig. 11. These bounding curves, at the present moment, are approximate and schematic in nature, as no more than two points on each of the curves have been obtained by experiments or computations. All full condensation cases in Table 3 and Fig. 11 are category II cases and the point of full condensation lies inside the test section (i.e. $\mathrm{X}_{\mathrm{fc}} \leq \mathrm{L}$ in Fig. 10). This was verified by simulations for all full condensation cases. The curve Y (with two computationally obtained points) depicts the right upper bound on the test matrix. For cases to the right hand side of this curve, the "natural" point of full condensation will lie out of the test section and any steady flow that will be realized will belong to the uninvestigated category I cases dealing with specified full condensation. If the L/V separator had a natural and open vapor outlet (which it does not have, because the valve $\mathrm{V}_{3}$ in Fig. 2 is closed), then curve $\mathrm{Y}$ would have represented the transition to partial condensation. Curve $\mathrm{X}$ (with two experimentally obtained points), on the left hand side in Fig. 11, represents the lower left bound on the test matrix. As the mass flow rate decreases below the value given by this curve, there is an experimentally observed instability in the flow which, in all likelihood, marks the transition from quasi-steady annular to a plug/slug (see [32]) regime. It can be seen in Fig. 13a that there exists a steady flow for $\dot{\mathrm{M}}_{\mathrm{in}} \approx 1.2 \mathrm{~g} / \mathrm{s}$ and $0.8 \mathrm{~g} / \mathrm{s}$ but as it is reduced to $\dot{\mathrm{M}}_{\mathrm{in}} \leq 0.6 \mathrm{~g} / \mathrm{s}$, the schematic curve-X (the suggested boundary between steady annular to unsteady plug/slug) in Fig. 11 is crossed from right to left. The inlet mass flow rate never stabilizes for these cases but the inlet pressure, as shown in Fig. 13b, appears to be less erratic. These transition points are evident, for the circled experimental points on curve-X, where unsteadiness/spikes of the type shown in Figs. 13a-b are observed. These unsteady 
spikes in the inlet flow rate is probably due to the bridges of the liquid that form across the cross section area when the flow undergoes a transition to plug/slug regime. These formations may introduce the observed unsteadiness (Figs. 13a-b) in the inlet mass flow rate and inlet pressure.

Although, at present, different boundaries defined in Fig. 8a and Fig.11 are approximate and schematic, some representative full and partial condensation cases on these boundaries have already been obtained (either by experiments or by computations).

The research outlined in this paper mainly focuses on the interior region bounded by these curves (see the shaded regions in Fig. 8a and Fig.11) and a careful investigation of the bounding curves and their proper non-dimensionalization is part of future (ongoing) research that awaits more detailed experimental results and better flow visualization.

Even though the exit pressure currently can not be actively specified for the full condensation cases, the response of the category II full condensation cases to disturbances in exit pressure was experimentally ascertained for a number of cases marked in Fig. 11. The exit pressure disturbance was given in "Natural-2" case (see Fig. 12a) by changing the pressure at L/V separator (Fig. 2) momentarily. It is seen from Fig. 12a that although this disturbance died out quickly for the inlet vapor flow rate $\dot{\mathrm{M}}_{\mathrm{in}}$, the disturbance died out much more slowly for the $\Delta \mathrm{p}$ which is an indicator of changes in the liquid vapor configuration in the test section. In fact, for all full condensation cases the exit pressure disturbance died out in the manner indicated above showing the generally robust nature of these cases and along with their sensitivity of the exit zone flow variables as indicated $\Delta \mathrm{p}$ response. In fact, even when the aforementioned momentary pressure disturbances in the L/V separator (by injecting liquid through a syringe) was followed by a permanent partial closing of valve V' in Fig. 2, the same dynamic recovery was observed - however the recovery time was longer. Also, as seen in Fig. 12a for "Natural-1 Repeated" case, these flows are stable to disturbances in inlet flow rates as well. In this sense, all the category II full condensation cases in the shaded region of Fig. 11, were 
found to be robust - pointing to the fact that this experimental procedure is conducive to getting to the steady flow situations associated with the presence of steady "attractors" (see [1]) or what was equivalently termed as "long term parabolicity (see [3])." It should be noted that the steady flow's robustness is in part a consequence of the appropriate flow loop design whereby the displacement pump P1 in Fig. 2 continually allows availability of suitable exit pressure being sought by the flow. This is due to the nature of pump P1 being "displacement" type and, also, due to its ability to track the inlet mass flow rate $\dot{\mathrm{M}}_{\mathrm{in}}$. For example, the observed robustness of these fully condensing flows is not at all present in full condensation cases investigated by others (see, e.g. [9]) under the earlier described set up for category-III flows.

\section{Comparisons With Relevant Computational Results (Full Condensation)}

The simulations for most of the full condensation cases reported in this paper confirm the fact that the point of full condensation lies within the test section and almost all the cases lie in the region bounded by the curves $\mathrm{X}$ and $\mathrm{Y}$ shown in Fig. 11. The simulations also predict that the length $\mathrm{X}_{\mathrm{fc}}$ for full condensation decreases as the mass flow decreases and $\overline{\Delta T}$ increases. For example, the length of the full condensation case estimated by the computations for Run no. 11 in Table 3 (with $\dot{\mathrm{M}}_{\text {in }} \approx 0.97 \mathrm{~g} / \mathrm{s}$ and $\overline{\Delta \mathrm{T}}=27{ }^{\circ} \mathrm{C}$ ) is approximately $0.3 \mathrm{~m}$ while that for Run no. 13 in Table 3 (with $\dot{\mathrm{M}}_{\mathrm{in}} \approx 0.8 \mathrm{~g} / \mathrm{s}$ and $\overline{\Delta \mathrm{T}}=36^{\circ} \mathrm{C}$ ) is $0.15 \mathrm{~m}$. The computationally obtained film thickness and local wall heat flux values for run no. 12 in Table 3 (with $\dot{\mathrm{M}}_{\text {in }} \approx 0.87 \mathrm{~g} / \mathrm{s}$ and $\overline{\Delta \mathrm{T}}=43{ }^{\circ} \mathrm{C}$ ) is shown in Fig. 14. As seen from Fig. 14, the computationally found length of full condensation was around $0.2 \mathrm{~m}$ and our current simulation methodology does not automatically extend to the region between $\mathrm{X}_{\mathrm{fc}}$ and $\mathrm{L}$ in Fig. 10. Experimental comparisons for these computationally predicted local variations in film thickness and heat flux are not currently available but are expected in the near future. 
Inclusion of correlations for local or average heat transfer coefficients is outside the scope of the present paper and is not desirable until a comprehensive synthesis of experimental results and computational results on local film thickness and heat-flux also becomes available. It should be noted that such data - if obtained without full development of the proposed framework of different flow categories, sub-categories, and their boundaries - will not be very useful.

\section{RESULTS/COMMENTS ON SYSTEM INSTABILITIES AND OSCILLATORY FLOWS}

While seeking the "natural" exit condition for some unspecified exit condition (category II) partial condensation flows, system instabilities - involving oscillatory flows - of the type shown in Figs. 15a - 15b are observed (see dotted curve- A in Fig. 8a). The origin of these oscillatory flows appear to be the auxiliary condenser which sees an approximate category-III flow (for which, in Fig. 2, the sought for pressure in the $\mathrm{L} / \mathrm{V}$ separator and the sought for pressure at the merger point $\mathrm{P}_{1}^{\prime}$ respectively approximate pressures $\mathrm{p}_{\text {Tank-in }}$ and $\mathrm{p}_{\text {Tank-out }}$ that appear in the definition given in section 1 for category III flows. Recall that these fully condensing flows in the auxiliary condenser, unlike the ones studied for the test section, are known (as in [11]) to become oscillatory under certain conditions. Since complete auxiliary condenser flow data were not obtained (because this component was not the focus of the reported investigations), relating this auxiliary condenser instability to the type of stability boundaries discussed in [11] and [13] is outside the scope of this study.

It is clear from Figs. 15a-15b that oscillations in vapor mass flow rate at the exit of the test section impose oscillations on the exit pressure and the pressure drop $\Delta \mathrm{p}$ across the test section while the inlet vapor mass flow rates remain relatively unaffected. Figure $15 \mathrm{~b}$ shows the oscillations in other pressure values and the temperature at the rotameter F2 (which is nearer to the auxiliary condenser). This, along 
with the known fact (see Fig. 6 in [1]) that there is one to one relation between exit vapor quality and exit pressure, indicate imposition of oscillatory pressures at the exit of the test-section.

It suffices here to note that the flow oscillations in the auxiliary condenser can induce an oscillatory exit pressure at the exit of the test-section condenser and this is the cause, in Figs. 15a-15b, of somewhat reduced level of oscillatory behavior of other test-section flow variables. As a result of the instability in the auxiliary condenser, the dotted curve-A in Fig. 8a is merely suggestive of the presence of system instability. This is because the actual onset of oscillatory conditions have only a very indirect and incomplete relation to test-section $\dot{\mathrm{M}}_{\text {in }}$ and $\overline{\Delta \mathrm{T}}$ values used in Fig. 8a.

\section{COMMENTS ON START-UP}

The start-up time to steady state depends critically on the factors listed below. (i) The size of the evaporator used and the typical amount of liquid contained in it. (ii) The type and accuracy of the pumps and the flow-meters used in implementing the various mass flow-rate tracking strategies. (iii) The strategy used for warming the liquid to evaporator temperature $T_{\text {sat }}\left(\mathrm{p}_{\mathrm{b}}\right)$ prior to its entrance in to the evaporator. (iv)The level of steadiness feasible for the heat load (i.e., in this case, steadiness of the temperature and flow rate of the coolant water in the secondary coolant loop). (v) The time and disturbances imposed by the procedure for purging the system of non-condensables. (vi) For unspecified exit condition (category II) flows, the nature of components downstream of the test-section condenser (e.g. the auxiliary condenser conditions and design) also affect the start-up time.

The current choices of the above factors require, on average, about three hours for reaching a steady unspecified exit condition (category II) partial condensation flow. The above listed factors change from system to system and can be optimized further to reduce the start-up time for flows in a certain operation zone (say a certain subset of the zone marked in Figs. 8a or 11). For example, for 
unspecified exit condition (category II) partial condensation flows in a horizontal rectangular crosssection duct, the apparatus of Lu and Suryanarayana [25] had a typical start-up time of ten-to-twelve hours. The current start up time for reaching a steady unspecified exit condition (category II) full condensation flow or a steady specified exit condition (category I) partial condensation flow is about one to two hours. For a typical category II case of steady full condensation, Fig. 16 shows the time required to attain the steady state. In Fig. 16, the representative parameters of boiler pressure and boiler temperature can be seen to have attained steady state after 75 minutes of transient time.

\section{CONCLUSIONS}

- This paper experimentally confirms the significance of exit conditions on the nature of quasi-steady internal condensing flows and proposes a novel and necessary exit-condition based categorization of these flows.

- The hardware arrangements employed for the reported experiments outlines feasible ways of operating a condenser under different exit conditions.

- In particular, a way for achieving steady and stable fully condensing (under unspecified exit condition cases of category II) flows is presented. These flows are typically more robust than the fully condensing flows (category III) achieved by a different procedure that is typically employed and discussed in the existing literature.

- The experiments reinforce simulation results that multiple steady states, with quite different local and average heat transfer rates, are often achieved under different exit condition specifications. Therefore, correlations for heat transfer coefficient are only meaningful if flow regimes are clearly defined and developed in the framework of proposed exit-condition based categories. 
- Various flow regime and system boundaries for annular category-I and category-II flows are observed and proposed. Though reported identifications need to be refined, they are clearly needed for steady performances of condensers.

- The existing simulation tool's ability to be quantitatively correct in identifying "natural" exit conditions for gravity driven partial condensation cases under unspecified exit conditions (category II) is very good and this is supported by the reported experiments. This agreement adds credibility to the experimental results, simulation tool, and the proposed exit condition based categorizations.

- The experiments indicate that the steady flows are definitely more robust under specified exit condition operation of condensers. This lends credibility to the simulation result that steady operation of shear driven condensers (in zero gravity and horizontal configurations) are much more difficult to achieve under unspecified exit condition cases while they will be more readily realized under an arrangement that would allow operation under specified exit-conditions (category I flows).

- The experiments also demonstrate the importance of components downstream of the condenser and they give several examples of system instabilities (such as oscillatory flows) that may result when one is seeking a "natural" partial or full condensation case under certain conditions.

\section{ACKNOWLEDGMENT}

This work was supported by the NSF grant CTS-0086988 and NASA grant NNC04GB52G.

\section{REFERENCES}

1. Narain, A., Q. Liang, G. Yu, and X. Wang, Jan. 2004, "Direct Computational Simulations for Internal Condensing Flows and Results on Attainability/Stability of Steady Solutions, their Intrinsic Waviness, and Their Noise-sensitivity,” Journal of Applied Mechanics, Vol. 71, pp. 69-88.

2. Liang, Q., X. Wang, and A. Narain, October 2004, "Effect of Gravity, Shear and Surface Tension 
in Internal Condensing Flows - Results from Direct Computational Simulations.” ASME Journal of Heat Transfer, 126 (5), pp. 676-686.

3. Phan L., X. Wang, and A. Narain, 2006, "Exit condition, Gravity and Surface-Tension Effects on Stability and Noise Sensitivity Issues for Steady Condensing Flows inside Tubes and Channels," International Journal of Heat and Mass Transfer, Vol. 49, Issues 13-14, pp.2058-2076.

4. Goodykoontz, J. H. and R. G. Dorsch, 1966, "Local heat transfer coefficients for condensation of steam in vertical down flow within a 5/8-inch-diameter tube," NASA TN D-3326.

5. Goodykoontz, J. H. and R. G. Dorsch, 1967, "Local heat transfer coefficients and static pressures for condensation of high-velocity steam within a tube," NASA TN D-3953.

6. Carpenter, F. G., 1948, "Heat transfer and pressure drop for condensing pure vapors inside vertical tubes at high vapor velocities," Ph. D. thesis, University of Delaware.

7. Yu, G., 1999, "Development of a CFD Code for Computational Simulations and Flow Physics of Annular/Stratified Film Condensation Flows," Ph.D. Thesis, ME-EM Department, Michigan Technological University.

8. Rabas, T. J., and B. Arman, 2000, "Effects of the Exit Condition on the Perofromance of In-Tube Condensers," Heat Tranfer Engineering, 21(1), pp. 4-14.

9. Wedekind, G. L. and B. L. Bhatt, 1977, “An Experimental and Theorotical Investigation in to Thermally Governed Transient Flow Surges in Two-Phase Condensing Flow," ASME Journal of Heat Transfer 99 (4), pp. $561-567$.

10. Bhatt, B. L. and G. L. Wedekind, 1980, “Transient and Frequency Characteristics of Two-Phase Condensing Flows: With and Without Compressibilty," ASME Journal of Heat Transfer 102 (3), 495-500.

11. Bhatt, B. L. and G. L.Wedekind, 1980b, “ A Self Sustained Oscillatory Flow Phenomenon in TwoPhase Condensing Flow Systems," ASME Journal of Heat Transfer 102 (4), 695-700. 
12. Wedekind, G. L. and B. L. Bhatt, 1989, “ Modeling the Thermally Governed transient Flow Surges in Multitube Condensing Flow Systems with Thermal Flow Distribution Asymmetry," ASME Journal of Heat Transfer 111 (3), pp. $786-791$.

13. Bhatt, B. L., G. L. Wedekind, and K. Jung, 1989, “ Effects of Two-phase pressure Drop on the Self-Sustained Oscillatory Instabilty in Condensing Flow," ASME Journal of Heat Transfer 111, $538-545$.

14. Boyer, D. B., G. E. Robinson, and T. G. Hughes, 1995, "Experimental Investigation of Flow Regimes and Oscillatory Phenomena of Condensing Steam in a Single Vertical Annular Passage," International Journal of Multiphase Flow, Vol. 21, No. 1, pp. 61 - 74.

15. Wedekind, G. L., C. J. Kobus, and B. L. Bhatt, 1997, "Modeling the Characteristics of Thermally Governed Transient Flow Surges in Multitube Two-Phase Condensing Flow Systems with Compressibility and Thermal and Flow Distribution Asymmetry," ASME Journal of Heat Transfer, Vol. 119, No. 3, pp. $534-543$.

16. Kobus, C. J., G. L. Wedekind, and B. L. Bhatt, 2000, "Predicting the Influence of Compressibility and Thermal and Flow Distribution Asymmetry on the Frequency-Response Characteristics of Multitube Two-Phase Condensing Flow Systems," ASME Journal of Heat Transfer, Vol. 122, No. 1, pp. $196-200$.

17. Kobus, C. J., 2003, “An Investigation into the Effect of Subcooled Liquid Inertia on Flowrate Induced Frequency-Response Characteristics of Horizontal Condensing Flow Systems," Proceedings of the 6th ASME/JSME Thermal Engineering Joint Conference (AJTEC), March 16 23, Hawaii.

18. Wallis, B. Graham, 1969, One-Dimensional Two-Phase Flow, McGraw-Hill Book Company, U. K.

19. Lahey, R. T. and D. A. Drew, 2000, “The Analysis of Two-Phase Flow and Heat Transfer Using A multidimensional, Four Field, Two-Fluid Model," Nuclear Engineering and Design, 204, 29-44. 
20. Liao, N. S., C. C. Wang, and C. L. Tien, 1988, "Analysis of Transient Flow Surge Phenomena in a Single-Tube Condenser," International Communications in Heat and Mass Transfer, Vol. 15, pp. $257-268$.

21. Liao, N. S. and C. C. Wang, 1990, “Transient response Characteristics of Two-Phase Condensing Flows," International Journal of Multiphase Flow, Vol. 16, pp. 139 - 151.

22. Wang, C. C. and N. S. Liao, 1989, “Transient Response of a Double-Pipe Condenser to Change of Coolant Flowrate," International Communications in Heat and Mass Transfer, Vol. 16, pp. 325 334.

23. Patankar S. V., 1980, Numerical Heat Transfer and Fluid Flow, Hemisphere, Washington D. C.

24. Phan L. and A. Narain, 2007, "Non-liner Stability of the Classical Nusselt problem of Film Condensation and Wave Effects,"in press for publication in the ASME Journal of Applied Mechanics, Vol.74, No.2.

25. Lu, Q. and N. V. Suryanarayana, 1995, "Condensation of a Vapor Flowing Inside a Horizontal Rectangular Duct," Journal of Heat Transfer, 117, pp. 418-424.

26. Nusselt, W., 1916, “Die Oberflächenkondesation des Wasserdampfes,” Z. Ver. Dt. Ing. 60 (27), pp. 541-546.

27. Palen, J. W., R. S. Kistler, and Y. Z. Frank, 1993, "What We Still Don't Know About Condensation in Tubes," In Condensation and Condenser Design (Edited by J. Taborek, J. Rose and I. Tanasawa), Pub.: United Engineering Trustees, Inc. for Engineering Foundation and ASME, New York, pp. $19-53$.

28. Tian W. Ng, 2006, "Development and Calibration of a Fluorescence and Fiber-Optics Based RealTime Thickness Sensor for Dynamic Liquid Films," Ph.D. Thesis, MEEM, Michigan Technological University.

29. Siemonko, A., 2006, "Design, Fabrication, and Operation of a System to Control FC-72 
Condensation Inside a Vertical Tube," Ph.D. Thesis, Chem Eng, Michigan Technological University.

30. Kurita, J. H., 2006, "Experimental Investigation of Fully Condensing Downward Vapor Flows in a Vertical Tube - Unspecified (Free) Exit Condition Cases," M. S. Thesis, MEEM, Michigan Technological University.

31. Parratt, L. G., 1961, Probability and Experimental Errors in Science - An Elementary Survey, Wiley, New York.

32. Carey, V. P., 1992, Liquid-Vapor Phase-Change Phenomena, Series in Chemical and Mechanical Engineering, Hemisphere Publishing Corporation.

\section{List of Figure Captions}

Fig. 1: The schematic for the flow through test-section and exit condition issues.

Fig. 2: The schematic of the flow loop for achieving specified exit condition category-I flows for partial condensation cases.

Fig. 3: The schematic of the flow loop for achieving unspecified exit condition category-II flows for partial or full condensation cases.

Fig. 4: For tube flow situations specified as in Phan et al. [3] (see their Table 1 and Fig. 2), the figure depicts three steady film thickness profiles for three different exit conditions. The figure also indicates time trends for two sets of $\delta(\mathrm{x}, \mathrm{t})$ predictions for $\mathrm{t}>0$, one curve starts at $\mathrm{Z}_{\mathrm{e}}=0.3$ at $\mathrm{t}=0$, and tends, as $\mathrm{t} \rightarrow \infty$, to the solution for $\mathrm{Z}_{\mathrm{e}} \mathrm{l}_{\mathrm{Na}}=0.215$. The other curve starts at $\mathrm{Z}_{\mathrm{e}}=0.15$ at $\mathrm{t}=0$ and tends, as $\mathrm{t} \rightarrow \infty$, to the same $\left.Z_{\mathrm{e}}\right|_{\mathrm{Na}}=0.215$ solution.

Fig. 5: (a) The photograph of condenser test-section. (b) The test-section schematic (diameters in (a) and (b) are not to the same scale). The condensing surface covers the zone $x_{0} \leq \mathrm{x} \leq \mathrm{x}_{10}$.

Fig. 6: Test section sensor mounting design. 
Fig. 7a: Time history depiction of $\dot{\mathrm{M}}_{\mathrm{in}}, \dot{\mathrm{M}}_{\mathrm{V}}$ and $\overline{\Delta \mathrm{T}}$ values for multiple steady states of partial condensation cases viz. Natural-1(run 1from Table 1), Specified-1(run 1 from Table 2), Specified-2 (run 18 from Table case 2), and Specified-1 Approx.

Fig. 7b: Time history of pressures (along the test section) and $\Delta \mathrm{p}$ values (across the test-section) for the cases shown in Fig. 7a.

Fig. 7c: Time history of temperature values along the test section (sub-system $B$ ) and $T_{\text {sat }}\left(p_{\text {in }}\right)$ for the cases shown in Fig. 7a.

Fig. 7d: Time history of temperature and pressure values at different locations in sub-systems A and D of the system for the cases shown in Fig. 7a.

Fig. 7e: Time history of temperature and pressure values at different locations in sub-system $\mathrm{C}$ of the system for the cases shown in Fig. 7a.

Fig. 8a: Two-dimensional test data matrix for category II (unspecified exit condition) partial condensation cases' points and different bounding curves represented on $\dot{\mathrm{M}}_{\text {in }}-\overline{\Delta \mathrm{T}}$ plane.

Fig. 8b: Three-dimensional test data matrix (a case point is represented by $\dot{\mathrm{M}}_{\mathrm{in}}, \overline{\Delta \mathrm{T}}$ and $\mathrm{Z}_{\mathrm{e}}$ value) for all partial condensation cases showing associated category I and II flow cases and their projections on $\dot{\mathrm{M}}_{\mathrm{in}}-\overline{\Delta \mathrm{T}}$ plane. The figure also shows a typical oscillatory flow case.

Fig. 9: For the "Natural-1" and "Specified-2" flow cases in Figs 7a-7e, this figure shows the computationally obtained representative film thickness and wall heat-flux variation along the test section. The film thickness and heat flux values shown have been obtained for smooth interface conditions. In fact, they are modulated by waves in presence of noise (see [3]).

Fig. 10: The schematic of full condensation showing point of full condensation and zero interfacial mass transfer region.

Fig. 11: Two-dimensional test data matrix for category II (unspecified exit condition) full condensation cases' points and different bounding curves represented on $\dot{\mathrm{M}}_{\text {in }}-\overline{\Delta \mathrm{T}}$ plane. 
Fig. 12a: Time history depiction of $\dot{\mathrm{M}}_{\text {in }}$ and $\overline{\Delta \mathrm{T}}$ values for multiple steady states of full condensation category II cases viz. Natural-1(run 1 from Table 3), Natural-2 (run 18 from Table 3), and Natural-1 Repeated.

Fig. 12b: Time history of pressures (along and outside the test section) and $\Delta \mathrm{p}$ values for the cases shown in Fig. 12a.

Fig. 12c: Time history of temperature values along the test section (sub-system B) for the cases shown in Fig. 12a.

Fig. 12d: Time history of temperature and pressure values at different locations in sub-systems A and D of the system for the cases shown in Fig. 12a.

Fig. 12e: Time history of temperature and pressure values at different locations in sub-system $\mathrm{C}$ of the system for the cases shown in Fig. 12a.

Fig. 13a: Time history of mass flow rate for an attempted unspecified exit condition case (category II) full condensation case that resulted in instability (likely to be a transition from annular to plug/slug regime) as the boundary curve $\mathrm{X}$ in Fig. 11 is crossed.

Fig. 13b: Time history of inlet vapor pressure for the case in Fig. 13a showing transition from stable zone to unstable zone.

Fig. 14: For a typical category II full condensation case, this figure shows the computationally obtained representative film thickness and wall heat-flux variation along the test section. The film thickness and heat flux value shown have been obtained for smooth interface conditions. In fact, they are modulated by waves in presence of noise (see [3]). The figure also shows that the length of full condensation $\mathrm{X}_{\mathrm{fc}}$ was found to be $0.2 \mathrm{~m}$, which is sufficiently shorter than the test section length $\mathrm{L}(0.7 \mathrm{~m})$.

Fig. 15a: Time history depiction of $\dot{\mathrm{M}}_{\text {in }}, \dot{\mathrm{M}}_{\mathrm{V}}, \dot{\mathrm{M}}_{\mathrm{L}}$ and $\Delta \mathrm{p}$ values for an oscillatory partial unspecified exit condition case (category II). In Fig. 8a, this flows' appearance is indicated by crossing of the dotted curve-A. 
Fig. 15b: For the case in Fig. 15a, this figure shows the time history depiction of rotameter temperature $T_{R}$ and the following pressures: inlet pressure $p_{i n}$, pressure at location 6 in Fig $5\left(p_{x 6}\right)$, and exit pressure pexit.

Fig. 16: For a typical category II full condensation case, this figure shows representative evaporator temperature and boiler pressure time history to indicate the start-up time to get to the steady state.

\section{List of Table Captions}

Table 1: Experimentally measured data and some key calculated and computed variables for steady states achieved for category II (unspecified exit condition) partial condensation flows.

Table 2: Experimentally measured data and some key calculated variables for steady states achieved for category I (specified exit condition) partial condensation flows

Table 3: Experimentally measured data and some key calculated variables for steady states achieved for category II (unspecified exit condition) full condensation flows. 
DIA

MIV $\}$ Liquid

Vapor

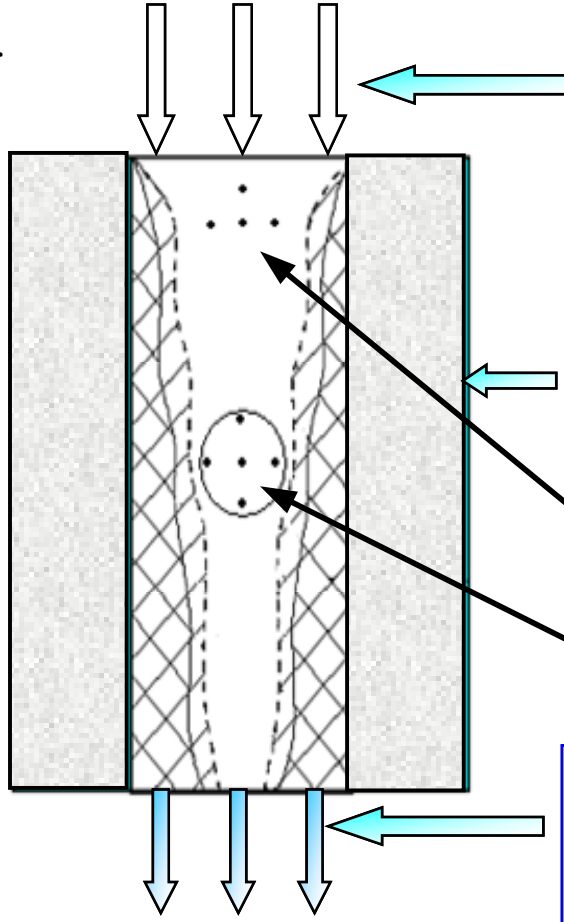

Inlet vapor (electronic flow control):

1. Fixed pressure $p_{0}$

2. Fixed temperature $\tau_{\text {sat }}\left(p_{0}\right)$

3. Fixed flow rate (or average speed $U$ )

Wall temperature $\mathcal{T}_{\mathrm{w}}$ :

1. Fixed \& Uniform

2. $\mathcal{T}_{\mathrm{w}}<\mathcal{T}_{\mathrm{sat}}\left(p_{0}\right)$

Fig. 1a

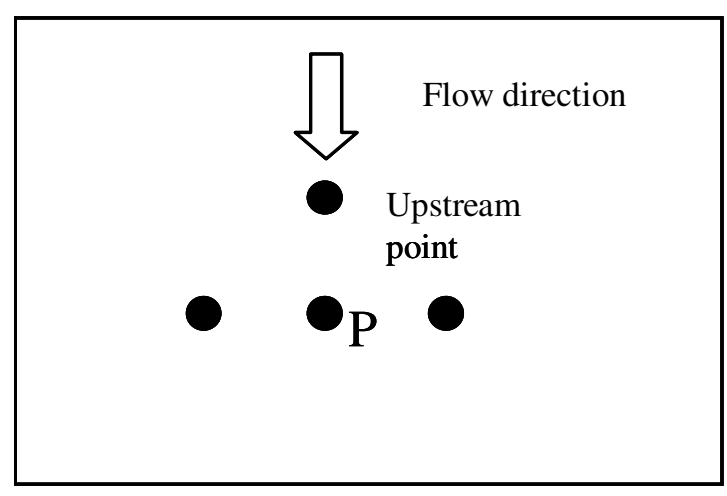

Fig. 1b

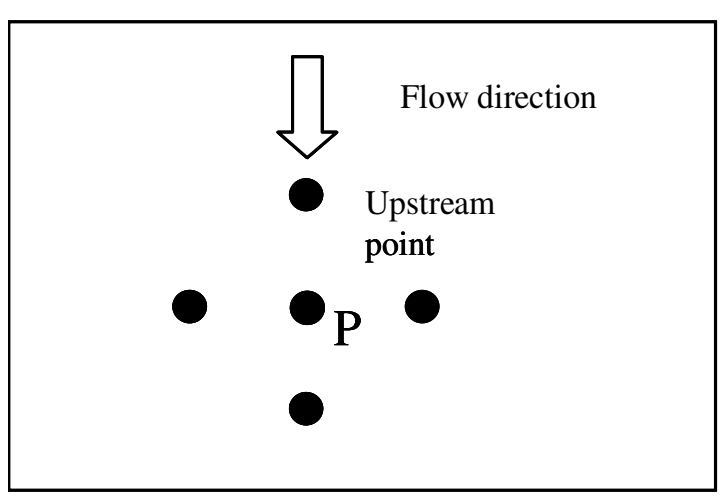

Fig. 1c 


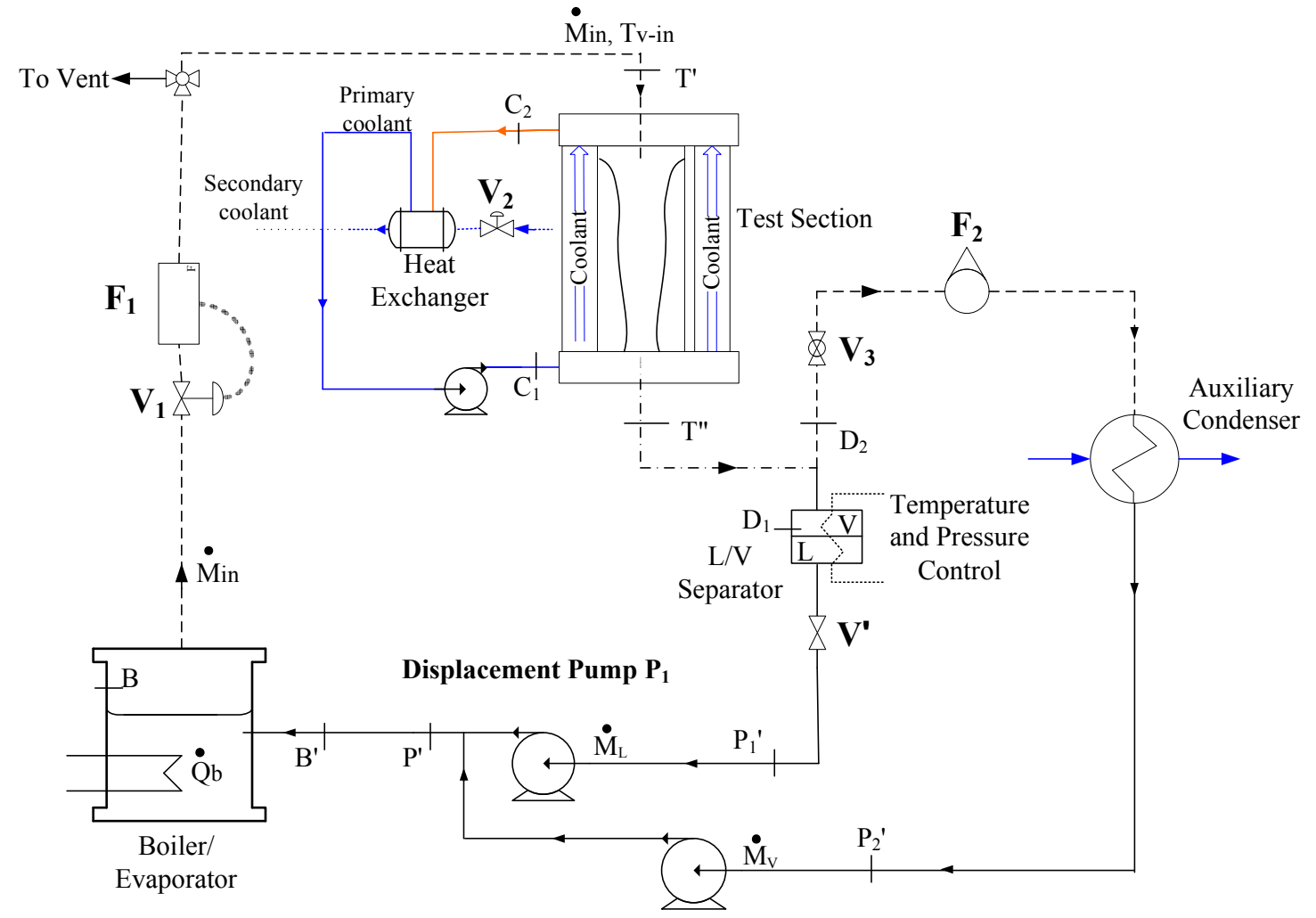

Displacement Pump $\mathbf{P}_{2}$

Fig. 2 


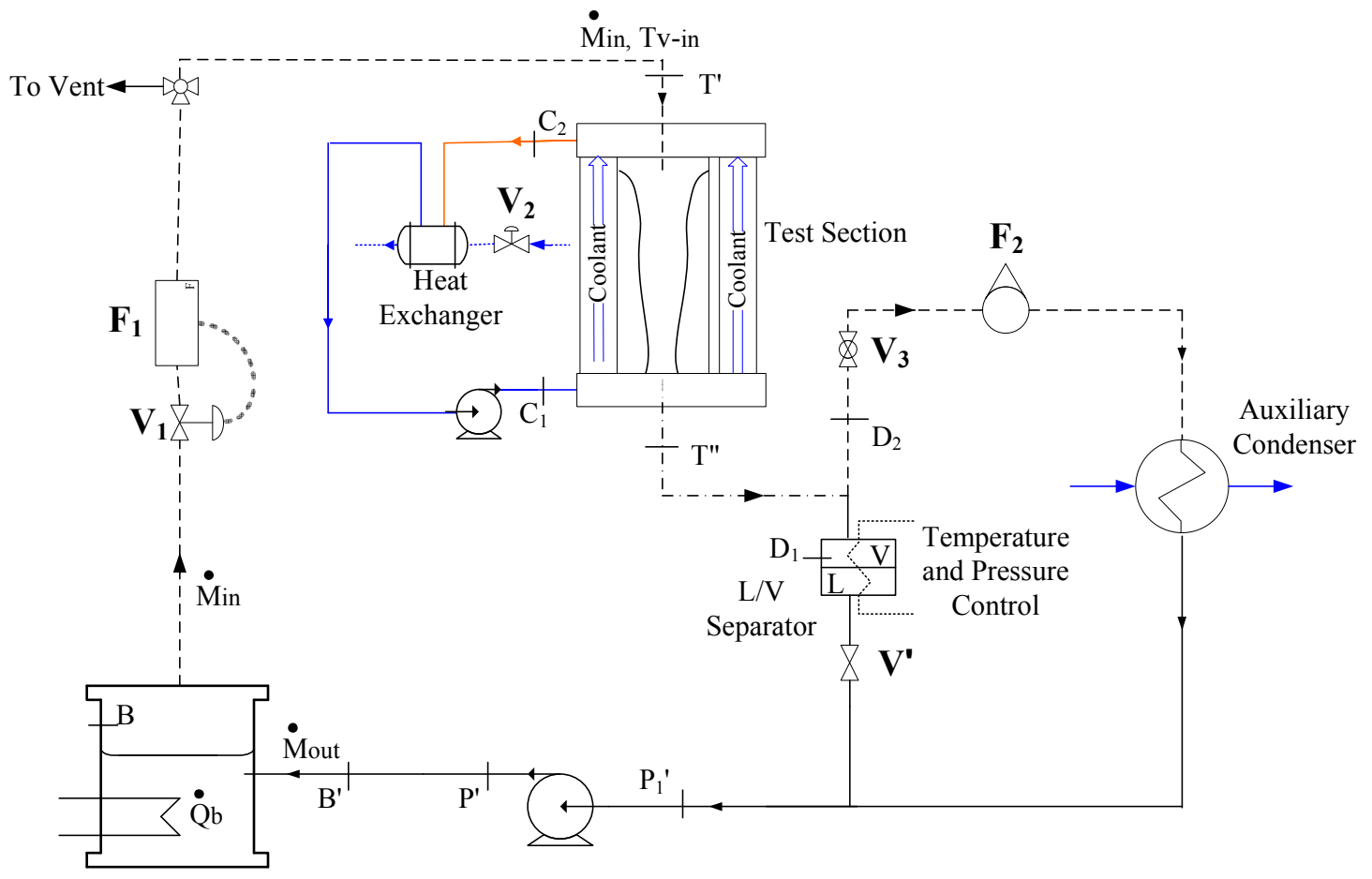

Evaporator

Displacement Pump $P_{1}$

Fig. 3 


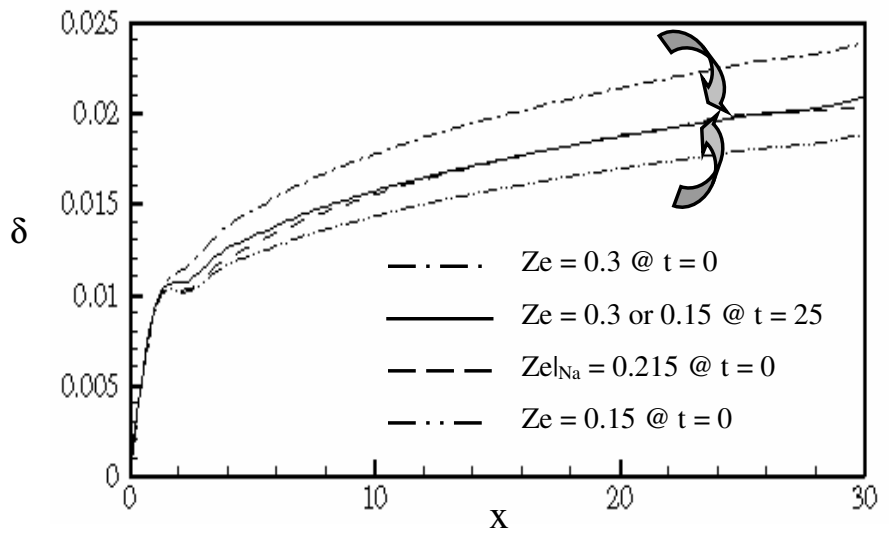

Fig. 4 


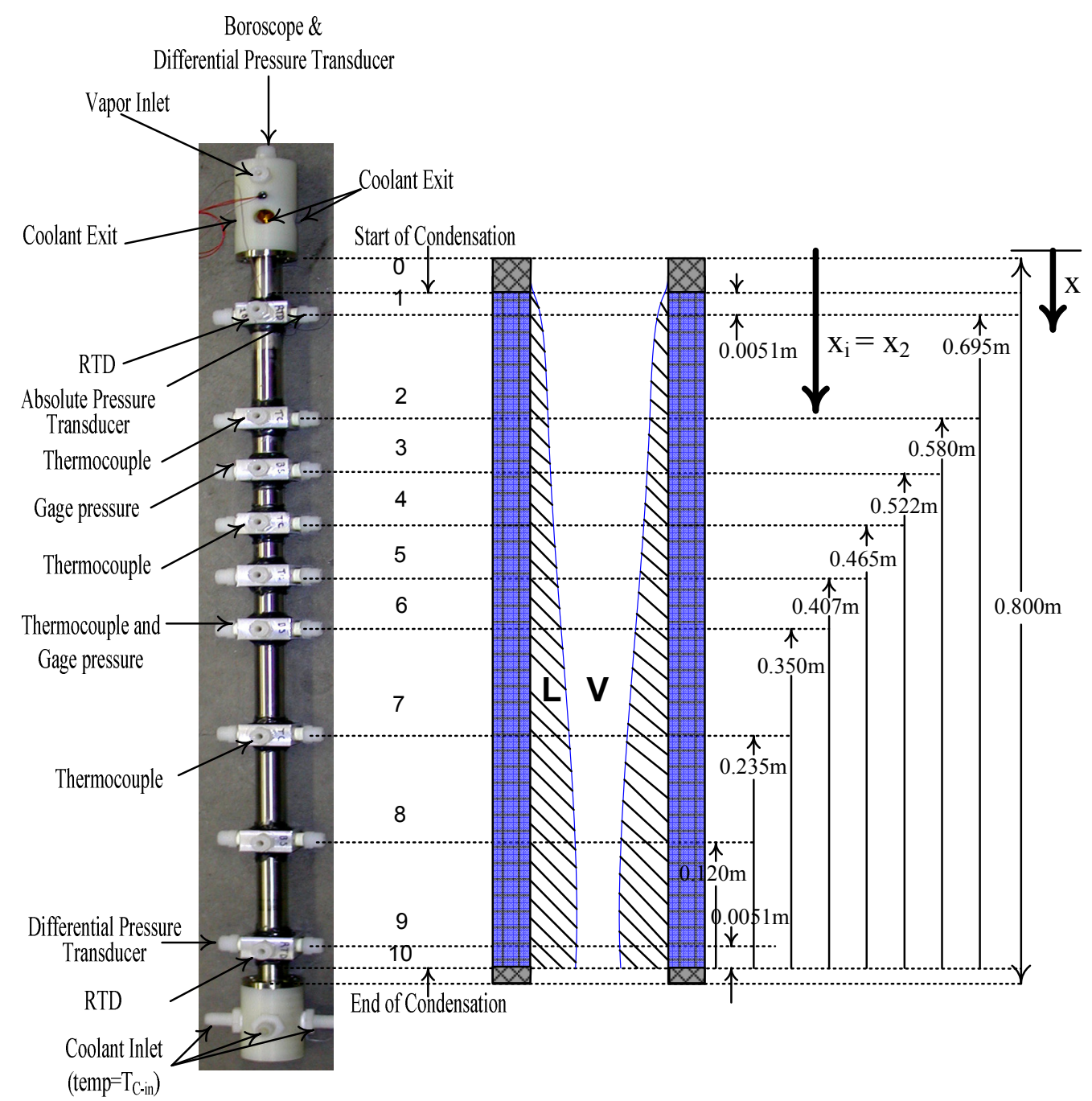

(a)

(b)

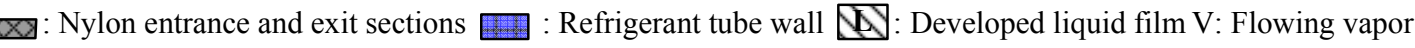

Fig. 5 


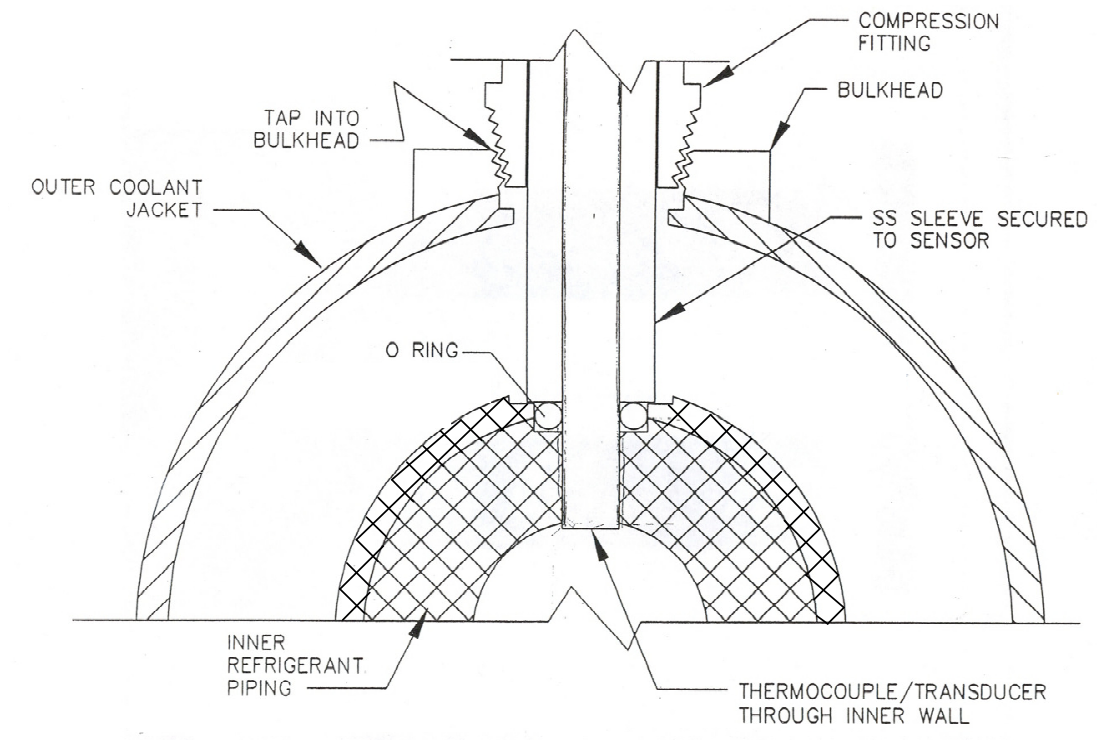

SENSOR MOUNTING DETAIL (SCALE 8:1)

Fig. 6 


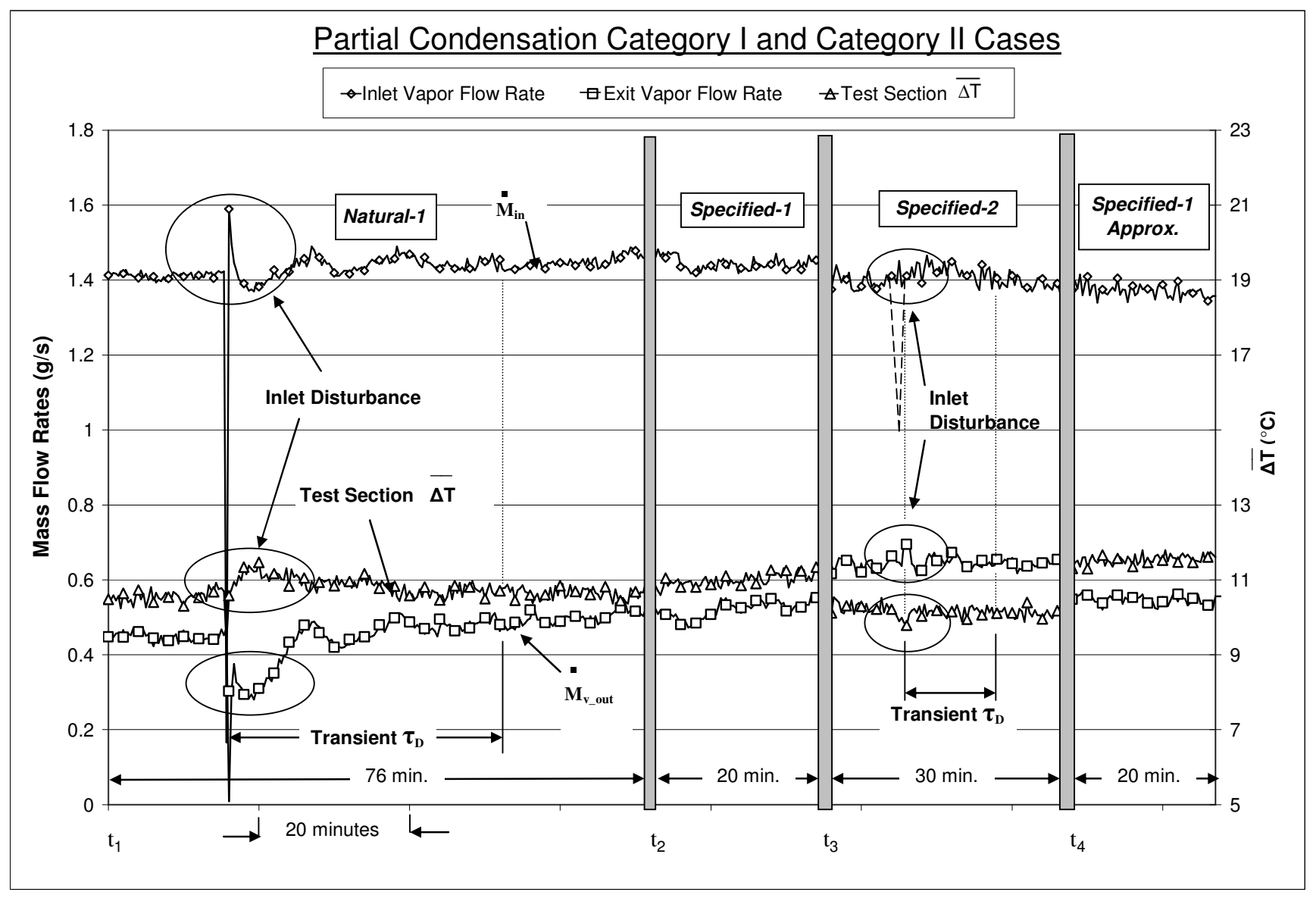

Fig. 7a 


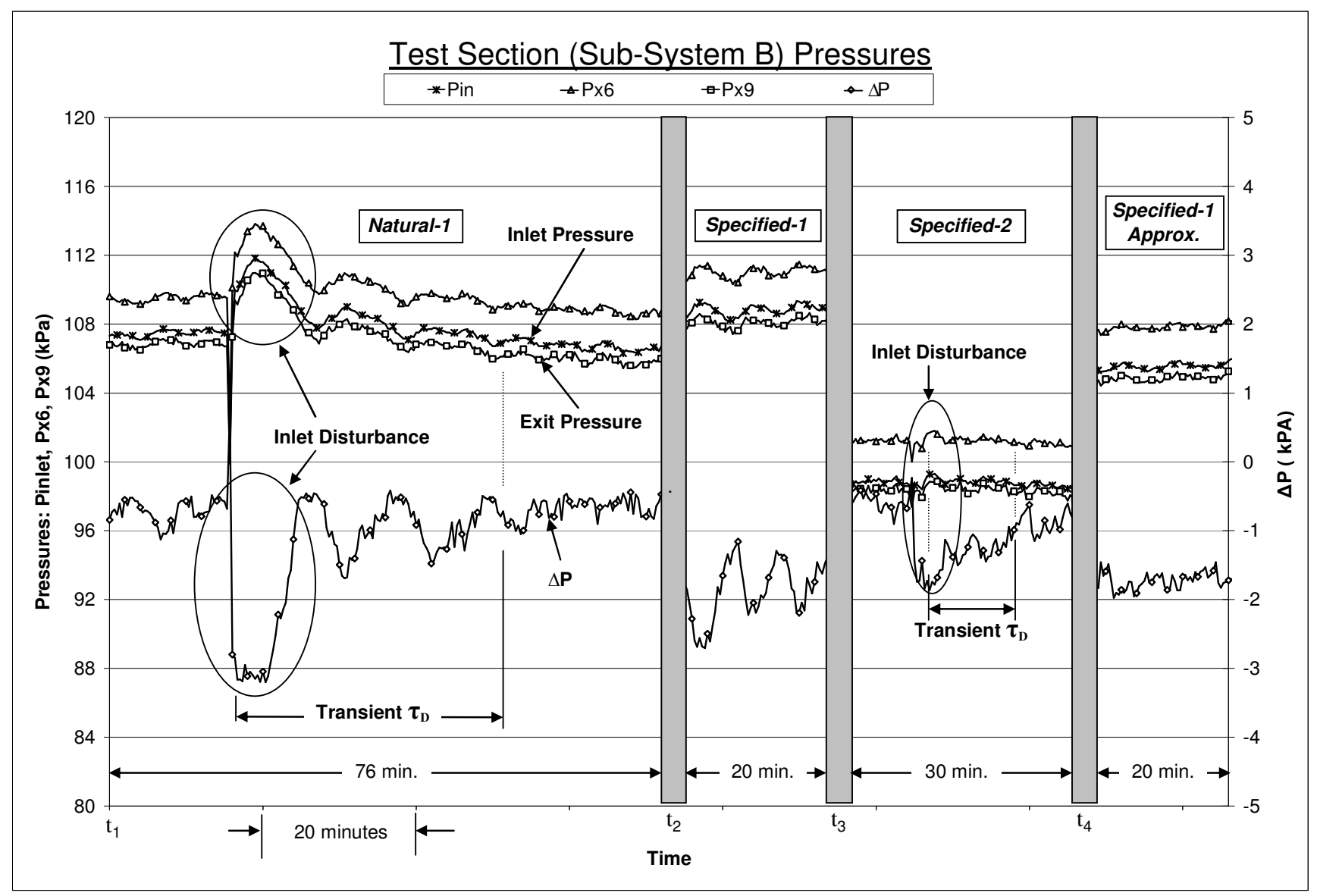

Fig. $7 b$ 


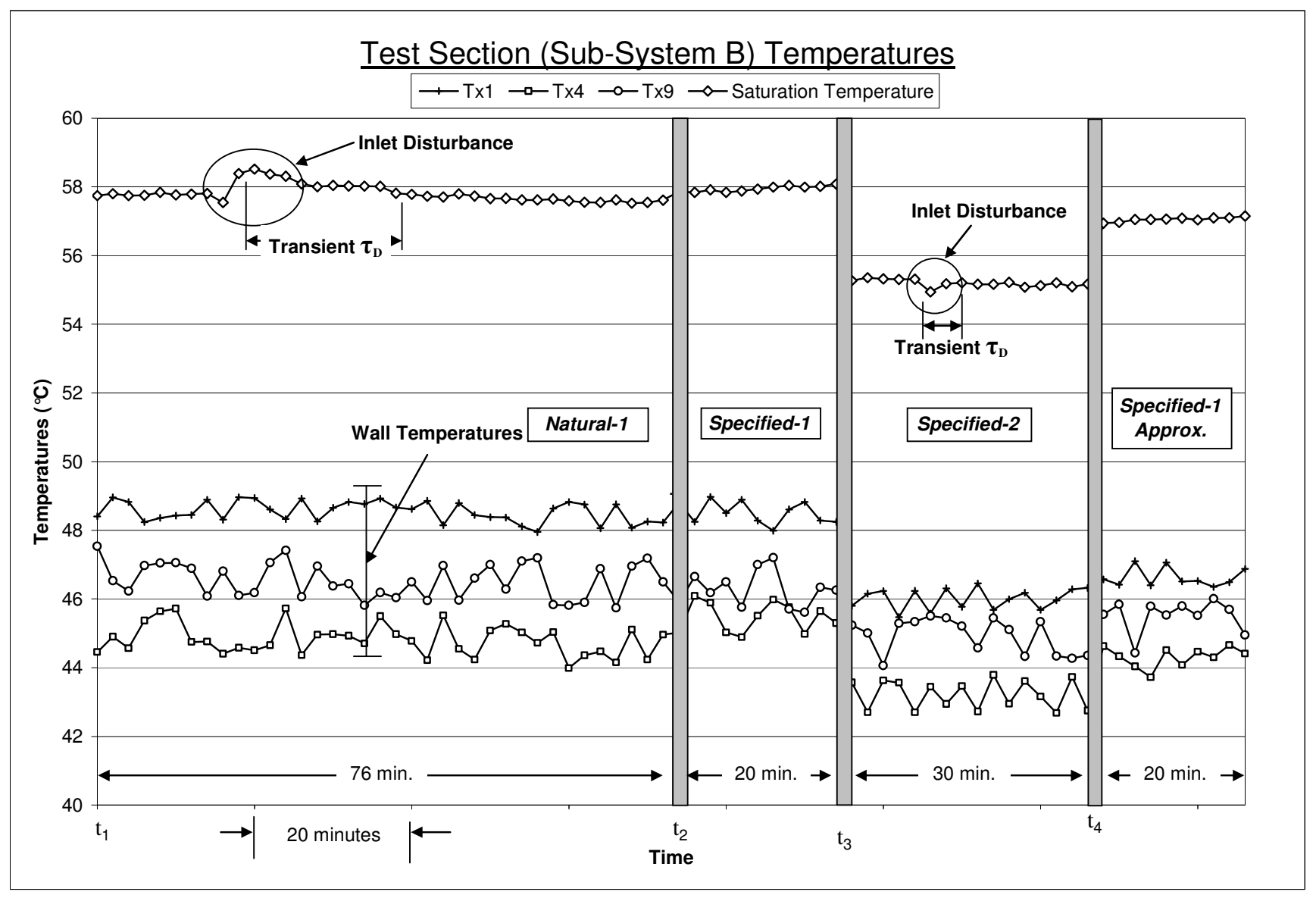

Fig. 7c 


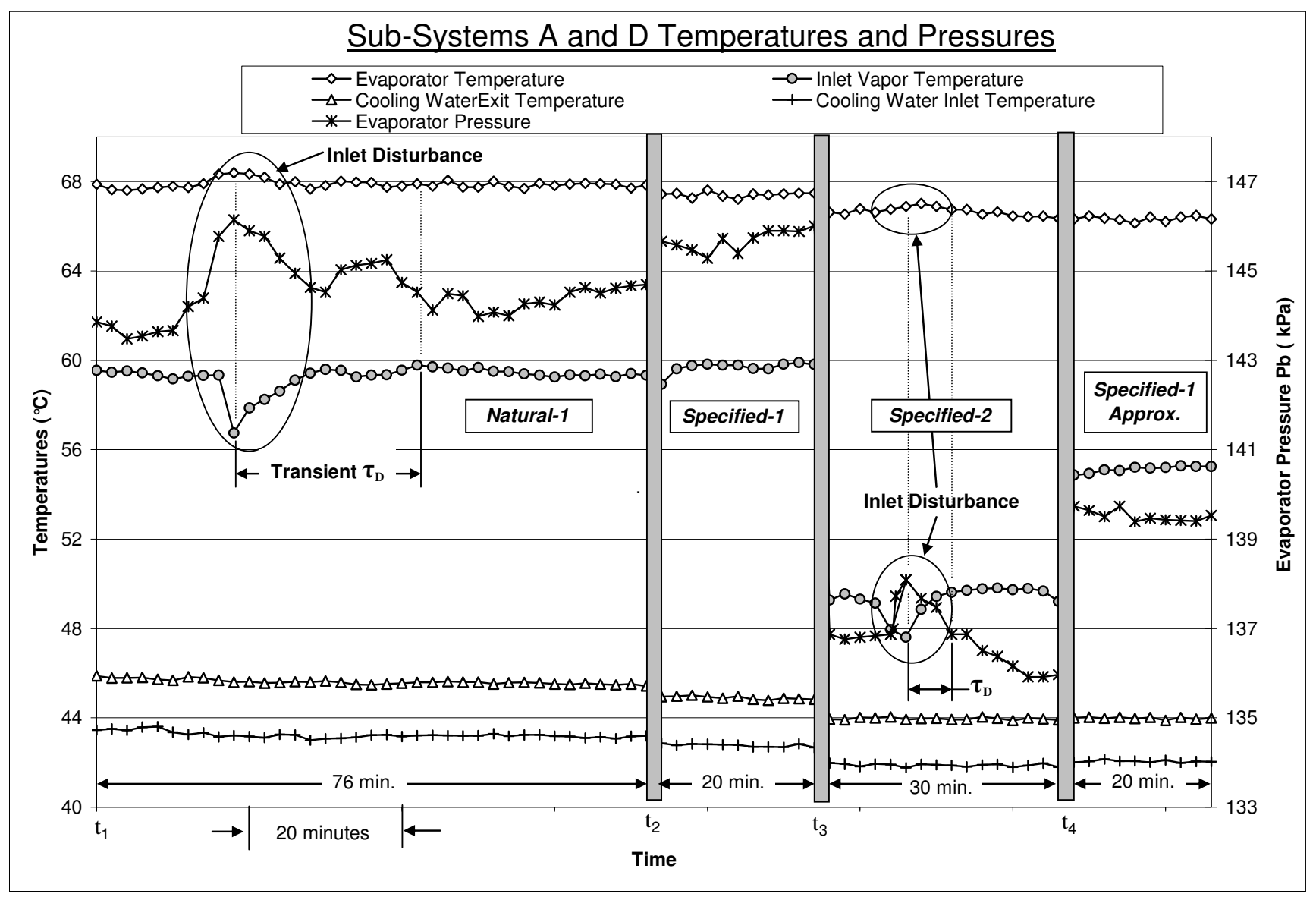

Fig. 7d 


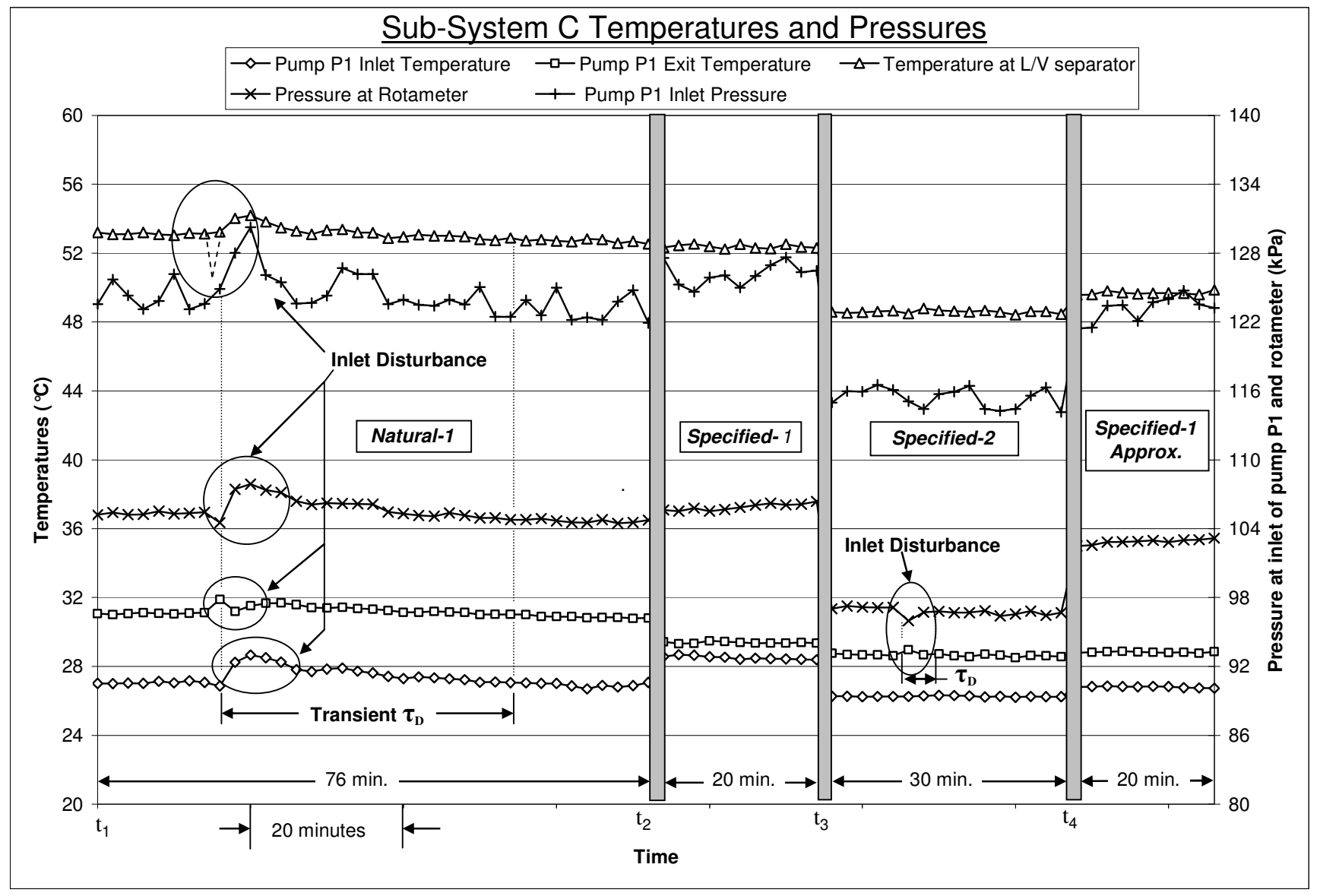

Fig. 7e 


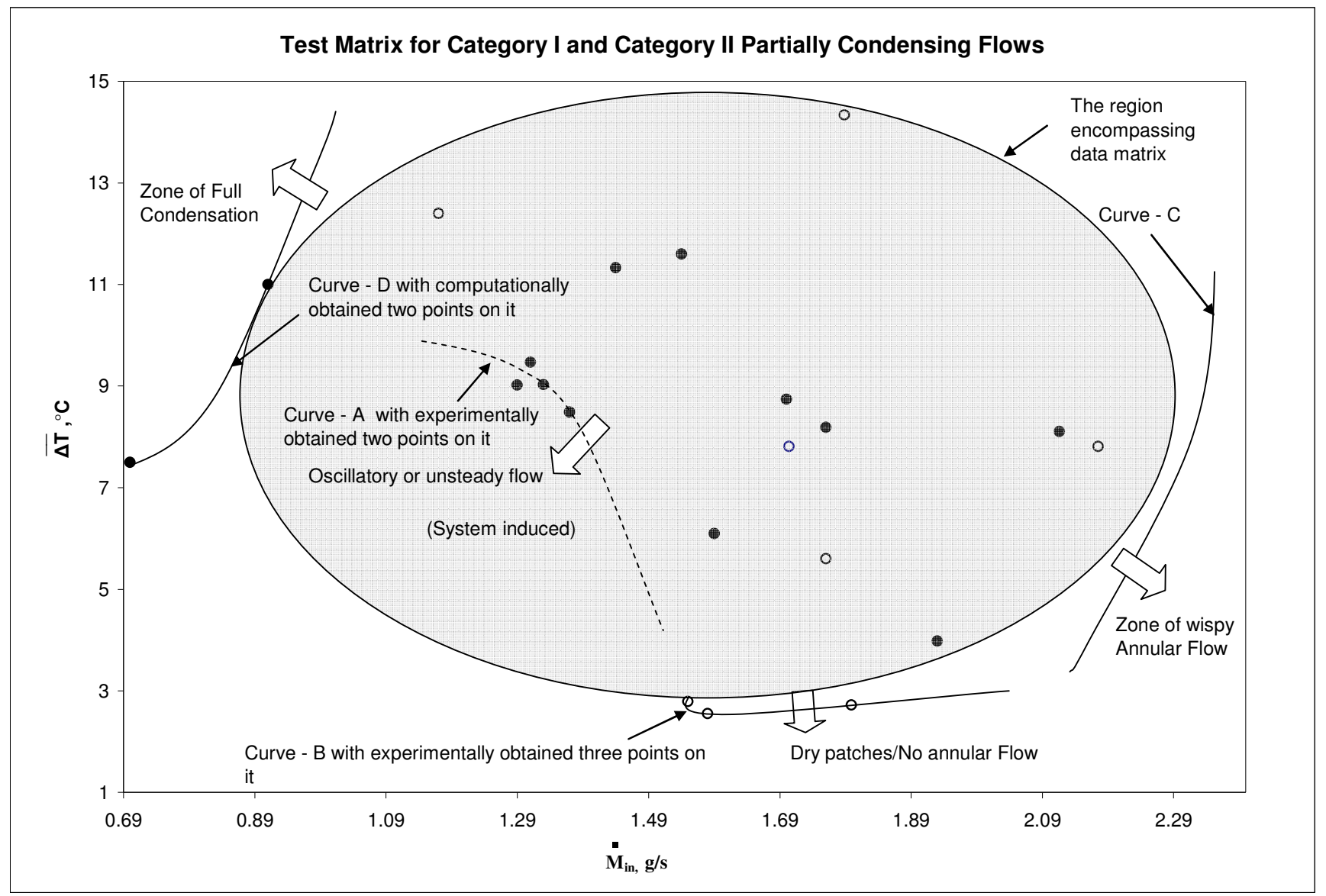

Fig.8a 


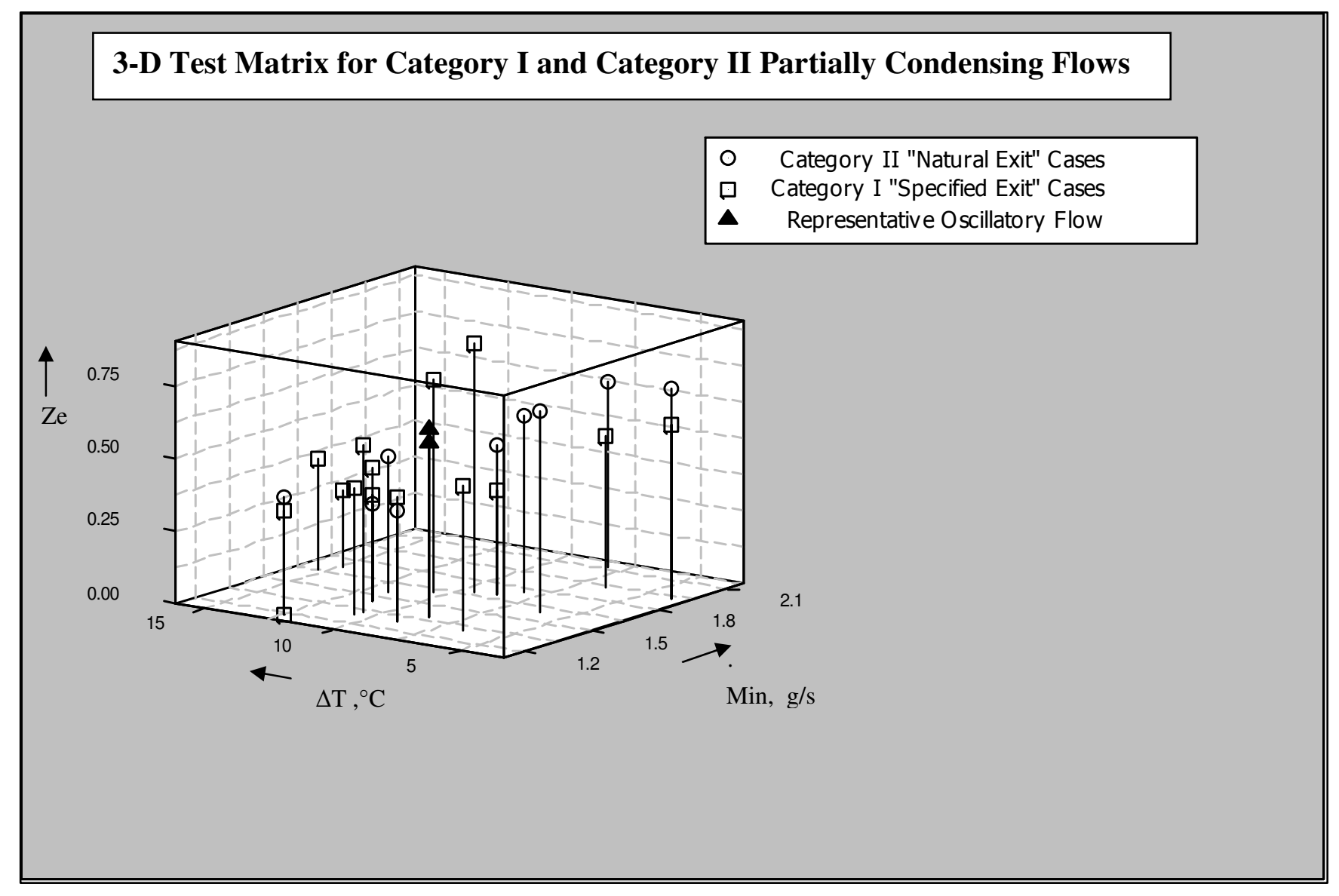

Fig. 8b 


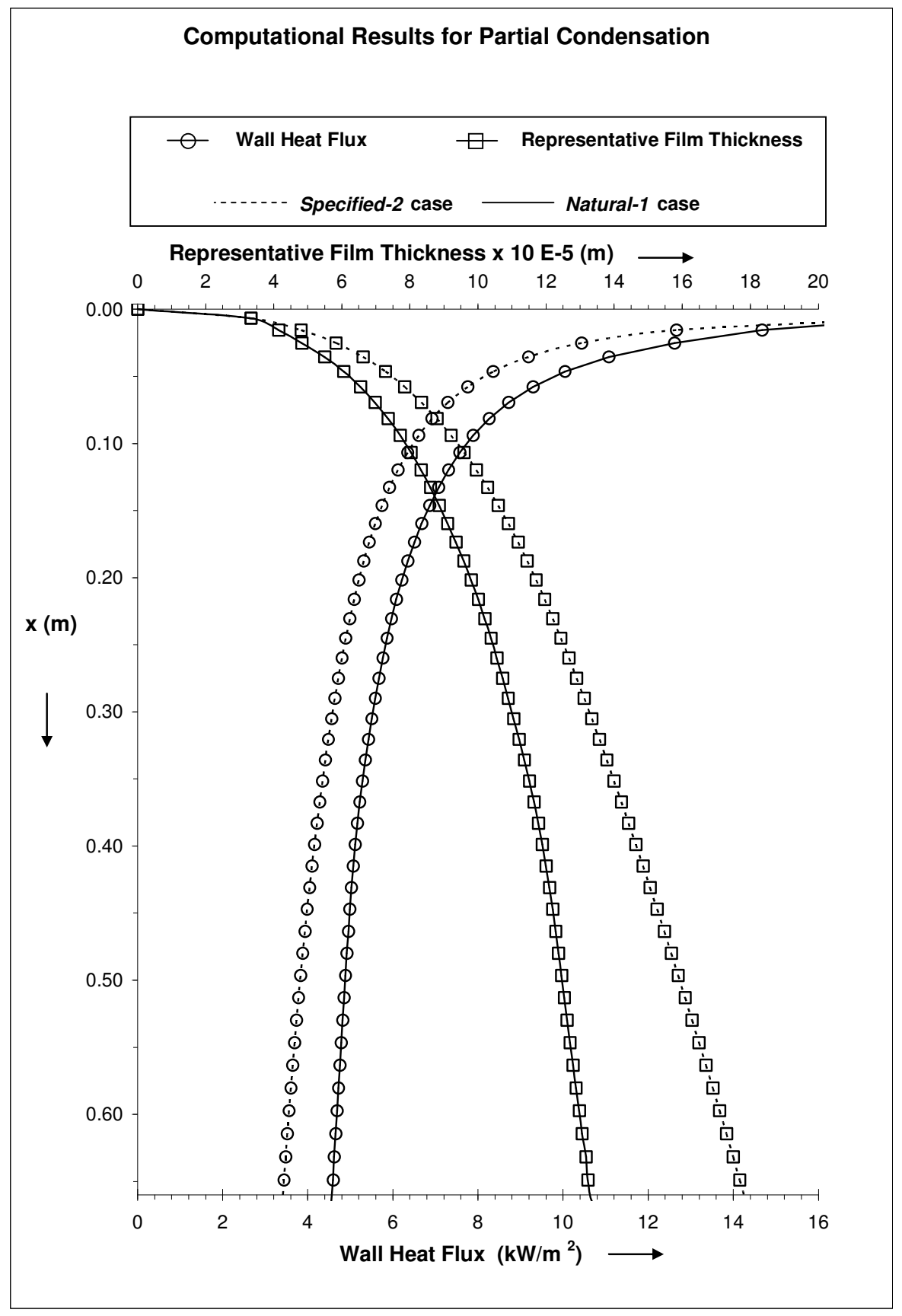

Fig. 9 


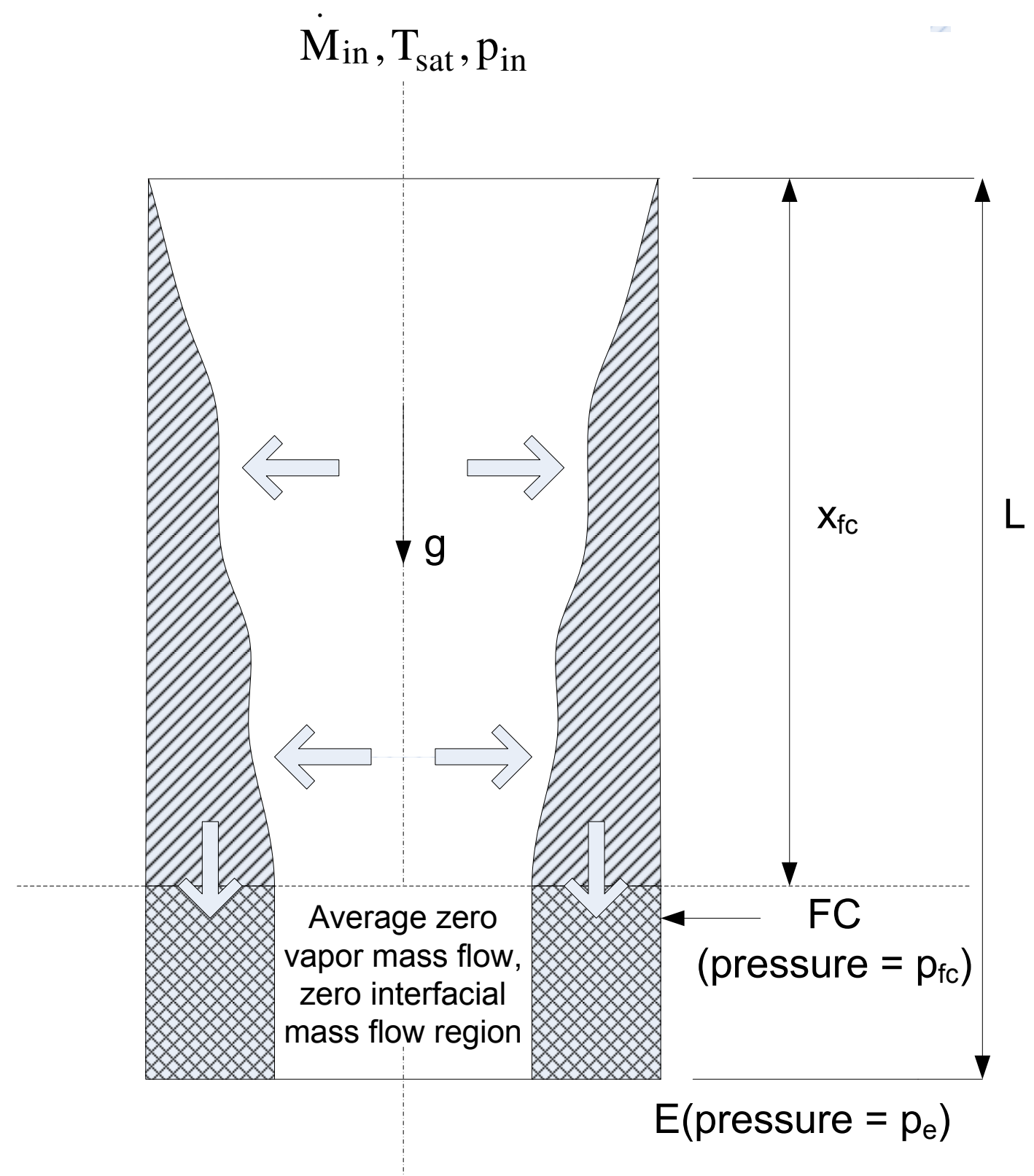

Fig. 10 


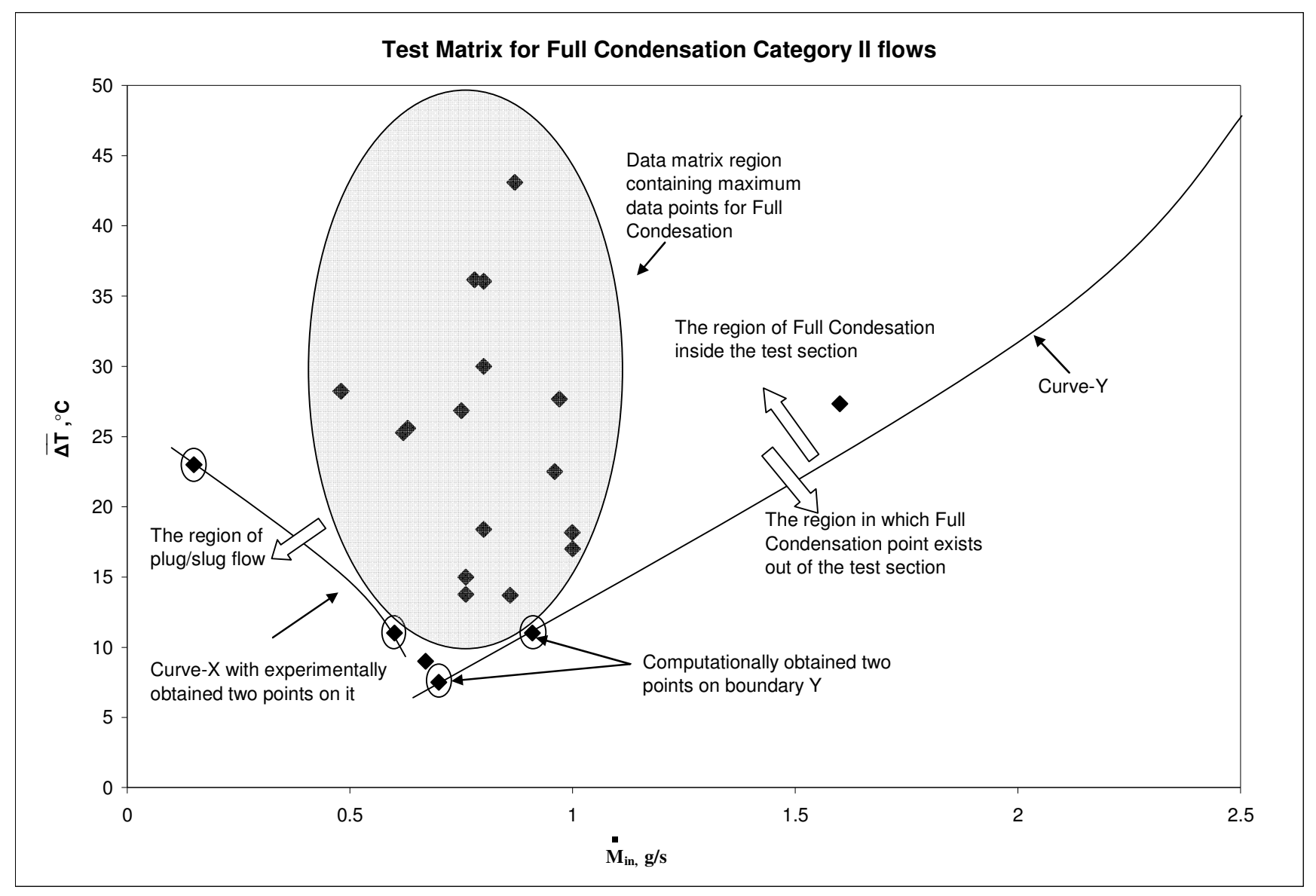

Fig. 11 


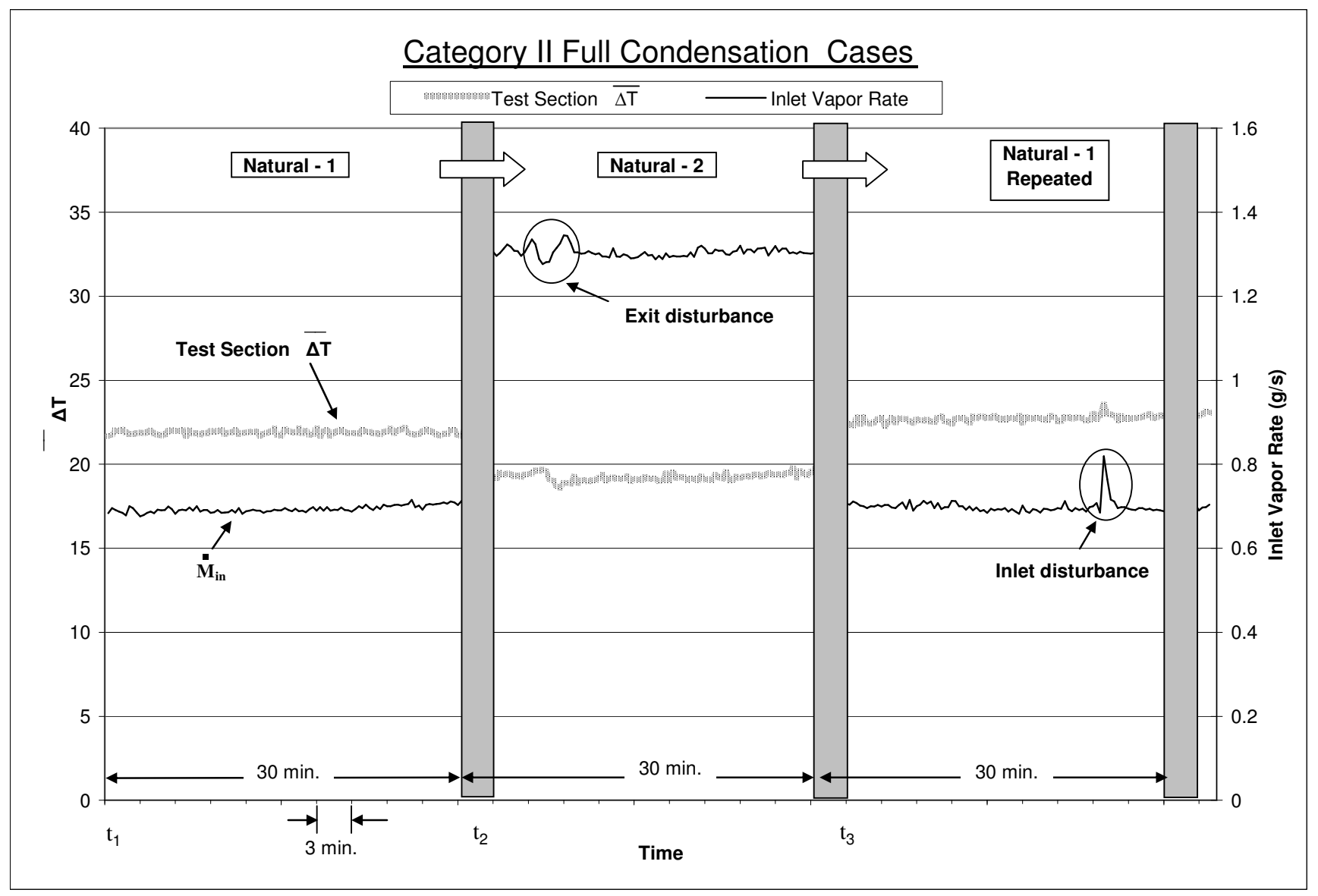

Fig. 12a 


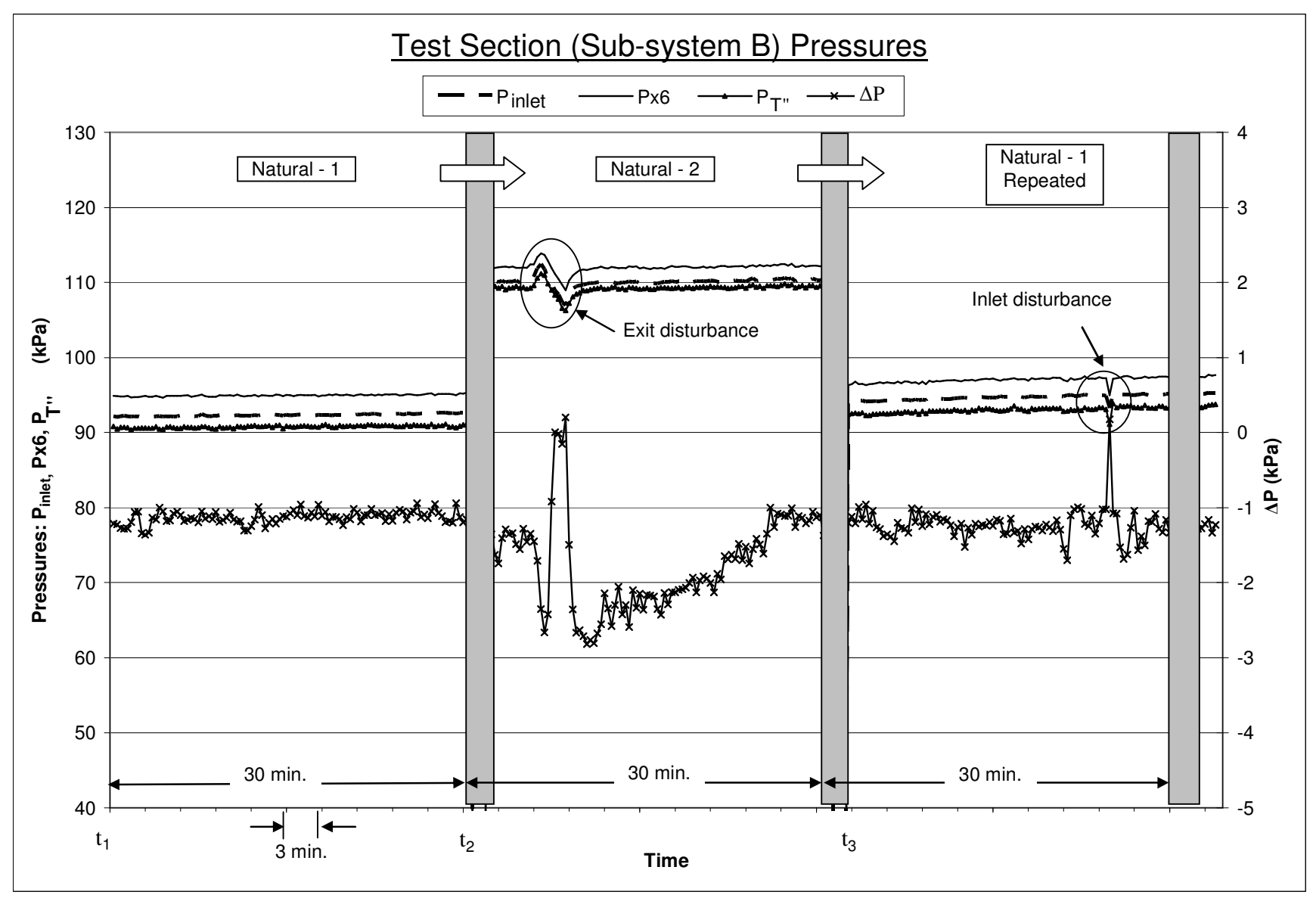

Fig. 12b 


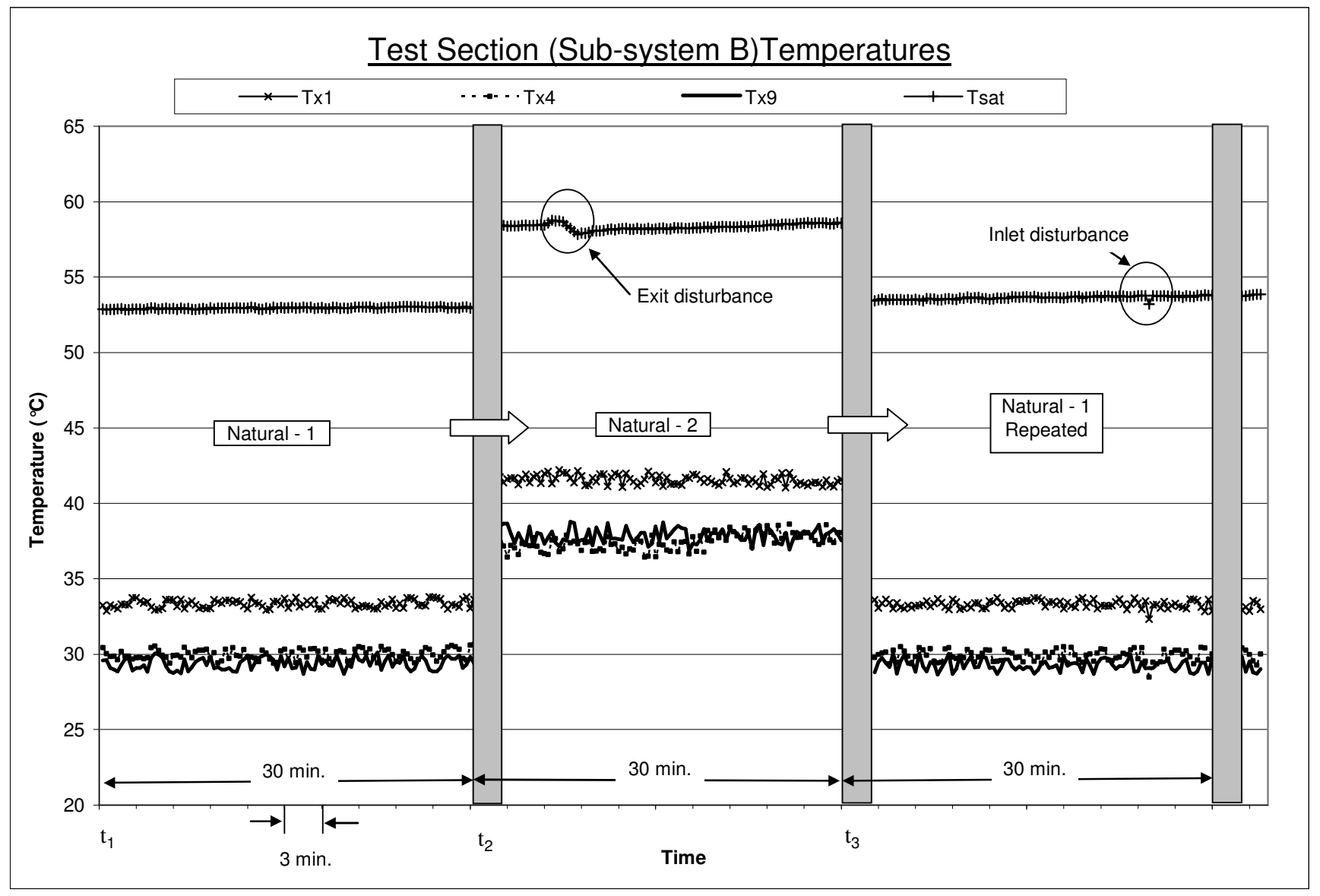

Fig. 12c 


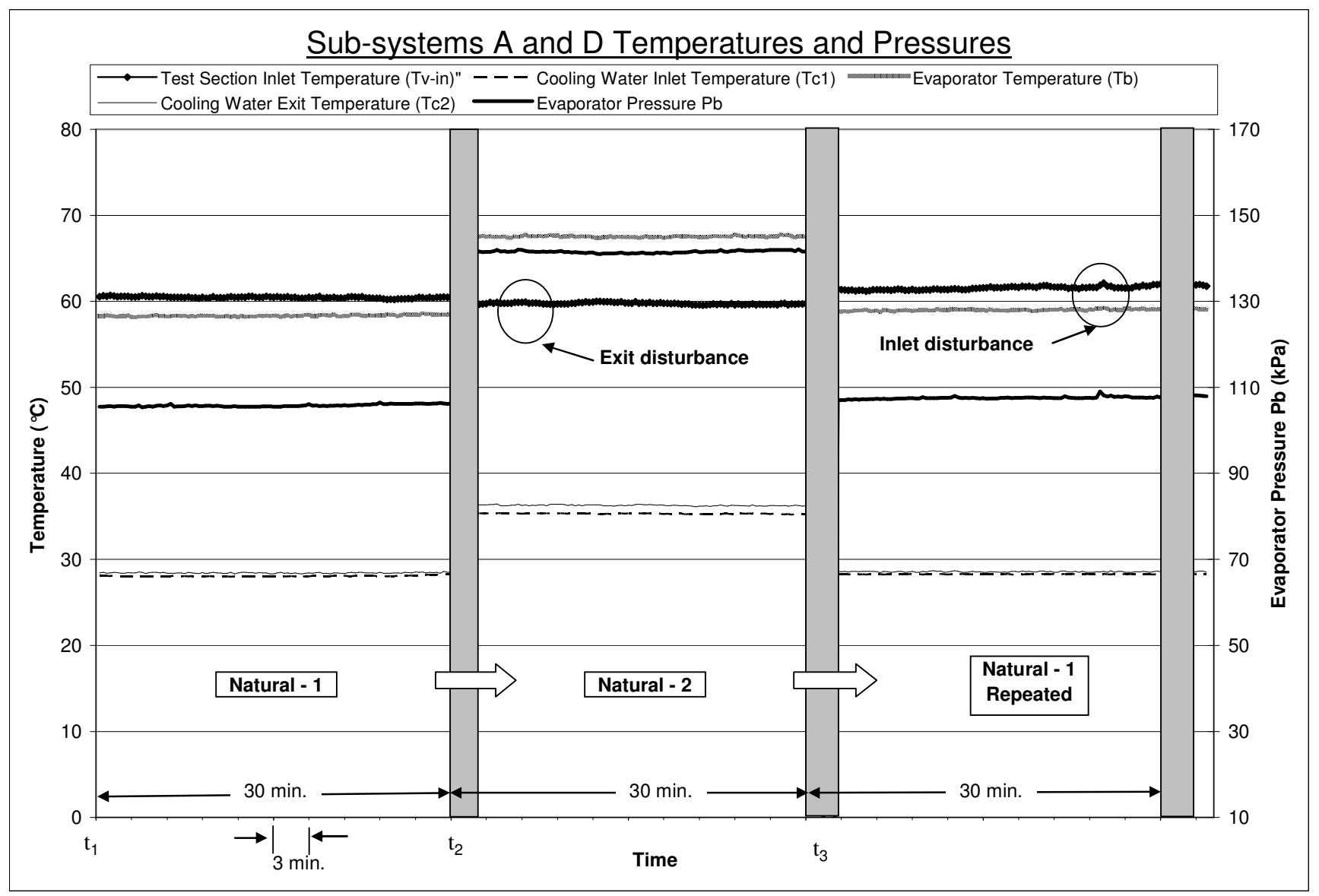

Fig. 12d 


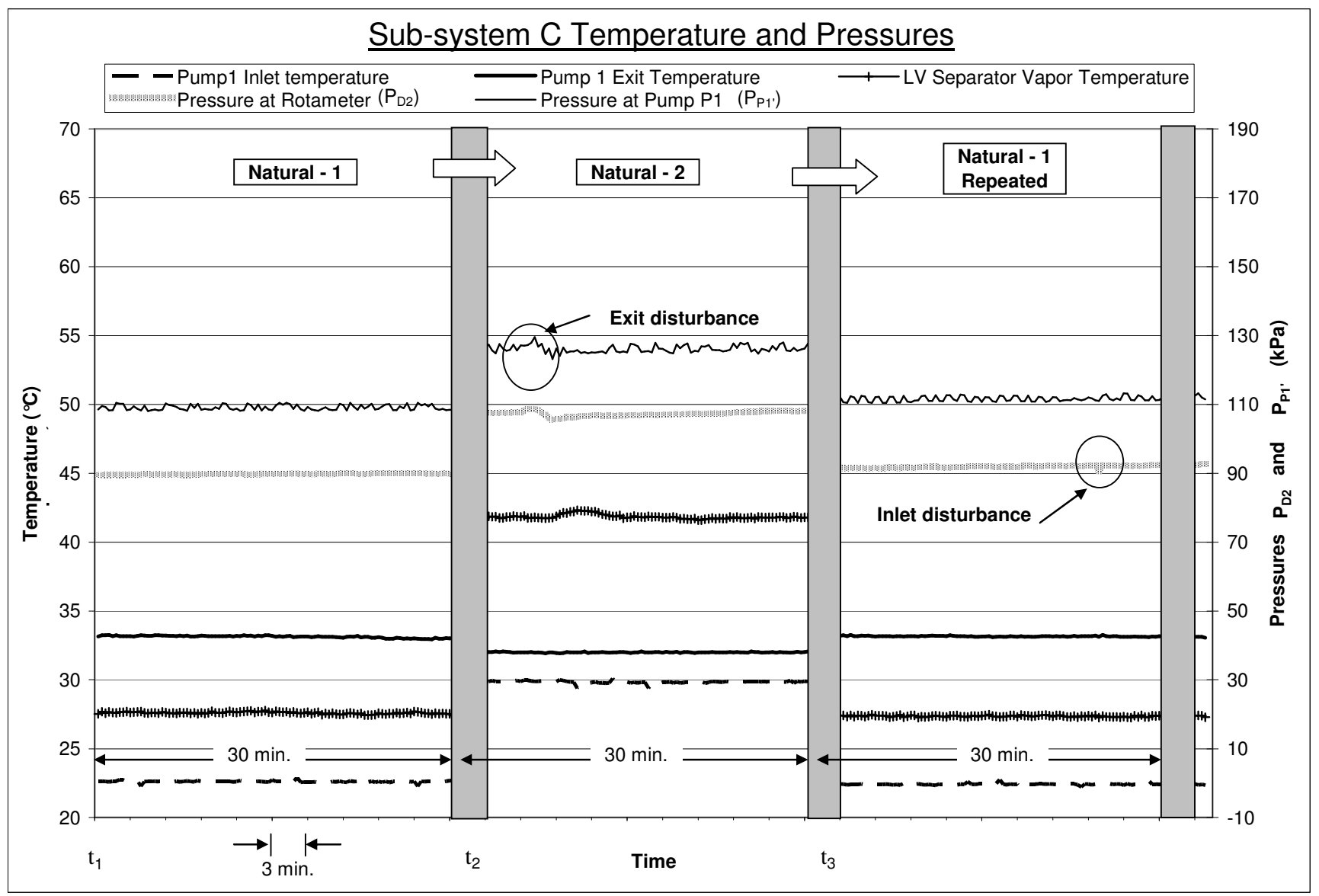

Fig. 12e 


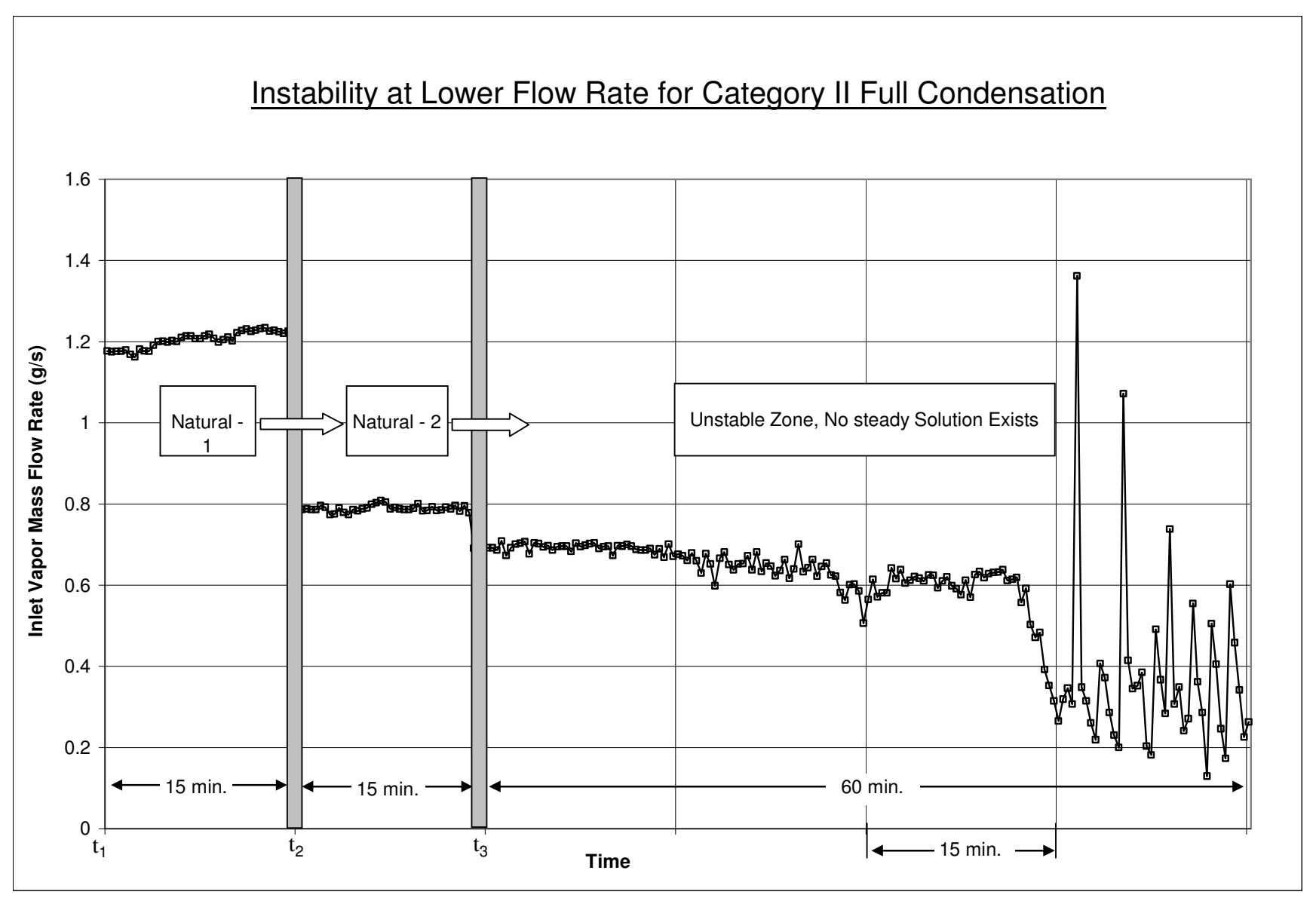

Fig.13a 


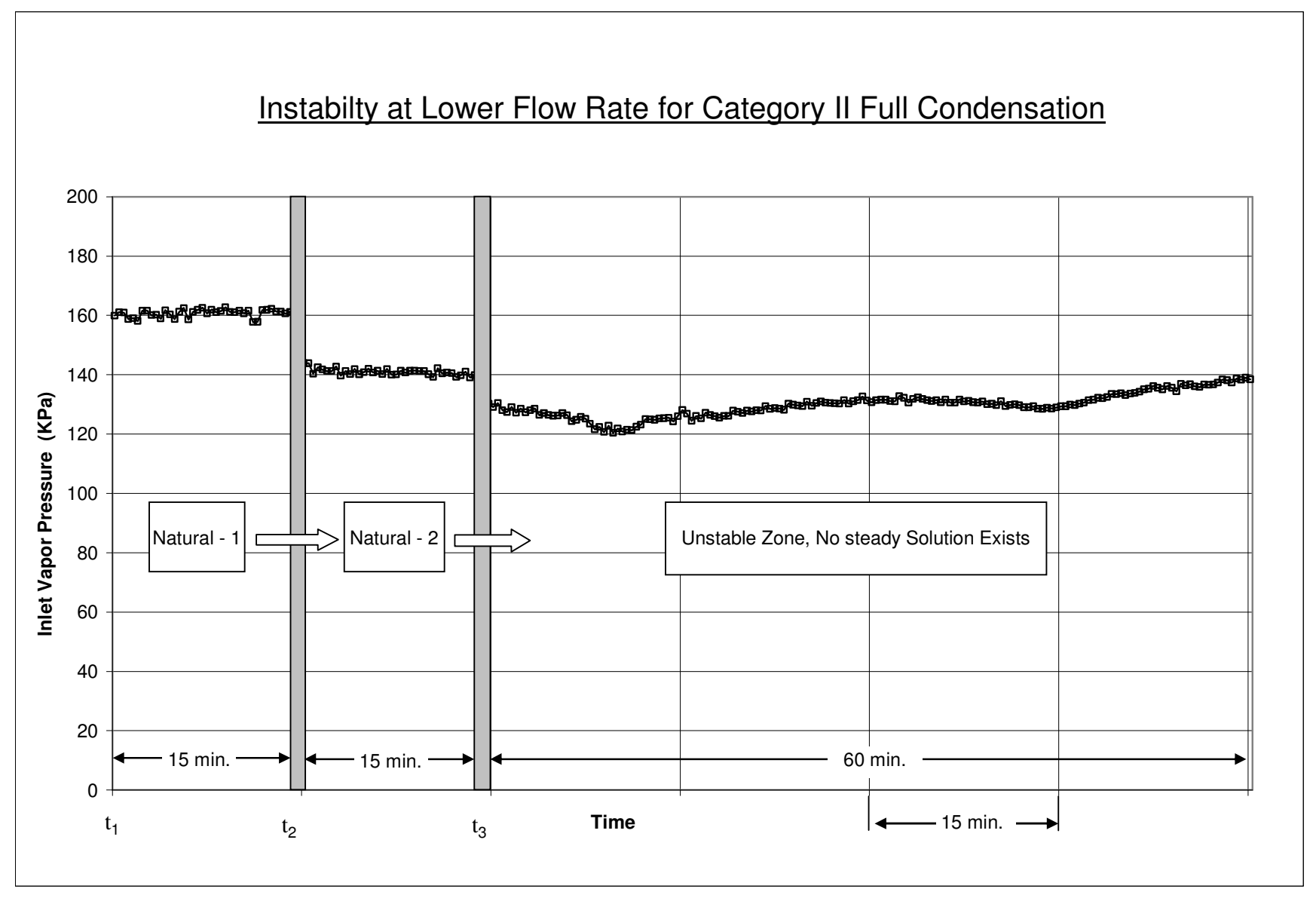

Fig.13b 


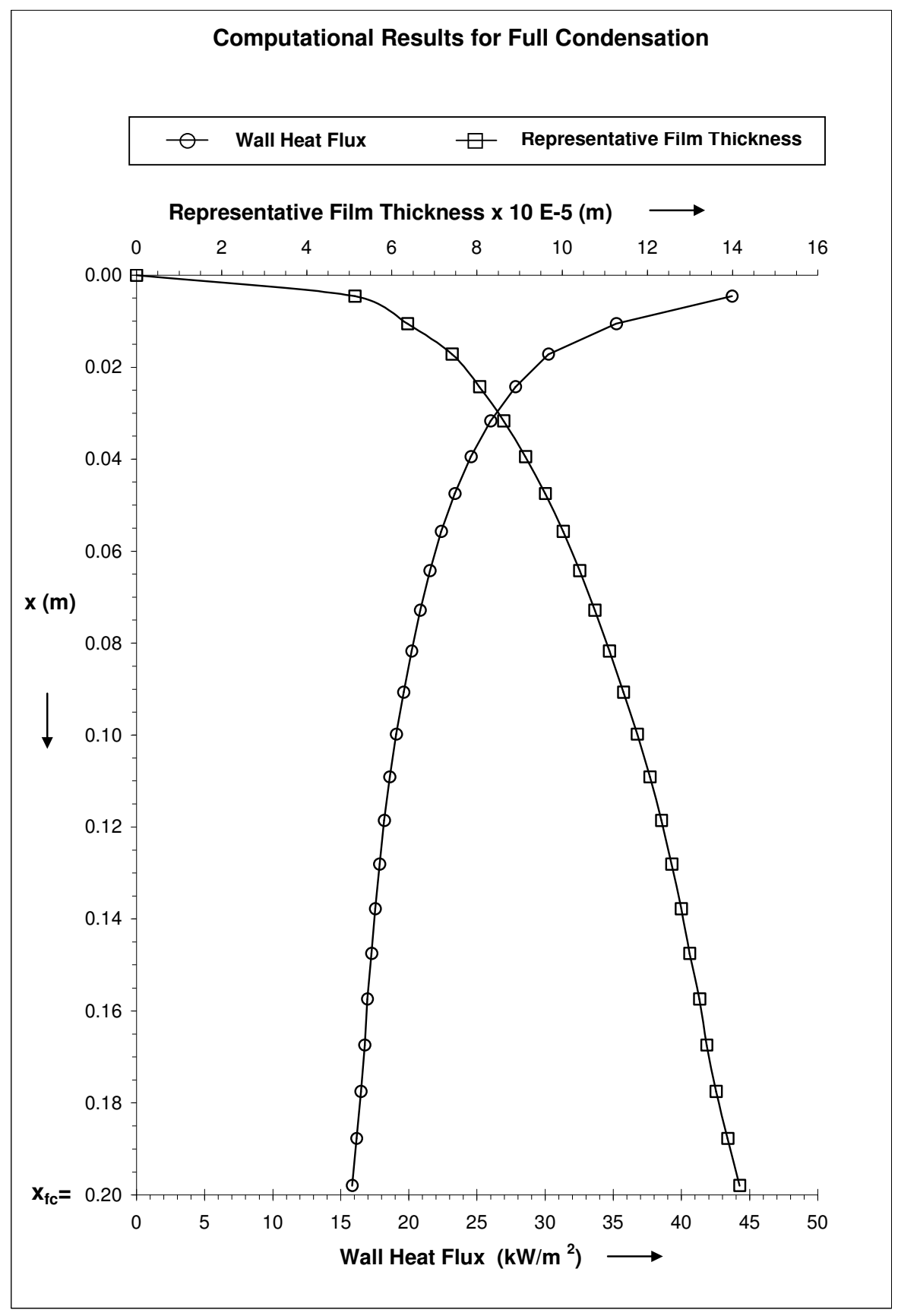

Fig. 14 


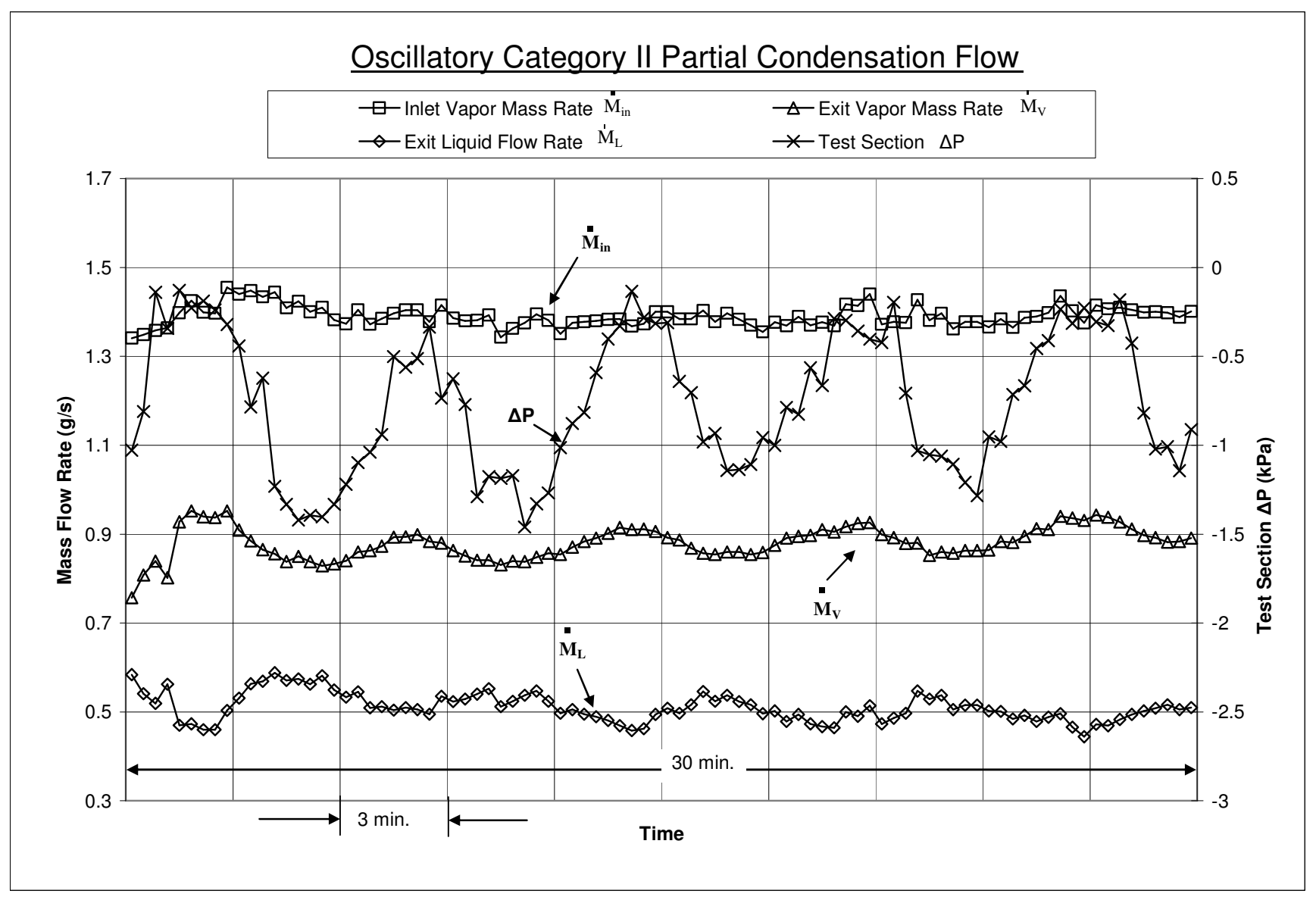

Fig. 15a 


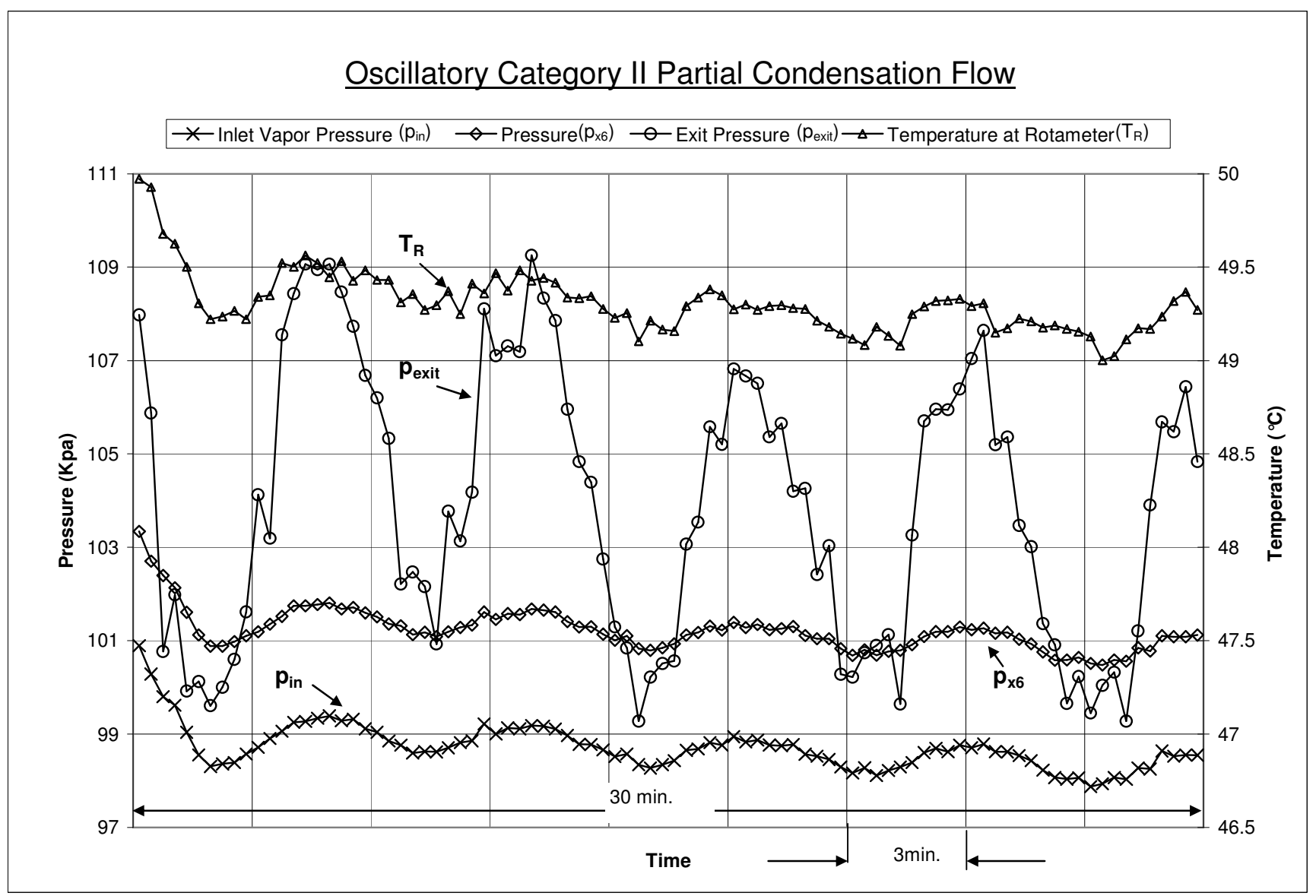

Fig.15b 


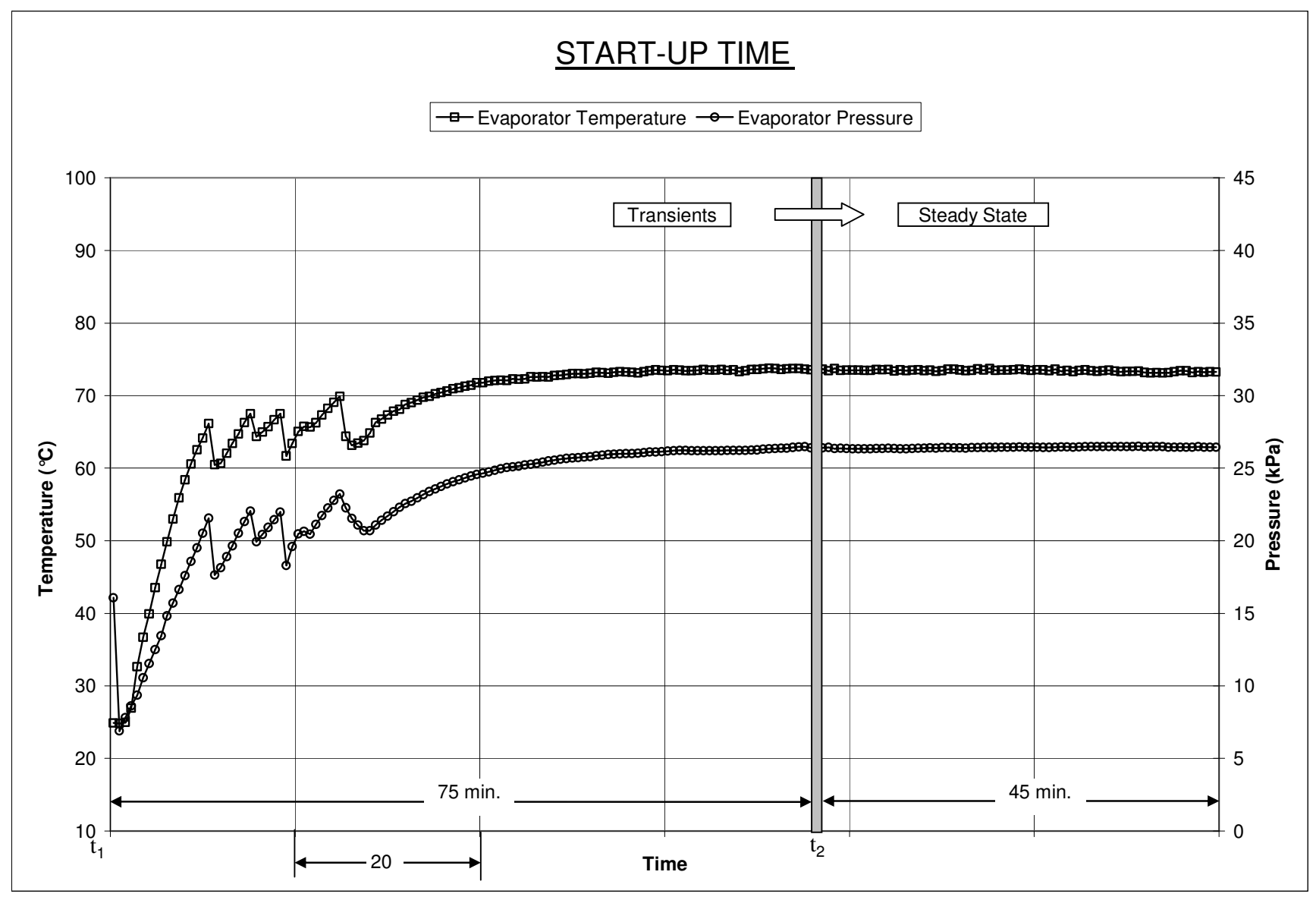

Fig.16 


\begin{tabular}{|c|c|c|c|c|c|c|c|c|c|c|c|c|c|c|c|c|c|c|c|c|c|}
\hline \multirow{3}{*}{$\begin{array}{l}\text { Run } \\
\text { No. }\end{array}$} & $\dot{\mathbf{M}}_{\mathrm{in}}$ & $\dot{\mathrm{M}}_{\mathrm{V}}$ & $\begin{array}{l}Z_{\mathrm{e}} \\
\exp \end{array}$ & $\begin{array}{c}\mathrm{Z}_{\mathrm{e}} \\
\text { comp }\end{array}$ & $\overline{\mathrm{T}} \mathrm{w}$ & $\mathrm{T}_{\mathrm{sat}}$ & $\overline{\Delta \mathrm{T}}$ & $\mathrm{p}_{\text {in }}$ & $\mathrm{p}_{\mathrm{x} 6}$ & $\mathrm{p}_{\mathrm{T}^{\prime \prime}}$ & $\Delta \mathrm{p}$ & $\mathrm{p}_{\mathrm{D} 2}$ & $\rho_{2} / \rho_{1}$ & $\mu_{2} / \mu_{1}$ & G & $\mathrm{Re}$ & $\mathrm{Ja}$ & $\operatorname{Pr}_{1}$ & Q out & $\overline{q^{\prime \prime}}$ & $\begin{array}{l}- \\
\mathrm{h}\end{array}$ \\
\hline & $(\mathrm{g} / \mathrm{s})$ & $(\mathrm{g} / \mathrm{s})$ & & & $(\mathrm{K})$ & $(\mathrm{K})$ & $(\mathrm{K})$ & $(\mathrm{kPa})$ & $(\mathrm{kPa})$ & $(\mathrm{kPa})$ & $(\mathrm{kPa})$ & $(\mathrm{kPa})$ & & & $\left(\mathrm{kg} / \mathrm{m}^{2} \mathrm{~s}\right)$ & & & & $(\mathrm{J} / \mathrm{s})$ & $\left(\mathrm{W} / \mathrm{m}^{2}\right)$ & $\left(\mathrm{W} / \mathrm{m}^{2} \mathrm{~K}\right)$ \\
\hline & \pm 0.05 & \pm 0.04 & \pm 0.04 & & \pm 1 & \pm 0.15 & \pm 1 & \pm 0.6 & \pm 0.6 & \pm 0.7 & \pm 0.05 & \pm 2 & \pm 0.0001 & \pm 0.0001 & \pm 1.5 & \pm 900 & \pm 0.02 & \pm 0.02 & \pm 5 & \pm 800 & \pm 80 \\
\hline 1 & 1.44 & 0.48 & 0.33 & 0.33 & 320 & 331.49 & 11 & 107.3 & 109.3 & 106.5 & -0.82 & 105 & 0.0085 & 0.0243 & 42.1 & 23900 & 0.14 & 9.61 & 81 & 5200 & 453 \\
\hline 2 & 1.76 & 1.08 & 0.62 & 0.57 & 317 & 325.23 & 8 & 87.0 & 86.4 & 88.0 & -0.36 & 85 & 0.0070 & 0.0223 & 51.5 & 29700 & 0.10 & 10.11 & 58 & 3700 & 450 \\
\hline 3 & 1.54 & 0.69 & 0.44 & 0.36 & 323 & 335.55 & 12 & 122.6 & 116.6 & 116.1 & -0.19 & 114 & 0.0097 & 0.0260 & 45.0 & 25300 & 0.15 & 9.21 & 71 & 4500 & 387 \\
\hline 4 & 1.29 & 0.49 & 0.38 & 0.38 & 320 & 329.64 & 10 & 101.0 & 102.4 & 100.8 & -2.09 & 98 & 0.0081 & 0.0230 & 37.7 & 21500 & 0.11 & 9.69 & 68 & 4300 & 476 \\
\hline 5 & 1.70 & 0.83 & 0.51 & 0.52 & 324 & 332.55 & 9 & 111.0 & 112.5 & 111.0 & -0.93 & 109 & 0.0089 & 0.0252 & 49.6 & 28100 & 0.11 & 9.37 & 70 & 4400 & 508 \\
\hline 6 & 1.17 & 0.47 & 0.40 & 0.39 & 320 & 332.64 & 13 & 111.3 & NA & 111.3 & -0.12 & 109 & 0.0088 & 0.0246 & 34.2 & 19325 & 0.16 & 9.55 & 59 & 3700 & 298 \\
\hline 7 & 1.31 & 0.49 & 0.37 & 0.37 & 321 & 330.85 & 10 & 105.0 & 106.8 & 104.5 & -2.06 & 102 & 0.0084 & 0.0244 & 38.3 & 21700 & 0.12 & 9.58 & 69 & 4400 & 462 \\
\hline $8^{*}$ & 1.93 & 1.39 & 0.72 & 0.72 & 322 & 325.55 & 4 & 84.6 & NA & NA & 0.01 & NA & 0.0071 & 0.0231 & 56.4 & 32500 & 0.05 & 9.85 & 47 & 3000 & 742 \\
\hline 9 & 1.59 & 1.11 & 0.69 & 0.63 & 328 & 334.25 & 6 & 113.0 & NA & NA & NA & NA & 0.0094 & 0.0265 & 46.5 & 26200 & 0.08 & 9.07 & 40 & 2500 & 418 \\
\hline 10 & 2.12 & 1.37 & 0.64 & 0.64 & 320 & 327.85 & 8 & 91.4 & NA & NA & -0.10 & NA & 0.0076 & 0.0234 & 62.0 & 35500 & 0.10 & 9.83 & 64 & 4100 & 503 \\
\hline 11 & 1.30 & 0.45 & 0.35 & 0.38 & 321 & 329.29 & 8 & 99.8 & 100.2 & 99.7 & -1.62 & 97 & 0.0080 & 0.0240 & 38.0 & 21700 & 0.10 & 9.70 & 72 & 4600 & 537 \\
\hline
\end{tabular}

\section{Table 1}

- $\quad *$ The error values for this case were greater than the representative error values shown in the column headers due to small $\overline{\Delta \mathrm{T}}$ and high relative error associated with its measurement.

- $\quad$ NA: The data was not available due to some equipment problem 


\begin{tabular}{|c|c|c|c|c|c|c|c|c|c|c|c|c|c|c|c|c|c|c|c|c|}
\hline \multirow{3}{*}{$\begin{array}{l}\text { Run } \\
\text { No. }\end{array}$} & $\dot{\mathrm{M}}_{\text {in }}$ & $\dot{\mathrm{M}}_{\mathrm{V}}$ & $\mathrm{Z}_{\mathrm{e}-}$ & $\overline{\mathrm{Tw}}$ & $\mathrm{T}_{\text {sat }}$ & $\overline{\Delta \mathrm{T}}$ & $\mathrm{p}_{\text {in }}$ & $\mathrm{p}_{\mathrm{x} 6}$ & $\mathrm{p}_{\mathrm{T}^{\prime \prime}}$ & $\Delta \mathrm{p}$ & $\mathrm{p}_{\mathrm{D} 2}$ & $\rho_{2} / \rho_{1}$ & $\mu_{2} / \mu_{1}$ & G & $\mathrm{Re}$ & $\mathrm{Ja}$ & $\operatorname{Pr}_{1}$ & Q́out & $\bar{q}^{\prime \prime}$ & $\frac{-}{\mathrm{h}}$ \\
\hline & $(\mathrm{g} / \mathrm{s})$ & $(\mathrm{g} / \mathrm{s})$ & & $(\mathrm{K})$ & $(\mathrm{K})$ & (K) & $(\mathrm{kPa})$ & $(\mathrm{kPa})$ & $(\mathrm{kPa})$ & $(\mathrm{kPa})$ & $(\mathrm{kPa})$ & & & $\left(\mathrm{kg} / \mathrm{m}^{2} \mathrm{~s}\right)$ & & & & $(\mathrm{J} / \mathrm{s})$ & $\left(\mathrm{W} / \mathrm{m}^{2}\right)$ & $\left(\mathrm{W} / \mathrm{m}^{2} \mathrm{~K}\right)$ \\
\hline & \pm 0.05 & \pm 0.04 & \pm 0.04 & \pm 1 & \pm 0.15 & \pm 1 & \pm 0.6 & \pm 0.6 & \pm 0.7 & \pm 0.05 & \pm 2 & \pm 0.0001 & \pm 0.0001 & \pm 1.5 & \pm 900 & \pm 0.02 & \pm 0.02 & \pm 5 & \pm 800 & \pm 80 \\
\hline 2 & 1.31 & 0.50 & 0.38 & 320 & 329.16 & 9 & 99.4 & 100.3 & 99.5 & -0.43 & 98 & 0.0080 & 0.0238 & 38.4 & 21900 & 0.11 & 9.72 & 69 & 4400 & 505 \\
\hline 3 & 1.34 & 0.59 & 0.44 & 320 & 328.55 & 9 & 97.4 & 98.4 & 97.3 & -0.32 & 96 & 0.0078 & 0.0236 & 39.1 & 22400 & 0.10 & 9.76 & 64 & 4100 & 491 \\
\hline $4^{*}$ & 1.80 & 0.64 & 0.36 & 323 & 330.53 & 8 & 103.9 & 105.9 & 104.4 & -0.59 & 103 & 0.0083 & 0.0246 & 52.6 & 29900 & 0.09 & 9.50 & 97 & 6200 & 851 \\
\hline $5^{*}$ & 1.92 & 1.00 & 0.52 & 323 & 329.64 & 7 & 101.0 & 103.3 & 101.7 & -0.40 & 100 & 0.0081 & 0.0244 & 56.1 & 32000 & 0.08 & 9.55 & 78 & 4900 & 771 \\
\hline 6 & 1.20 & 0.00 & 0.00 & 320 & 332.23 & 12 & 110.5 & 113.2 & 110.5 & -0.80 & 108 & 0.0088 & 0.0245 & 35.0 & 19800 & 0.16 & 9.57 & 101 & 6400 & 514 \\
\hline 7 & 1.22 & 0.44 & 0.35 & 320 & 331.71 & 12 & 108.0 & 110.6 & 108.0 & -0.62 & 106 & 0.0086 & 0.0243 & 36.6 & 20200 & 0.15 & 9.62 & 66 & 4200 & 351 \\
\hline $8^{*}$ & 1.93 & 1.15 & 0.60 & 322 & 325.21 & 3 & 87.15 & NA & NA & -1.30 & NA & 0.0071 & 0.0231 & 56.4 & 32600 & 0.04 & 9.87 & 67 & 4300 & 1174 \\
\hline 9 & 1.61 & 1.14 & 0.70 & 322 & 332.57 & 11 & 111.4 & 104.6 & 107.0 & -0.87 & 103 & 0.0089 & 0.0250 & 47.1 & 26630 & 0.13 & 9.46 & 35 & 2200 & 212 \\
\hline 10 & 1.67 & 1.37 & 0.82 & 322 & 331.45 & 10 & 105.8 & 98.6 & 100.8 & -0.74 & 97 & 0.0085 & 0.0245 & 49.0 & 27800 & 0.12 & 9.57 & 16 & 1000 & 108 \\
\hline 11 & 1.81 & 1.02 & 0.56 & 317 & 331.48 & 14 & 106.8 & 102.1 & NA & -0.58 & 99 & 0.0085 & 0.0237 & 52.9 & 30000 & 0.18 & 9.80 & 54 & 3400 & 236 \\
\hline 12 & 1.66 & 0.60 & 0.36 & 318 & 333.15 & 15 & 113.5 & 108.6 & NA & -1.46 & 106 & 0.0090 & 0.0243 & 48.5 & 27400 & 0.20 & 9.66 & 88 & 5600 & 363 \\
\hline 13 & 1.71 & 0.49 & 0.28 & 316 & 331.14 & 15 & 108.0 & 107.9 & 108.1 & -2.10 & 105 & 0.0085 & 0.0237 & 50.1 & 28400 & 0.19 & 9.81 & 103 & 6500 & 441 \\
\hline 14 & 1.30 & 0.65 & 0.50 & 320 & 326.34 & 6 & 90.5 & 92.1 & 90.5 & -1.15 & 88 & 0.0073 & 0.0230 & 38.0 & 21800 & 0.08 & 9.90 & 56 & 3500 & 545 \\
\hline 15 & 1.29 & 0.55 & 0.43 & 321 & 331.63 & 11 & 107.7 & 113.2 & 110.1 & -1.60 & 107 & 0.0086 & 0.0245 & 37.7 & 21400 & 0.14 & 9.57 & 62 & 3900 & 366 \\
\hline 16 & 1.31 & 0.76 & 0.58 & 321 & 331.07 & 11 & 105.8 & 109.1 & 105.8 & -0.95 & 104 & 0.0084 & 0.0243 & 38.3 & 21700 & 0.13 & 9.62 & 46 & 2900 & 279 \\
\hline 18 & 1.39 & 0.64 & 0.46 & 318 & 329.01 & 11 & 98.9 & 101.3 & 98.4 & -0.65 & 97.1 & 0.0079 & 0.0234 & 40.6 & 23200 & 0.14 & 9.85 & 64 & 4100 & 377 \\
\hline
\end{tabular}

Table 2

- $\quad$ *The error values for this case were greater than the representative error values shown in the column headers due to small $\overline{\Delta \mathrm{T}}$ and high relative error associated with its measurement.

- $\quad$ NA: The data was not available due to some equipment problem 


\begin{tabular}{|c|c|c|c|c|c|c|c|c|c|c|c|c|c|c|c|c|c|c|}
\hline \multirow{3}{*}{$\begin{array}{l}\text { Run } \\
\text { No. }\end{array}$} & $\dot{\mathrm{M}}_{\text {in }}$ & $\overline{\mathrm{T}} \mathrm{w}$ & $\mathrm{T}_{\mathrm{sat}}$ & $\overline{\Delta \mathrm{T}}$ & $\mathrm{p}_{\text {in }}$ & $\mathrm{p}_{\mathrm{x} 6}$ & $\mathrm{p}_{\mathrm{T}^{\prime \prime}}$ & $\Delta \mathrm{p}$ & $\mathrm{p}_{\mathrm{D} 2}$ & $\rho_{2} / \rho_{1}$ & $\mu_{2} / \mu_{1}$ & G & $\mathrm{Re}$ & $\mathrm{Ja}$ & $\operatorname{Pr}_{1}$ & Q̇out & $\overline{\mathrm{q}^{\prime \prime}}$ & $\begin{array}{l}- \\
\mathrm{h}\end{array}$ \\
\hline & $(\mathrm{g} / \mathrm{s})$ & (K) & (K) & (K) & $(\mathrm{kPa})$ & $(\mathrm{kPa})$ & $(\mathrm{kPa})$ & $(\mathrm{kPa})$ & $(\mathrm{kPa})$ & & & $\left(\mathrm{kg} / \mathrm{m}^{2} \mathrm{~s}\right)$ & & & & $(\mathrm{J} / \mathrm{s})$ & $\left(\mathrm{W} / \mathrm{m}^{2}\right)$ & $\begin{array}{c}\left(\mathrm{W} / \mathrm{m}^{2}\right. \\
\mathrm{K})\end{array}$ \\
\hline & \pm 0.05 & \pm 1 & \pm 0.15 & \pm 1 & \pm 0.6 & \pm 0.6 & \pm 0.7 & \pm 0.05 & \pm 2 & \pm 0.0001 & \pm 0.0001 & \pm 1.5 & \pm 800 & \pm 0.02 & \pm 0.02 & \pm 5 & \pm 500 & \pm 26 \\
\hline 1 & 0.69 & 304 & 326.93 & 23 & 92.3 & 94.9 & 90.8 & -1.13 & 89 & 0.0073 & 0.0207 & 20.2 & 11600 & 0.28 & 10.74 & 59 & 3800 & 165 \\
\hline 2 & 0.70 & 304 & 328.46 & 24 & 97.2 & 99.8 & 95.5 & -1.54 & 94 & 0.0077 & 0.0210 & 20.4 & 11700 & 0.30 & 10.65 & 60 & 3800 & 156 \\
\hline 3 & 1.01 & 317 & 329.67 & 13 & 101.1 & 104.0 & 100.1 & -0.57 & 99 & 0.0081 & 0.0234 & 29.7 & 17000 & 0.16 & 9.87 & 86 & 5500 & 438 \\
\hline 4 & 0.86 & 316 & 330.20 & 14 & 102.8 & 104.1 & 101.4 & -3.05 & 99 & 0.0082 & 0.0234 & 25.1 & 14300 & 0.17 & 9.88 & 73 & 4600 & 331 \\
\hline 5 & 0.96 & 304 & 326.95 & 23 & 92.4 & 93.1 & 90.4 & -0.62 & 89 & 0.0074 & 0.0208 & 28.1 & 16000 & 0.28 & 10.72 & 82 & 5200 & 230 \\
\hline 6 & 0.75 & 302 & 328.61 & 27 & 97.6 & 98.2 & 95.4 & -3.01 & 92 & 0.0077 & 0.0207 & 22.0 & 12500 & 0.33 & 10.79 & 64 & 4000 & 151 \\
\hline 7 & 0.62 & 302 & 327.17 & 25 & 93.0 & 94.8 & 91.1 & -2.41 & 89 & 0.0074 & 0.0204 & 18.1 & 10400 & 0.31 & 10.86 & 53 & 3375 & 133 \\
\hline 8 & 0.63 & 301 & 326.97 & 26 & 92.4 & 94.2 & 90.5 & -0.54 & 90 & 0.0073 & 0.0203 & 18.4 & 10600 & 0.39 & 10.90 & 54 & 3400 & 134 \\
\hline 9 & 0.48 & 301 & 327.07 & 26 & 92.8 & 94.6 & 90.7 & -1.18 & 90 & 0.0074 & 0.0209 & 14.0 & 8000 & 0.32 & 10.90 & 41 & 2600 & 102 \\
\hline 10 & 0.78 & 305 & 341.13 & 36 & 146.0 & NA & NA & -0.35 & 129 & 0.0116 & 0.0240 & 22.9 & 12700 & 0.47 & 9.95 & 64 & 4100 & 112 \\
\hline 11 & 0.97 & 316 & 343.27 & 27 & 155.8 & NA & NA & -0.33 & 140 & 0.0127 & 0.0265 & 28.3 & 15600 & 0.37 & 9.25 & 79 & 5000 & 180 \\
\hline 12 & 0.87 & 300 & 343.11 & 43 & 155.0 & NA & NA & -0.14 & 138 & 0.0125 & 0.0236 & 25.4 & 14000 & 0.57 & 10.06 & 71 & 4500 & 104 \\
\hline 13 & 0.80 & 306 & 342.02 & 36 & 150.0 & NA & NA & -0.25 & 136 & 0.0120 & 0.0244 & 23.4 & 12900 & 0.48 & 9.80 & 65 & 4200 & 115 \\
\hline 14 & 0.80 & 322 & 340.69 & 19 & 144.1 & 135.7 & 140.4 & -0.29 & 143 & 0.0115 & 0.0277 & 23.6 & 13000 & 0.25 & 9.04 & 66 & 4200 & 228 \\
\hline 15 & 0.99 & 324 & 342.32 & 18 & 151.4 & NA & 152.3 & -2.05 & 148 & 0.0123 & 0.0279 & 29.2 & 16000 & 0.24 & 8.87 & 81 & 5200 & 283 \\
\hline 16 & 1.59 & 306 & 333.56 & 27 & 115.0 & 110.5 & 109.3 & -0.24 & 112 & 0.0090 & 0.0225 & 46.4 & 26100 & 0.35 & 10.25 & 133 & 8400 & 309 \\
\hline 17 & 0.76 & 324 & 337.82 & 14 & 131.7 & 125.7 & 126.3 & -0.23 & 130 & 0.0105 & 0.0266 & 22.2 & 12400 & 0.18 & 9.10 & 63 & 4000 & 289 \\
\hline 18 & 1.30 & 312 & 342.32 & 30 & 109.4 & 111.4 & 108.5 & -1.32 & 107 & 0.0122 & 0.0256 & 38 & 20900 & 0.40 & 9.46 & 107 & 6700 & 223 \\
\hline
\end{tabular}

Table 3

- NA: The data was not available due to some equipment problem 